\title{
19 Gewebs- und regionsspezifische Krankheiten der Haut
}

\begin{tabular}{|c|c|c|c|}
\hline \multirow[t]{8}{*}{ ÜBERSICHT } & 19.1 & Störungen des Pigmentsystems & .. 647 \\
\hline & 19.2 & Krankheiten des Fettgewebes & ... 659 \\
\hline & 19.3 & Krankheiten des Haarapparats & ... 663 \\
\hline & 19.4 & Krankheiten der Talgdrüsen & 675 \\
\hline & 19.5 & Krankheiten der Schweißdrüsen & 683 \\
\hline & 19.6 & Krankheiten der Nägel & 685 \\
\hline & 19.7 & Krankheiten der Mundschleimhaut & 690 \\
\hline & 19.8 & Krankheiten der äußeren Genitalien & 696 \\
\hline
\end{tabular}

\subsection{Störungen des Pigmentsystems}

Störungen des Pigmentsystems sind häufig; sie wirken sich entweder als Überschuß (Hypermelanose) oder als Mangel an Melanin (Hypomelanose) aus. Beiden kann eine Vielzahl von Pathomechanismen zugrunde liegen, die man grob in genetisch fixierte, ontogenetisch bedingte und erworbene unterteilen kann. Sowohl Hyper-als auch Hypomelanose können durch Systemprozesse oder durch Dysfunktion des Pigmentsystems selbst hervorgerufen werden. Beide können das gesamte Integument betreffen oder nur fokal auftreten. Da die Hautfarbe ein bedeutendes kosmetisches und soziales Attribut ist, kommt allen Pigmentstörungen ein hoher individueller Stellenwert zu. Die Therapie - vor allem geringfügiger - Hyperpigmentierungen ist gut etabliert, die der Hypopigmentierungen meist schwierig oder noch nicht möglich.

Pathophysiologie des Pigmentsystems und Definitionen. Das Pigmentsystem ist als integraler Teil der Epidermis grundsätzlich von allen krankhaften Prozessen der Haut mitbetroffen - allerdings nicht immer wahrnehmbar, wenn seine Reaktion vom eigentlichen Krankheitsprozeß überdeckt wird (Beispiel: Hypopigmentierung beim atopischen Ekzem). Bei vielen Krankheiten prägt das Pigmentsystem die Eigenart des klinischen Bildes mit, ohne selbst primär betroffen zu sein (Beispiel: postinflammatorische Hyperpigmentierung). Nur bei einer kleinen Krankheitsgruppe ist das Pigmentsystem alleiniger oder Hauptträger der pathologischen Vorgänge.
Das Pigmentsystem kann seine Aufgabe, die Zellen vor UV-Licht, freien Radikalen und anderen Noxen zu schützen, nur erfüllen, wenn alle Anteile ordnungsgemäß funktionieren.

Dies impliziert die normale Funktion der ca. 150 Gene der Melaninproduktionsmaschinerie, das Fehlen interferierender pathologischer Gene, normale Auswanderung der Melanozyten aus der Neuralleiste und Einwanderung in die Epidermis sowie schließlich Interaktion mit den Keratinozyten (s.Allgemeiner Teil).

Fehlentwicklungen in diesem „langen Marsch“ manifestieren sich in der Regel als Pigmentmangel (Hypomelanosen). Einem solchen kann entweder ein Mangel an Melanozyten zugrundeliegen (Melanozytopenie z. B. Piebaldismus) oder Mangel an Melanin bei Vorhandensein funktionsuntüchtiger Melanozyten (Melanopenie - z. B. Albinismus). Die übrigen Hypomelanosen resultieren aus Störungen eines korrekt ausgebildeten Pigmentsystems (entzündlich, degenerativ, Störungen des Pigmenttransfers). Totaler Pigmentverlust wird als Depigmentierung, partieller als Hypopigmentierung bezeichnet. Analog können auch Hypermelanosen auf bloßer Vermehrung von Melanin (z. B. Epheliden) oder auf Vermehrung von Melanozyten (z. B. Lentigo simplex) beruhen.

Das Pigmentsystem läßt eine Reihe gesetzmäßiger Reaktionsweisen gegenüber pathophysologischen Reizen erkennen:

- Aktivierung der Melanozyten. Die auffallendste Fähigkeit der Melanozyten ist, durch verschiedene Noxen zu höherer Aktivität stimuliert zu werden Dendritogenese, Steigerung von Melaninproduktion und -transfer sowie oft auch der Mitosetätigkeit. Die wichtigsten solchen zu Hyperpigmentierung führenden Stimuli sind UV-Licht (Sonnenbräunung) und 
Mediatoren der Entzündung (proinflammatorische Zytokine, Lipidmediatoren - postinflammatorische Hyperpigmentierung). Weitere stimulierende Faktoren sind Hormone (M. Addison, Melasma), chronische Wärmeexposition (Erythema e calore) und chronisch-mechanisches Trauma.

- „Gedächtnis“. Ein typisches Phänomen bei vielen erworbenen Hyperpigmentierungen ist ihre Fähigkeit, auch noch nach Jahren und mittlerweile vollständiger Abblassung, wie ein „Reibebild“ nach UV-Exposition plötzlich wieder hervorzutreten (Beispiele: Melasma, Epheliden, Berloque-Dermatitis).

- Melanozyten sind empfindliche Zellen. Sie können durch physikalische (Kälte, Röntgenstrahlen), toxische (z.B. verschiedene organische Verbindungen, bakterielle Toxine) und entzündliche Reize relativ leicht zerstört werden (Beispiele: unachtsame Behandlung mit flüssigem Stickstoff, beruflicher Kontakt mit Vinylchlorid, postinflammatorische Depigmentierung nach Varizellen, Herpes zoster etc).

- Melanozyten sind soziale Zellen. Für die normale Funktion der Melanozyten ist die Interaktion mit den Keratinozyten unerläßlich. Bei krankhaften Veränderungen der Epidermis resultieren häufig Störungen des Pigmenttransfers, die sich als Hypopigmentierung manifestieren (Beispiele: Psoriasis, atopische Dermatitis, Pityriasis alba).

In diesem Zusammenhang ist interessant, daß man Melanozyten erst in Reinkultur züchten konnte, als man dem Medium Wuchsstoffe der Keratinozyten zusetzte (z. B.MSH).

- Langsamkeit der Migration. Die Repigmentierung depigmentierter (melanozytenfreier) Areale (etwa Narben) erfolgt außerordentlich langsam. Dies liegt an der sehr geringen Wanderungsgeschwindigkeit der Melanozyten entlang der dermoepidermalen Junktionszone: Eine Wunde ist oft schon nach einigen Tagen reepithelisiert, ihre Repigmentierung kann Wochen bis Monate dauern. Die Melanozyten wandern hierbei meist aus den Haarfollikeln aus.
- Pigmentabtropfung (-inkontinenz). Diese tritt bei Zugrundegehen von Melanozyten auf. Es kommt zum Abtropfen von Melanin in die Dermis, wo es von Histiozyten langzeitig gespeichert wird (Melanophagen); es resultiert eine „dermale“ Pigmentierung von charakteristisch schmutzig graublauer Farbe (Tyndall-Phänomen) (Beispiele: Lichen ruber, Incontinentia pigmenti, Melanome).

Aus den genannten Eigenschaften des Pigmentsystems ergibt sich zwangsweise die Neigung zu einer gewissen Heterogenität; selbst die scheinbar völlig homogen getönte Haut des jungen Menschen scheint bei stärkerer Vergrößerung im Auflichtmikroskop wolkig scheckig, da Melanozyten und Melanozytenklone in verschiedener Dichte und von verschiedenem Funktionszustand nebeneinander bestehen. Durch Zerstörung und Selektion von Klonen wird im Rahmen des Alterungsprozesses der scheckige Charakter der Haut immer deutlicher und findet schließlich seinen Ausdruck im Bild der sog. „Altershaut“ (chronischer UV-Schaden).

\subsubsection{Hypermelanosen}

Epidermale Melaninhyperpigmentierung manifestiert sich als bräunlich-schwarze Färbung, die je nach vorliegender Ursache diffus oder umschrieben, in letzterem Fall einzeln, multipel oder gemustert (streifig, netzartig etc.) sein kann. Dermale Hyperpigmentierung ist durch grau-bläuliche Färbung gekennzeichnet; sie tritt in der Regel in umschriebener Form auf. Dermale Hyperpigmentierung ist manchmal mit epidermaler assoziiert, als isolierter Befund jedoch selten. Beide Typen der Melaninpigmentierung müssen von der Einlagerung anderer Pigmente unterschieden werden.

Tabelle 19.1. Diffuse generalisierte Hyperpigmentierung

\begin{tabular}{|c|c|c|}
\hline Epidermale Pigmentierung & Dermale Pigmentierung & Andere Pigmente \\
\hline $\begin{array}{l}\text { Ethnisch } \\
\text { Dispositionell } \\
\text { Erworben } \\
\text { Hormonstörungen } \\
\text { M. Addison, ACTH-Therapie, ACTH- } \\
\text { produzierender Tumor, M.Cushing, Hyperthyreose } \\
\text { Leberkrankheiten } \\
\text { Zirrhose,POEMS-Syndrom } \\
\text { metabolische Störungen } \\
\text { Marasmus, Vitamin-B-, Folatmangel, Porphyrien, AIDS, } \\
\text { Hämochromatose } \\
\text { Paraneoplasie } \\
\text { Dermatosen } \\
\text { Sézary-Syndrom, chron. photoallergisches Ekzem, Sklerodermie } \\
\text { medikamentös } \\
\text { Cyclophosphamid,MTX, 5-FU,Clofazimin }\end{array}$ & $\begin{array}{l}\text { Marasmus } \\
\text { Einzelmetastasierung bei } \\
\text { Melanom } \\
\text { medikamentös } \\
\text { Phenothiazine, Thiazide }\end{array}$ & $\begin{array}{l}\text { Ochronose } \\
\text { Argyrose, Chrysiasis } \\
\text { Wismuth, Arsen } \\
\text { Amiodaron } \\
\text { Tetrazykline }\end{array}$ \\
\hline
\end{tabular}




\subsubsection{Diffuse Hypermelanosen}

Diffuse (d. h. die gesamte Körperhaut betreffende) epidermale Melaninhyperpigmentierung kommt - außer bei dispositionell bzw. ethnisch bedingter dunkler Hautfarbe - bei einer Reihe innerer Krankheiten, Kachexie, als Paraneoplasie, bei verschiedenen Dermatosen und auch als Medikamentennebenwirkung vor (Tabelle 19.1).

Diffuse erworbene Hyperpigmentierung ist ein dermatologisches Alarmzeichen, das in erster Linie auf M. Addison hinweist (s.S. 384). Bei diesem entspricht die Pigmentierung einem „natürlichen“ Farbton und ist morphologisch charakteristisch. Bei der Hämochromatose tritt hingegen ein erdfarbener Braunton auf („Bronzediabetes“), ein fahlgrauer bei der generalisierten Argyrose (s. Abb. 11.50).

Eine extrem seltene, wahrscheinlich durch Neumutation entstandene diffuse Hyperpigmentierung ist die universelle acquirierte Melanose bei Weißen („Kohlenbaby"). Bei betroffenen Kindern entwickelt sich, von den Akren ausgehend, progredient eine pechschwarze Hautfarbe, die (im Gegensatz zu ethnisch schwarzen Menschen) die Handflächen und Fußsohlen nicht ausspart. Ultrastrukturell liegen zahlreiche große, einzelliegende Melanosomen vor.

\subsubsection{Umschriebene Hypermelanosen}

Bei diesen kann das Melanin gleichfalls epidermal oder (seltener) dermal lokalisiert sein

\section{Epidermale umschriebene Hypermelanosen}

Epheliden (Sommersprossen) (Abb.19.1). Multiple, kleine, runde, scharf begrenzte disseminierte bräunliche Pigmentflecken an den lichtexponierten Körperstellen, die bei hellhäutigen (rothaarigen) Kindern nach Sonnenbränden auftreten. Epheliden sind permanente Läsionen, blassen jedoch winters stark $a b$ und treten bei neuerlicher Sonneneinstrahlung wieder hervor. Histologisch ist zwar das Melanin vermehrt, die Melanozytenzahl jedoch unverändert. Epheliden treten auch als Teilsymptom von Fehlbildungssyndromen auf (Neurofibromatose, Progerie-Syndrome, Xeroderma pigmentosum).

Vermutete Ursache: Phäomelanin setzt bei UV-Bestrahlung Sauerstoffradikale frei, die zur Aktivierung (und Schädigung) der Melanozyten führen.

Gruppe der Lentigines (Linsenflecke). Lentigines beruhen auf einer Vermehrung der Melanozyten und sind unveränderliche Läsionen. Sie ähneln Epheliden (sind aber meist größer - ca. $5 \mathrm{~mm}$ - und dunkler als

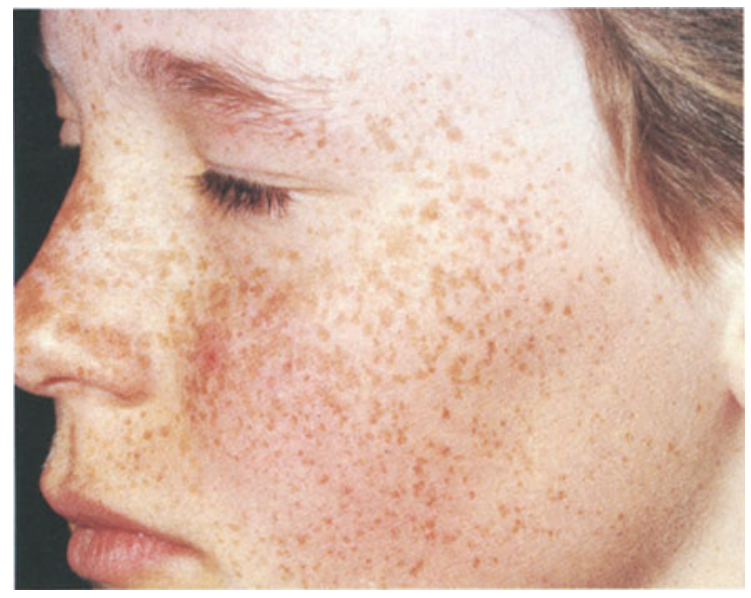

Abb. 19.1. Epheliden (Sommersprossen). Punktierte runde Pigmentläsionen an lichtexponierten Stellen bei Kindern mit lichtempfindlichem Hauttyp

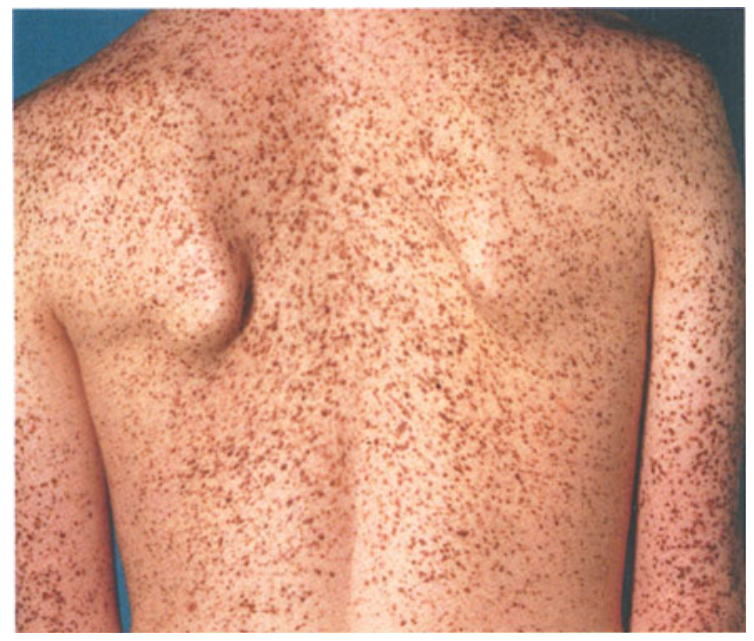

Abb. 19.2. Lentiginosis profusa. Bei diesem jungen Patienten bestanden keine weiteren Fehlbildungen (s. Text)

diese) und Junktionsnävi (diese sind leicht erhaben; die Unterscheidung ist oft nur histologisch möglich bei Junktionsnävi Nävuszellnester). Lentigines treten unter folgenden Manifestationen auf:

- Lentigo simplex: eine meist solitäre Läsion ohne Prädilektionsstelle; von UV-Bestrahlung unabhängig. Auftreten im Kindesalter;

- Multiple Lentigines (Abb.19.2): Diese sind meist generalisiert (Lentiginosis profusa), gleichfalls UV-unabhängig und treten häufig im Rahmen bestimmter Fehlbildungssyndrome auf (s. unten). Multiple Lentigines können auch regional bzw. nävogen entlang den Blaschko-Linien auftreten;

- Lenitigines der Mund- bzw. Genitalschleimhaut (s. Abb.19.55 u. 19.62): einzelne oder mehrere oft unregelmäßig begrenzte Pigmentflecken. Wahrscheinlich als exzessive physiologische Pigmentierung zu interpretieren, doch wurde die Entstehung von Melanomen beschrieben; 


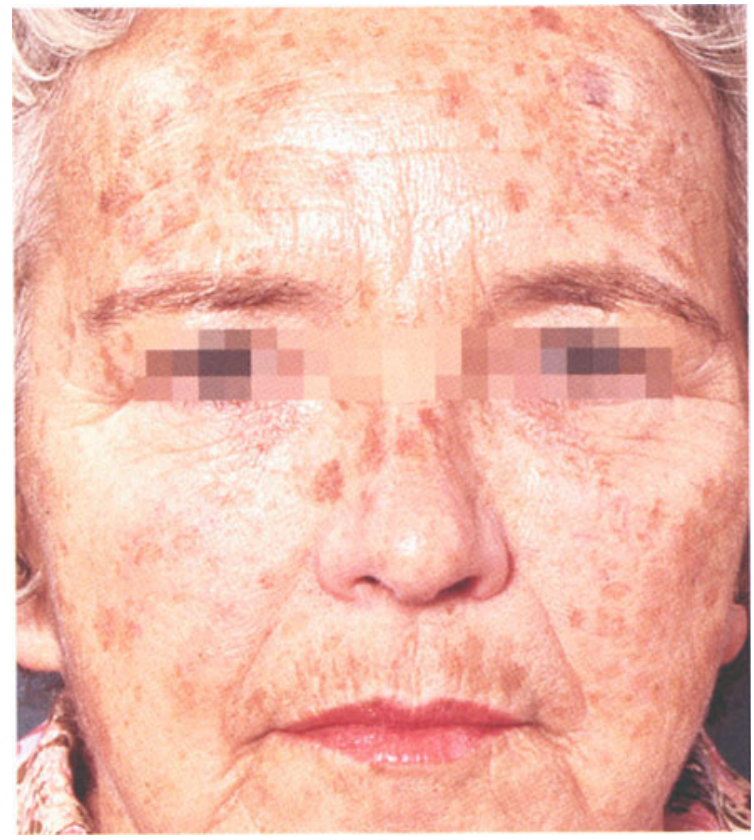

Abb. 19.3. Senile Lentigines. Multiple, kreisrunde, mittelbraune, runde Flecken. Sie finden sich ausschließlich in sonnenexponierten Arealen

- Lenitigines seniles (solares) (Abb. 19.3): durch chronischen UV-Schaden entstanden, auf lichtexponierte Areale beschränkt (Gesicht, Handrücken). Sie sind mit flachen seborrhoischen Warzen eng verwandt. Eine Sonderform sind die durch forcierte Photochemotherapie oder Solariumbestrahlung entstandenen Lentigines (besonders massiv an den sonst unbestrahlten Hautpartien - Gesäß!).

\section{Mit multiplen Lentigines assoziierte Syndrome}

- Mit intestinaler Polypose assoziierte Syndrome: Cronkhite-Canada- und Peutz-Jeghers-Syndrom (s.S. 538).

- LEOPARD- (Moynahan-)Syndrom: ein seltenes, autosomal-dominant vererbtes Syndrom, das durch Lentigines, EKG-Störungen, okulären Hypertelorismus, Pulmonalstenose, abnormale Genitalien (Hypogonadismus), retardiertes Wachstum und Taubheit (deafness) gekennzeichnet ist.

- LAMB- (Carney-) Syndrom: Lentigines, atriales Myxom, mukokutane Myxome, blaue Nävi. Zusätzliche Symptome sind autoantikörpermediierte Nebennierenrindenhyperplasie mit Cushing-Syndrom, Hodentumoren, Wachstumshormon-produzierende Hypophysentumoren (Riesenwuchs, Akromegalie).

- Andere: zentrofaziale neurodysraphische Lentiginose, Tay-Syndrom, Sotos-Syndrom.

Größerflächige nävoide Pigmentflecken. Eine Gruppe kongenitaler Läsionen, die nicht durch Nävuszellnester charakterisiert sind:

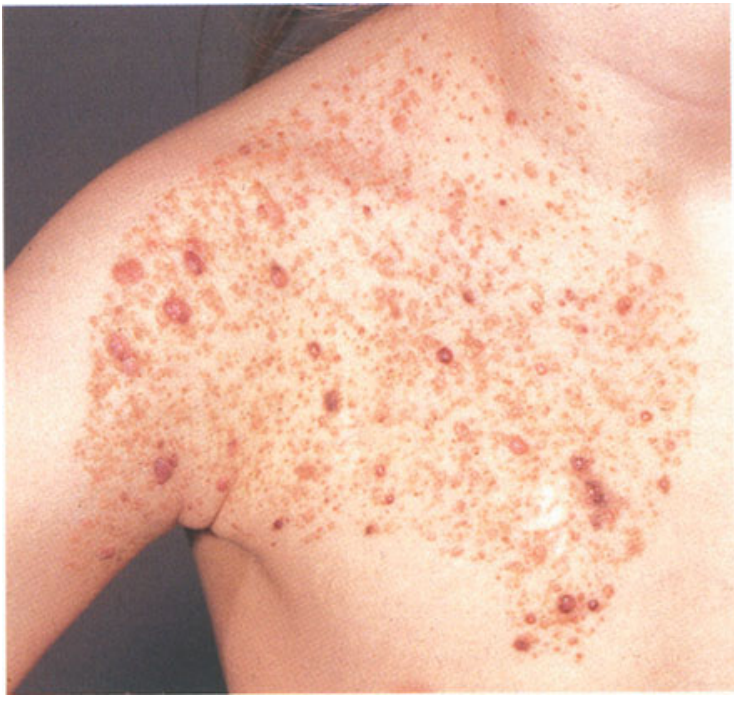

Abb. 19.4. Naevus spilus mit zahlreichen Spitznävi. Ein großflächiger, scharf begrenzter hellbrauner Fleck der rechten Schulterregion, in dem zahlreiche kleinere und größere fleckige bis knotige Sekundärläsionen erkennbar sind (Spitznävi)

- Café-au-lait-Flecken (s. S. 528, s. Abb. 17.30) sind hellbraune, scharf begrenzte Flecken, die entweder solitär oder als Teilsymptom des M. Recklinghausen oder M. Pringle auftreten.

- Naevus spilus (Abb.19.4). Ein relativ häufiger fleckförmiger (nicht tastbarer!) kongenitaler Nävus. Er ist hell- bis dunkelbraun, scharf und manchmal polyzyklisch begrenzt und histologisch durch vermehrt Melanin und milde Vermehrung der Melanozyten gekennzeichnet. Er ähnelt Cafè-au-lait-Flecken, unterscheidet sich jedoch durch dunkel punktierte Sprenkoelung. Die Sprenkeln entsprechen Spindelzellnävi, die im Lauf der Jahre knotig anwachsen können. In seltenen Fällen wurde die Entstehung von Melanomen beobachtet.

Naevi spili sind ein Läsionstyp, in dem sich nävogene Pigmentläsionen mit und ohne Ausbildung von Nävuszellnestern überschneiden.

- Becker-Nävus (Abb.19.5) ist ein meist handflächengroßer, wohl abgegrenzter, dunkel pigmentierter linearer epidermaler Nävus, der durch milde epidermale Hyperplasie, aber starke Hypertrichose und verstärkten Melaningehalt (bei normaler Zahl von Melanozyten) gekennzeichnet ist. Der Becker-Nävus tritt fast stets bei Männern auf, bevorzugt die Schulterregion und entwickelt sich meist in der zweiten Dekade. Keine assoziierten Symptome.

- Familiäre Hyperpigmentierung der Augenlider sind ein seltenes, autosomal dominant vererbtes $\mathrm{Zu}$ standsbild, das durch persistente „halonierte“ Augen gekennzeichnet ist. Histologie: epidermale und dermale Pigmentierung.

Erbkrankheiten mit progredienter retikulärer Pigmentierung. Als isolierter Befund tritt eine solche reti- 
kuläre Hyperpigmentierung, beginnend in den Intertrigoregionen und sich langsam auf die restliche Haut ausbreitend, beim M. Dowling-Degos auf; als Nebenbefund bedeutsamer Systemsymptome bei der Dyskeratosis congenita und der Fanconi-Anämie (s. S. 535).

Postinflammatorische Hyperpigmentierungen. Zahlreiche entzündliche Dermatosen werden von oft Monate dauernder Hyperpigmentierung gefolgt; die Neigung hierzu ist umso größer, je dunkler der Hauttyp ist. Beispiele sind (Kontakt)Ekzeme, medikamentös toxische Exantheme, physikochemische Traumen- z.B. Röntgenbestrahlung!, chronisches Druck-, Reibetrauma), UV-Photosensitivität (z. B. Pellagra), phototoxische Reaktionen (z. B. Berloque-Dermatitis - s. S. 154, Abb. 19.6) u.a.m.

Der Übergang zwischen epidermaler und dermaler Hypermelanose ist ein fließender, da es bei entzündlichen Dermatosen stets, wenn auch in unterschiedlichem Ausmaß, zur Pigmentabtropfung kommt. Die Neigung zur Pigmentinkontinenz ist ethnisch verschieden (höher bei ostasiatischer oder lateinamerikanischer Herkunft).

\section{Gemischt epidermal-dermale Hypermelanosen}

Melasma (alter Name:Chloasma uterinum). Eine häufige großfleckige, meist symmetrische Eruption von scharf, oft bizarr begrenzten Pigmentflecken im Gesicht (Schläfen, Stirn, Wangen). Epidermale Melasmen sind dunkelbraun; je mehr dermales Melanin vorhanden ist, umso grauer wird die Farbe. Das Melasma ist wahrscheinlich eine Hormon- und UV-Licht-abhängi-

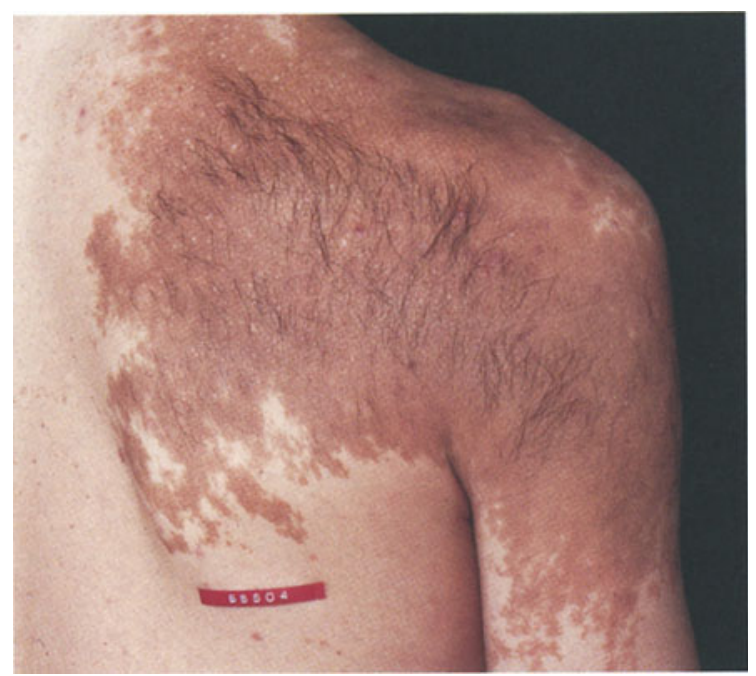

Abb. 19.5. Becker-Nävus. Großflächiger pigmentierter, flacher epidermaler Nävus mit dunklen und hypertrophen Haaren. Becker-Nävi sind fast stets an der Schulter (von Männern) lokalisiert

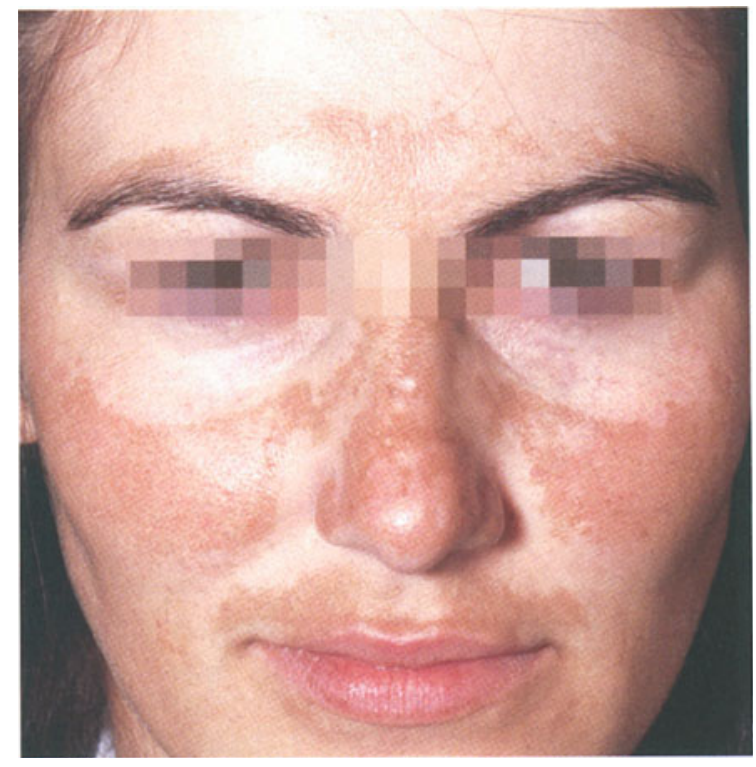

Abb. 19.6. Berloque-Dermatitis. Scharf und unregelmäßig begrenzte Hyperpigmentierung an Stirn, Wangen und perioral. Die Läsion entstand durch Sonnenexposition nach Kühlen des Gesichtes mit Eau de Toilette

ge Läsion (eine zusätzliche Rolle von Kosmetika wird diskutiert); es tritt hauptsächlich bei jungen Frauen (jedoch selten auch bei Männern) auf und ist häufige Begleiterscheinung der Schwangerschaft oder der Einnahme oraler Kontrazeptiva, selten hormonproduzierender Tumoren (Ovarialkarzinom). In der Postpartalperiode bilden sich Melasmen meist spontan zurück, können jedoch auch viele Jahre persistieren. Deutliche Abhängigkeit von Sonnenbestrahlung (Abblassen im Winter, Hervortreten im Frühjahr).

Differentialdiagnose. Berloque-Dermatitis.

Therapie. Bleichsalbe (beim dermalen Typ allerdings kaum wirksam) und UV-Schutz.

Melanodermitis toxica (Riehl-Melanose, Teermelanose). Hierbei zeigt sich eine fleckige grau-braune Hyperpigmentation des Gesichts oder - berufsbedingt (z. B. Teerarbeiter) - an Händen und Unterarmen. Zugrunde liegt eine chronische phototoxische Reaktion gegen Teer, Pech, Öle, Kohlenwasserstoffe, aber auch Inhaltstoffe von Kosmetika.

Die Riehl-Melanose war während des 1.Weltkriegs in Österreich epidemieartig an Soldaten, Transportarbeitern etc. beobachtet und zunächst als Vergiftung durch kontaminierte Lebensmittel gedeutet worden. Die eigentliche Ursache lag wahrscheinlich in der kriegsbedingten starken Exposition gegenüber Ölen, Ruß und Teer und Sonnenexposition (Transport auf unüberdachten Bahnwaggons). Die Riehl-Melanose wird in der damals beschriebenen exzessiven Form heute nicht mehr beobachtet. Nicht selten sind jedoch durch Kosmetikaabusus bedingte fleckige Hyperpigmentationen der Gesichtshaut. Melanodermitis toxica ist der Berloque-Dermatitis verwandt. 


\section{Dermale Hypermelanosen}

Dermale Melaninpigmentierung wird entweder durch dermale Melanozyten oder durch nach Pigmentabtropfung in dermalen Melanophagen gespeichertes Melanin (Pigmentinkontinenz) verursacht. Der Pigmentabtropfung gehen in der Regel entzündliche Veränderungen der Epidermis voraus.

Dermale Melanozytosen. Mongolenfleck (kongenitale dermale Melanozytose) (Abb. 19.7). Ein oder mehrere, mäßig scharf begrenzte, graublaue Flecken der Lumbosakralregion Neugeborener, die sich in den ersten Lebensmonaten (-jahren) spontan zurückbilden. Vorkommen häufig bei Ostasiaten, sporadisch bei Weißen (Osteuropa). Genese: Verzögerung der normalen Besiedlung der Epidermis durch Melanozyten. Histologie: in der mittleren Dermis bandförmig angeordnete dendritische Melanozyten. Selten sind aberrierende (Lokalisation z.B. Gesicht oder Extremitäten) und persistierende Mongolenflecke.

Nävus Ota (okulodermale Melanozytose) (Abb. 19.8). Eine „nävoide“, meist schiefergraue (manchmal mit Braun-, Rot- oder Schwarztönen) flächige und fleckige Verfärbung der Haut im Bereich der beiden ersten Trigeminusäste sowie der Sklera und der inneren Augenanteile. Der Nävus Ota betrifft vorwiegend Ostasiaten, ist meist einseitig, gynäkotrop und tritt meist schon bei Geburt oder in der Kindheit auf. Seine Größe ist variabel. Er ist eine persistente Läsion; erfolgreiche Lasertherapie wurde berichtet. Die Entwicklung von Melanomen wurde beobachtet.

Der Nävus Ito ist eine Variante des Nävus Ota in der Schulter- und seitlichen Armregion.

Knotige Akkumulationen dermaler Melanozyten erscheinen klinisch als blaue Nävi (dermale Melanozytome - s. S. 581).

Dermatosen mit dermaler Pigmentspeicherung. Eine dermale postinflammatorische Hyperpigmentierung kann nach Lichen ruber, fixem Arzneimittelexanthem, infektiösen Hautkrankheiten (z. B. Pinta) und anderen entzündlichen Dermatosen entstehen; dunkler Hauttyp und ostasiatische bzw. lateinamerikanische Herkunft sind wichtige prädisponierende Faktoren. Eine charakteristische Sonderform ist das Erythema dyschromicum perstans („ashy dermatosis“), eine in Lateinamerika verbreitete, sonst seltene Pigmentstörung, die durch gruppierte kleine, konfluierende, unscharf begrenzte aschgraue Herde vorwiegend am Stamm ansonsten gesunder Menschen gekennzeichnet ist. Der Pigmentierung geht ein mildes entzündliches Stadium voraus, das histologisch dem Lichen ruber ähnlich ist (als dessen Variante das Erythema dyschromicum perstans auch angesehen wird).

Dermale Pigmentierung, die teils aus Melanin, zusätzlich jedoch aus exogenen Substanzen besteht, findet sich bei der makulären Amyloidose und als Nebenwirkung von Medikamenten (Phenothiazin, Tetrazykline, Minocyklin, Amiodaron).

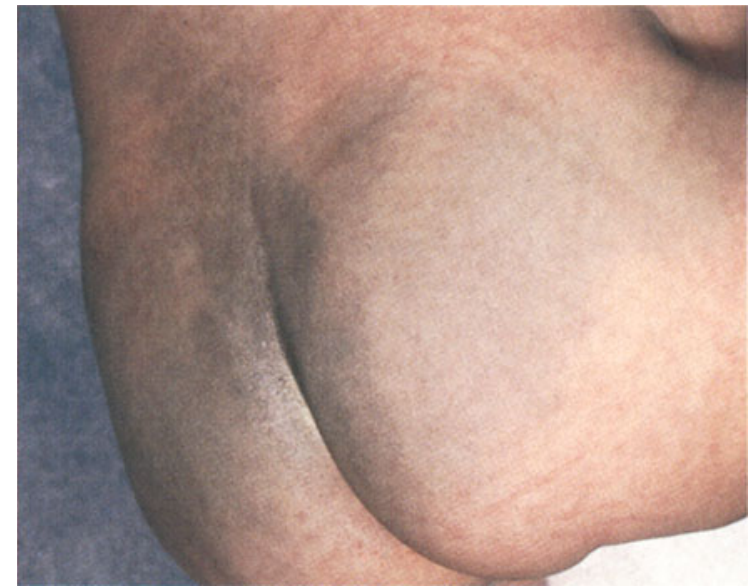

Abb. 19.7. Mongolenfleck. Unscharf begrenzte, graublaue Flecken der Sakralregion

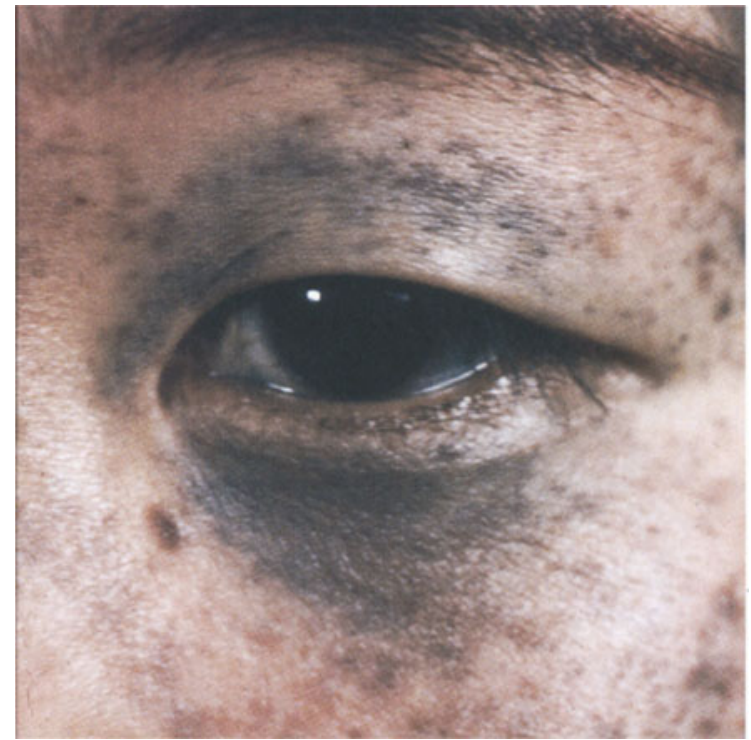

Abb. 19.8. Naevus ota. Eine flächige und fleckige schiefergraue Verfärbung der linken Periorbitalregion, Oberlider und Skleren (Prof.T.Nishikawa,Tokyo)

Incontinentia pigmenti (Bloch-Sulzberger). Eine Xchromosomal vererbte (Xp11?) Systemkrankheit, die bei Homozygotie (also auch Knaben) einen Letalfaktor darstellt und bei heterozygoten Mädchen durch charakteristische Hautveränderungen, physischen und geistigen Entwicklungsrückstand, neurologische Symptome, Skelett- und Zahnanomalien sowie retrolentikuläre Fibroplasie gekennzeichnet ist. Die Hautveränderungen laufen in 3 charakteristischen Stadien ab. Augenfällig ist ihre streifige Verteilung entlang der Blaschko-Linien, die Ausdruck chromosomalen Mosaizismus sind.

Klinik. Die Hautläsionen sind bei Geburt schon vorhanden oder stellen sich innerhalb der ersten Lebenswochen ein: v.a. am seitlichen Rumpf und den proximalen Extremitäten disseminierte, linear angeordnete Erytheme und Bläschen (vesikulöses Stadium) (Abb.19.9). Einige Wochen später Umwandlung in verruköse, papillomatöse, hypertrophe Läsionen (ver- 


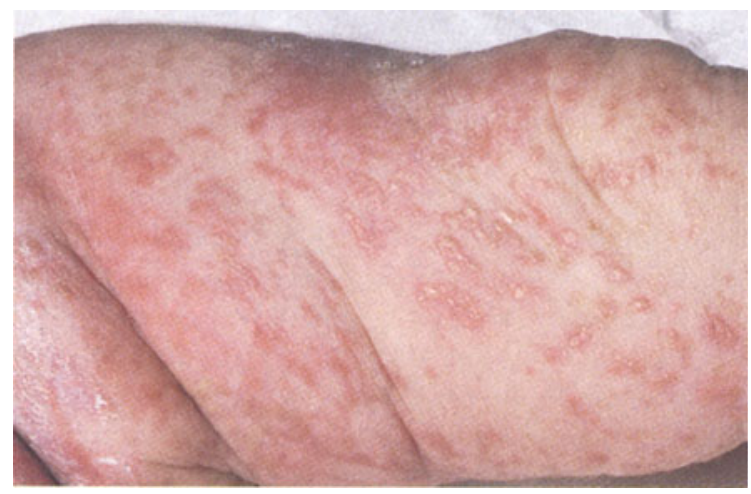

Abb. 19.9. Incontinentia pigmenti, vesikulöses Stadium. Streifige Erytheme und Blasen am Oberschenkel eines neugeborenen Mädchens

ruköses Stadium), nach 2-3 Monaten stellt sich das pigmentierte Stadium ein. Die Pigmentierungen sind charakteristisch striär, wirbelartig und von schmutzig- bis schiefergrauer Farbe. Sie bleiben einige Jahre bestehen und klingen später langsam ab, manchmal sogar mit Hypopigmentierung und Atrophie.

Histologie. Im frühen Stadium Spongiose mit reichlich Eosinophilen, später verruköse Hypertrophie, reichlich dermale Melanophagen.

Differentialdiagnose. Bullöse Dermatosen, lineare epidermale Nävi und Hypomelanosis Ito.

Mildere Varianten sind das Franceschetti-JadassohnSyndrom (keine Augen- und ZNS-Zeichen) und das Naegeli-Syndrom (nicht X-chromosomal vererbt).

\subsubsection{Hypomelanosen}

Mangel an Melaninpigment kann durch angeborene Malfunktion des Pigmentsystems oder durch sekundäre Störungen entstehen. In beiden Fällen kann der Defekt diffus oder umschrieben, partiell oder total sein.

\subsubsection{Diffuse Hypomelanosen}

Diffuse (die gesamte Haut betreffende) Hypomelanose tritt überwiegend auf genetischer Basis auf: ethnische bzw. dispositionelle Pigmentarmut (Hauttyp I), erbliche Defekte der Melaninproduktion (Albinismus), erbliche Stoffwechselkrankheiten mit Auswirkungen auf das Pigmentsystem (Phenylketonurie, andere Aminazidurien, Menke-Syndrom). Erworbene universelle Hypomelanose tritt nur bei der seltenen universellen Vitiligo, bei schweren Ernährungsstörungen bzw. manchen Systemkrankheiten (Malabsorptionssyndrom, Nephrose etc.) und Hormonanomalien auf (Hypopituitarismus, Hypogonadismus).

Diffuse Hypomelanosen zeigen mit Ausnahme des Tyrosinase-negativen Albinismus (IA) und der universellen Vitiligo keinen vollständigen, sondern nur partiellen Pigmentverlust.

\section{Okulokutaner Albinismus (OCA)}

Eine Gruppe von (fast ausschließlich) autosomal-rezessiven Erbleiden, bei denen die Melanozyten zwar in normaler Zahl vorhanden, jedoch nicht zur Synthese reifer Melanosomen befähigt sind. Den insgesamt 11 bekannten Unterarten liegen unterschiedliche Defekte zugrunde, auch die klinische Ausprägung ist verschieden. Gemeinsame klinische Leitsymptome sind universelle Verminderung oder Fehlen von Melanin in Haut, Haar und Augen, Nystagmus, Photophobie und Sehschwäche. Durch mangelnden UV-Schutz besteht erhöhtes Risiko von Hauttumoren.

Weitere vier Formen von okulärem Albinismus (Pigmentveränderungen der Haut sind sehr diskret oder fehlen überhaupt) werden hier nicht behandelt.

Epidemiologie. Die Prävalenz des OCA ist 1:20.000; die beiden Haupttypen (tyrosinase-positiver und tyrosinase-negativer OCA) stellen je knapp $50 \%$, die 9 restlichen Typen sind selten.

Klassifikation. Eine vollständige molekularbiologische Klassifikation existiert derzeit noch nicht. Man unterscheidet Formen, bei denen die Melaninsynthese selbst defekt ist, von solchen, wo sie indirekt durch andere Defekte betroffen ist (Tabelle 19.2). Bei ersteren spielen Defekte der Tyrosinase (dem Schlüsselenzym der Melanogenese) eine Hauptrolle; der Gendefekt liegt auf Chromosm $11 \mathrm{q}$.

\begin{tabular}{ll}
\hline Defekt der Melaninsynthese & Defekt außerhalb der Melaninsynthese \\
\hline Defekt der Tyrosinase:Typ I & Chédiak-Higashi Syndrom \\
Typ I-A: Tyrosinase-negativ & Hermansky-Pudlak-Syndrom \\
Typ II-B: "Yellow mutant" & Prader-Willi-Syndrom \\
Typ I-MB: "Minimal pigment" & \\
Typ I-TS: "Temperature-sensitive" & \\
Defekt nicht der Tyrosinase & \\
Typ II: Tyrosinase-positiv & \\
roter OCA & \\
brauner OCA & \\
autosomal-dominanter OCA &
\end{tabular}

Tabelle 19.2. Klassifikation des okulokutanen Albinismus 


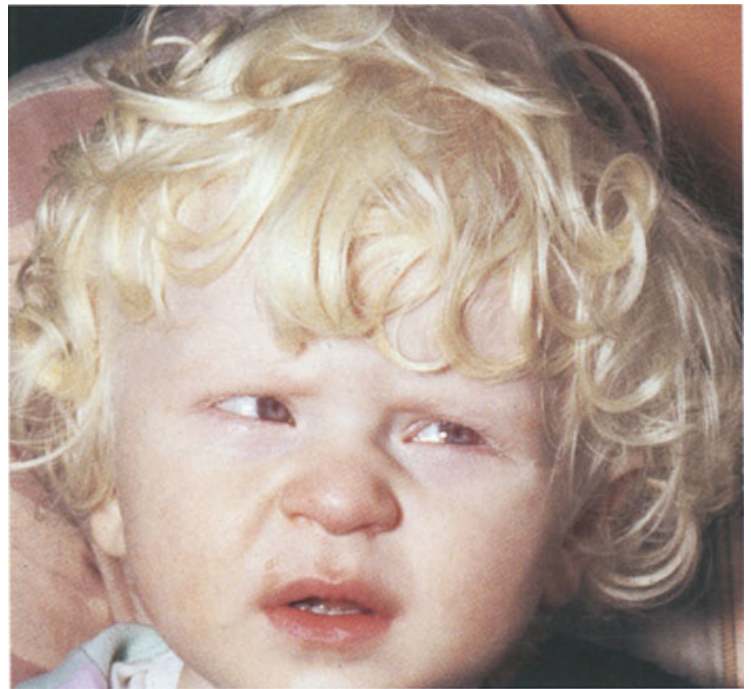

Abb.19.10. Tyrosinase-negativer okulokutaner Albinismus. Weiße Haut, weißblonde Haare, wässrig-blaue Iris, rot durchschimmernde Pupillen

Gemeinsame Eigenschaften der Formen des OCA. Pigmentverdünnung findet sich stets, doch in unterschiedlichem Maß. Völlig weiße Haut und Haare hat nur Typ IA; bei allen anderen finden sich Spuren von Pigment, die einen gelblichen, bräunlichen oder rotbräunlichen Farbton bewirken (so kann ein Afrikaner mit OCA sogar dunkler sein als ein normal pigmentierter Weißer). Häufig dunkeln die Betroffenen im Lauf des Lebens leicht nach. Auch das Auge ist nur bei Typ IA völlig unpigmentiert, die Iris daher hellblau, die $\mathrm{Pu}-$ pille rot reflektierend (unpigmentierter Augenfundus), bei allen anderen Typen findet sich zarte Pigmentierung.

Die Iris ist bei OCA häufig stärker pigmentiert als die Haut, da die Pigmentzellen des Auges „kontinent“ sind (d.h. nicht beständig Melanosomen in die Nachbarschaft abgeben).

Abhängig vom Grad der Pigmentverdünnung besteht eine starke UV-Empfindlichkeit, die die Gefahr von Sonnenbränden, Lichtalterung und Tumoren der Haut mit sich bringt (Plattenepithelkarzinom, Melanom). Allen Typen gemeinsam (und für die Diagnose zu fordern) ist ferner die Augensymptomatik: Nystagmus, Photophobie, Hypoplasie der Fovea, herabgesetzte Sehstärke, manchmal Strabismus und Refraktionsstörungen; auch diese Symptome sind verschieden ausgeprägt und nicht stets vollzählig ausgebildet.

Die Augensymptome sind nur teilweise Folge des Pigmentmangels. Bei allen Formen von OCA (ungeachtet der Genese) liegen Fehlentwicklungen des N. opticus vor, insbesondere ein Fehlen ipsilateraler Fasern im Chiasma opticum (daher kein räumliches Sehen!); diese Fehlentwicklung kann mittels evozierter Potentiale nachgewiesen werden. Man vermutet, daß das Melanin des Auges die richtige Einwanderung der Nervenfasern induziert.

\section{Klinische Manifestationen des OCA}

Tyrosinase-negativer OCA. Bei allen 4 Untereinheiten wird wird in den Melanozyten eine nicht bzw. mangelhaft funktionelle Tyrosinase synthetisiert, die Melanosomen enthalten ultrastrukturell kein Melanin (Melanosomen nur von Grad I und II)(s. Tabelle 19.2). Zahlreiche Punktmutationen des Tyrosinasegens wurden bisher entdeckt, Art und Lokalisation bestimmen das Ausmaß der Symptomatik. Typ IA stellt die schwerste Erscheinungsform mit völliger Depigmentierung von Haut und Haaren und schwerer Augensymptomatik dar (Abb.19.10). Typen IB und IMP sind mildere Formen. Typ IB ist durch ein auffallendes, gelb-rötliches Pigment der Haare, einem geringfügig positiven DOPA-Haarwurzeltest bei Zusatz von L-Cystein und sein hauptsächliches Vorkommen bei Amerikanern deutscher (Amish!) und polnischer Abkunft ausgezeichnet. Typ ITS besitzt durch Pigmentierung der Akren bei Pigmentmangel am Stamm ein auffallendes Verteilungsmuster (die produzierte Tyrosinase ist temperaturabhängig - d.h. sie wird bei Normaltemperatur inaktiviert).

Tyrosinase-positiver OCA (Typ II) ist klinisch ähnlich, doch werden geringe Mengen von Melanin produziert (langsame Zunahme im Laufe des Lebens). Die molekularen Mechanismus sind unbekannt; auch hier enthalten die Melanozyten nur wenige ausgereifte Melanosomen.

Der Unterscheidung zwischen tyrosinase-positivem und -negativem Albinismus dient ein einfacher Labortest: Einige Haare werden ausgezupft und in einer Lösung von Dopa (Melaninpräkursor) inkubiert. Kommt es zur Schwärzung der Haarwurzeln (enthalten viable Melanozyten!), ist das Vorhandensein von Tyrosinase nachgewiesen.

Hermansky-Pudlak-Syndrom. Ein seltenes, autosomal rezessives Erbleiden, das durch relativ milde Haut-, aber schwere Augenbeteiligung, assoziiert mit einem Defekt der Thrombozyten (Epistaxis, Hämatome, Hämorrhagien) und multiplem Organversagen in der Lebensmitte (Lungenfibrose, Herz-, Nierenversagen) gekennzeichnet ist. Dieses Syndrom ist wahrscheinlich eine Speicherkrankheit (zeroidähnliche Einschlüsse in Lymphozyten und diversen Organzellen - Niere, Herz, Darm, Alveolarmakrophagen).

Chediak-Higashi-Syndrom. Ein seltenes, autosomal-rezessives Erbleiden, das durch Abwehrschwäche (häufige Kokkeninfektionen), OCA, neurologische Symptomatik und Neigung zu Neoplasien (lymphoproliferative Krankheiten) gekennzeichnet ist und meist schon im Kindesalter zum Tod führt. Pathomechanismus: ein lysosomaler Defekt, der die Fusion mit Phagosomen beeinträchtigt (daher Defekt des ,intracellular killing“ von phagozytierten Mikroorganismen, aber auch des Pigmenttransfers). Es finden sich ultrastrukturell in den Neutrophilen Riesenlysosomen, in Melanozyten 
Riesenmelanosomen. Klinisch ist die Haut beim Chediak-Higashi-Syndrom durch einen silbergrauen Farbton gekennzeichnet (Analogon im Tierreich: der silbergraue Aleutennerz).

Prader-Willi-Syndrom. Ein seltenes Entwicklungsstörungssyndrom mit unbekannter genetischer und pathophysiologischer Basis, das durch milden OCA, geistige Retardation, Verhaltensstörungen und Hypogonadismus gekennzeichnet ist.

Therapie. OCA, gleichgültig welchen Untertyps, ist therapierefraktär. Besonders wichtig ist daher die Prophylaxe von UV-Schäden: Dies gilt sowohl für das Auge (Sonnenbrillen) als auch für die Haut (konsequente Verwendung von Sonnenschutzmittel), v. a. in Ländern mit hoher UV-Einstrahlung. So findet man bei einheimischen Albinos in Afrika häufig schon in der Jugend aktinische Keratosen oder Plattenepithelkarzinome.

\subsubsection{Umschriebene Hypomelanosen}

Umschriebener Melaninmangel kann durch fokal fehlende oder mangelhafte Anlage des Pigmentsystems in der Haut oder durch dessen sekundäre (Zer)störung zustandekommen. Bei der ersteren Gruppe spielen Defekte der Ontogenese eine entscheidende Rolle.

Melanoblasten wandern aus dem Neuroektoderm aus, durch das Mesenchym hindurch, in die Epidermis ein und differenzieren dort zu mit den Keratinozyten interagierenden Melanozyten. Auf dieser Wanderschaft können Fehler eintreten, die sich gesetzmäßig als umschriebene Pigmentanomalien (allenfalls mit assoziierten Organsymptomen) manifestieren. Prototypen dieser ontogenetisch bedingten Pigmentstörungen sind Piebaldismus, Hypomelanosis Ito, Nävus depigmentosus und die dermale Melanozytose.

\section{Ontogenetisch bedingte Hypomelanosen}

Piebaldismus (Abb.19.11). Ein relativ seltener (Prävalenz ca. 1/15.000) autosomal-dominant vererbter, vitiligoähnlicher Zustand mit großfleckiger Depigmentierung an Rumpf und Extremitäten, der schon bei Geburt gegeben ist und lebenslang unverändert bestehen bleibt. Die Flecken sind weiß (depigmentiert), unregelmäßig begrenzt, auffallend symmetrisch und können in sich hyperpigmentierte Areale aufweisen. Prädilektionsstellen sind Rumpfseiten, die Mittelpartie der Extremitäten (unter Aussparung der Akren) sowie ein zwickelförmiger zentraler Bereich an Stirn und Kapillitium. Innerhalb der Flecken sind die Haare weiß; ein charakteristisches Symptom ist daher eine frontale Strähne weißen Haares („white forelock“). Die klinische Ausprägung kann sehr verschieden sein; die „white forlock“ ist das konstanteste Symptom (ca. 90\%) und kann auch isoliert als Abortivform vorkommen.

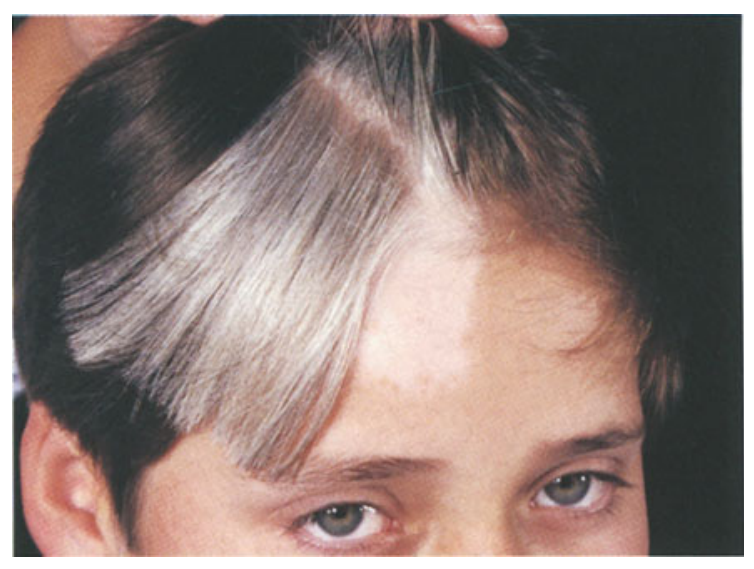

Abb. 19.11. Piebaldismus. Zwickelförmiges, depigmentiertes Areal an der Stirn, in diesem Bereich eine weiße Haarsträhne ("white forlock")

Analogie: Frontale Schecken sind im Tierreich häufig, etwa bei Pferden.

Assoziierte Befunde sind manchmal Heterochromia iridum und Schwerhörigkeit bzw. Taubheit.

Histologie. In den betroffenen Arealen nur vereinzelte Melanozyten mit atypischen, nicht melaninisierten Melanosomen.

Pathogenese. Der Piebaldismus ist mit Deletionen des c-kit-Protoonkogens (Chromosom 4q12) assoziiert (kodiert für die Mastzell/Stammzell-Faktor-RezeptorTyrosinkinase). Da SCF auch ein Wachstumsfaktor für Melanozyten ist, vermutet man eine Reifungsstörung und Untergang der Melanoblasten entweder schon in der Neuralleiste oder bald nach Kolonisierung der Haut. Beim klassischen Piebaldismus scheint dieser Gendefekt auf Pigmentzellen beschränkt $\mathrm{zu}$ sein (Mastzellen unauffällig!).

Waardenburg-Syndrom. Ein sehr seltenes (Prävalenz 1: 200.000) autosomal-dominantes piebaldismusähnliches Syndrom, das durch zusätzliche Symptome erschwert ist: Heterochromia iridum, neurosensorische Taubheit, hypopigmentierte Augenfundi, Hypertelorismus, vorzeitiges Ergrauen der Haare, M. Hirschsprung u. a.m.

In der Literatur finden sich Fälle von ausgeprägter ZNS-Beteiligung bei Piebaldismus bzw. Waardenburg-Syndrom: zerebelläre Ataxie, geistige Retardierung u. a.m. Es ist wahrscheinlich, daß alle genannten Leiden einen einheitlichen Komplex ergeben, der von isolierter „white forlock“ über klassischen Piebaldismus und das Waardenburg-Syndrom zum Waardenburg-Syndrom mit schwerer ZNS-Beteiligung reicht.

Hypomelanosis Ito. Ein seltenes, wahrscheinlich autosomal-dominantes Erbleiden, das durch auffällige Hautzeichen und häufig (bis 90\%) assoziierte Systemzeichen charakterisiert ist. Die Haut zeigt generalisierte bizarr streifige Areale von Hypopigmentierung entlang der Blaschko-Linien. Diese sind meist schon bei Geburt vorhanden (oder entstehen in der ersten Lebenszeit), können sich aber nach jahrelangem Bestand 
Abb. 19.12. Naevus depigmentosus. Ein lanzettförmiger, hypopigmentierter Fleck

spontan zurückbilden. Assoziierte Zeichen sind verschiedenartige Fehlbildungen des Muskel/Skelettsystems, der Augen, Zähne, ZNS-Symptome, Epilepsie und geistige Retardierung.

Histologie. Im befallenen Bereich sind die Melanozyten nicht wesentlich verringert, sind aber klein und besitzen nur wenige reife Melanosomen.

Pathogenese. Es handelt sich um ein Mosaikmuster, das durch einen Klon normaler und einen aus mangelhaft differenzierten Melanozyten gebildet wird. Auch die Hypomelanosis Ito ist vermutlich durch einen molekularen Defekt bedingt, der an den Melanoblasten der Neuralleiste wirksam wird und Melanosomenreifung und -transfer behindert.

Die Hypomelanosis Ito wirkt wie ein Umkehrbild der Incontinentia pigmenti und wurde deshalb auch als „Incontinentia pigmenti achromians“ bezeichnet. Dies ist irreführend.

Naevus depigmentosus (Abb.19.12). Eine relativ seltene kongenitale, solitäre, nicht hereditäre, scharf, bizarr und unregelmäßig begrenzte hypopigmentierte Läsion, die entlang der Blaschko-Linien verläuft. Prädilektionsstelle: Rumpf. Die Haare in Naevi depigmentosi sind weiß. Assoziierte Zeichen sind selten (neurologische Störungen). Der Nävus depigmentosus ist vermutlich eine forme fruste der Hypomelanosis Ito.

Histologie. Wie bei dieser.

Differentialdiagnose. Naevus anaemicus (rötet sich nicht bei Reiben) und segmentale Hypopigmentierung bei tuberöser Hirnsklerose.

\section{Erworbene umschriebene Hypomelanosen}

Hauptursachen erworbener umschriebener Hypomelanosen sind immunologisches, toxisches, entzündliches und aktinisches Trauma.

Vitiligo. Vitiligo ist eine klinisch durch charakteristischen fleckartigen Pigmentverlust gekennzeichnete, häufige und kosmetisch bedeutsame Dermatose, die auf der Destruktion epidermaler Melanozyten wahr- scheinlich durch Autoaggressionsmechanismen beruht und oft mit Systemsymptomen assoziiert ist.

Die kosmetische Bedeutsamkeit resultiert aus der großfleckigen, kreideweißen Entfärbung insbesondere an den freigetragenen Körperregionen (Gesicht, Handrücken), die bei dunkelhäutigen Völkern klarerweise besonders auffällig ist. Menschen mit Vitiligo wurden seit altersher häufig für „aussätzig“ gehalten und sozial stigmatisiert - die Gleichsetzung der Vitiligo mit Leukodermen bei Lepra geht schon auf die Bibel zurück.

Epidemiologie. Vitiligo ist mit einer Prävalenz von $0,5-4 \%$ relativ häufig. Sie ist weltweit verbreitet, tritt vorwiegend bei Jugendlichen bzw. in der ersten Lebenshälfte auf und ist deutlich familiär gehäuft (bei ca. $30 \%$ positive Familienanamnese). Autosomal-dominante oder polygene Vererbung wird diskutiert. Klare Assoziationen mit HLA-Typen bestehen nicht.

Krankheiten analog der Vitiligo werden auch im Tierreich beobachtet: die Lipizzanerpferde sowie verschiedene Schweineund Fischarten.

Klinik (Abb.19.13). Vitiligo ist durch völlig depigmentierte, kalkweiße, ansonsten aber unauffällige Herde gekennzeichnet. Diese sind meist rund, von einem dunkleren (manchmal entzündlichen) Halo umgeben und scharf begrenzt. Zu Beginn einige Millimeter groß, vergrößern sich die Herde langsam durch peripheres Wachstum, werden polyzyklisch und sind somit in der Wachstumsphase nach außen konvex. In Herden befindliche Haare bleiben oft lange Zeit pigmentiert. Prädilektionsstellen sind periorifizielle Regionen (um Augen, Nase, Mund, perianal und -genital) sowie häufig traumatisierte Stellen: Streckseiten der großen Gelenke, Achseln, Handgelenksbeugen sowie Hand- und Fingerrücken. Die Herde sind auffallend symmetrisch verteilt. Auch die hautnahen Schleimhäute sowie Handflächen und Fußsohlen können befallen sein. Ein positives Köbnerphämomen ist häufig (bis zu $30 \%$ ). Die Perianalregion ist eine differentialdiagnostisch sehr wichtige Prädilektionsstelle, da sie fast stets und sehr früh betroffen ist.

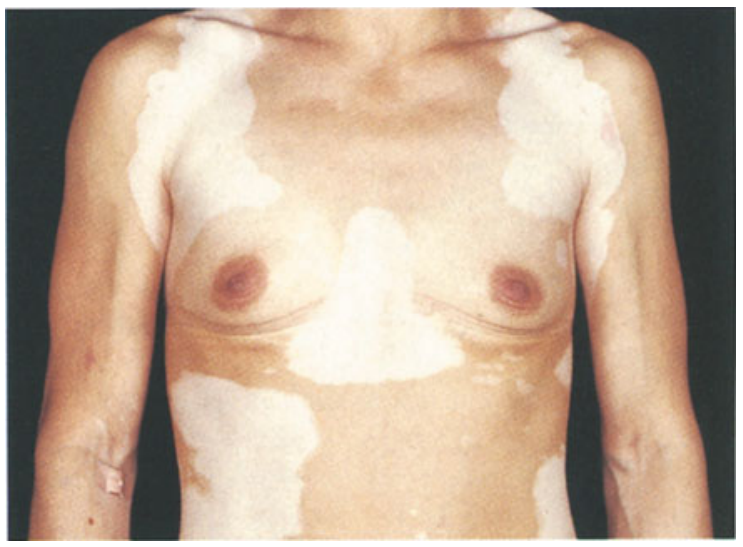

Abb. 19.13. Vitiligo. Auffallend symmetrische, scharf und polyzyklisch begrenzte depigmentierte Herde 


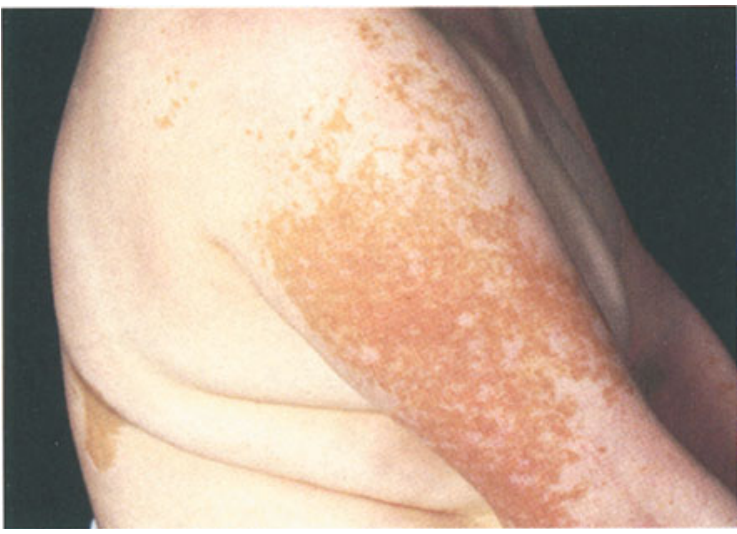

Abb. 19.14. Subtotale Vitiligo. Es verbleiben nur mehr einzelne pigmentierte Hautstellen, die einem Naevus spilus ähneln

Bei Progredienz entsteht ein (wegen des Befalls der freigetragenen Körperregionen) sehr auffälliges grobscheckiges Bild. Schließlich können die depigmentierten Areale durch Konfluenz den gesamten Körper überziehen, wobei nicht selten Inseln normaler Haut inmitten der vitiliginösen Haut übrig bleiben (Abb. 19.14).

In solchen Fällen wird häufig zunächst die vitiliginöse Haut für blaß, aber normal, und die verbleibende normale Haut für einen Naevus spilus gehalten. Bei derart ausgedehnter Vitiligo ist die komplette Depigmentierung das Therapieziel.

Morphologische Klassifikation. Man unterscheidet eine fokale (einzelne Herde), eine regionale (Verteilung entspricht ungefähr einem Dermatom; diese Form gilt als besonders persistent) und eine generalisierte Vitiligo (häufigster Typ). Eine Sonderform ist die sog. Trichrom-Vitiligo: zusätzlich zu den normalen und den depigmentierten Arealen finden sich, deutlich abgesetzt, hypopigmentierte Anteile (Zwischenstadium zu völliger Depigmentierung).

Verlauf. Sehr variabel und kaum vorhersagbar. Der Krankheitsbeginn ist meist schleichend, nur selten rapide. Manchmal lassen sich mechanische Traumen oder starke Sonnenbestrahlung als präzipitierender Faktor feststellen (Köbner-Phänomen); starke UV-Expositionen können schubartige Verschlechterungen auslösen. Psychische Erschütterungen werden häufig als auslösender Faktor angegeben (und auch geglaubt). In der Folge kommt es zur unterschiedlich schnellen (meist sehr langsamen) schubartigen Progredienz. Die Vitiligo kommt entweder nach Jahren zum Stillstand und hinterläßt einige oder zahlreiche permanent depigmentierte Herde (häufiger), oder schreitet zum totalen Pigmentverlust fort (progressiver Verlaufstyp). Perioden fokaler bzw. multifokaler Repigmentierung kommen während des gesamten Krankheitsverlaufs vor. Auch gänzliche spontane Rückbildung wird beobachtet, ist jedoch der Ausnahmefall.

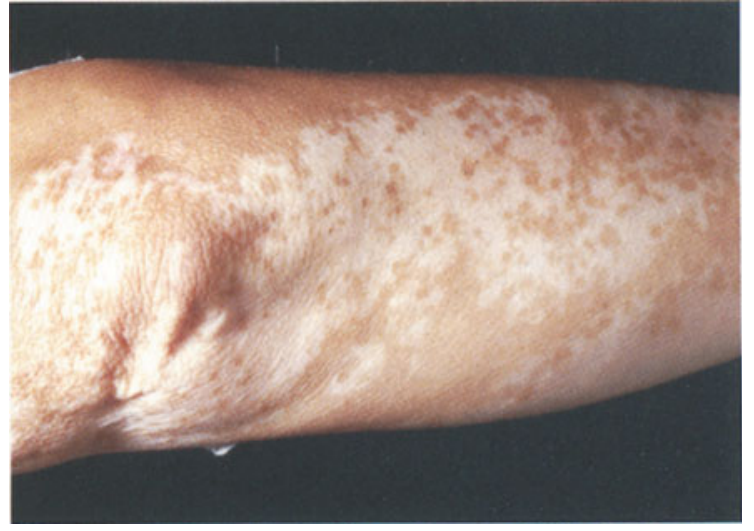

Abb. 19.15. Repigmentierung eines Vitiligoherdes aus den Haarfollikeln

Die Rückbildung der Herde erfolgt durch Einwandern von Melanozyten entweder vom Rande her und/oder aus den meist unbefallenen Haarfollikeln (Abb.19.15). Typische Repigmentierungsmuster sind daher Epheliden-bzw. konfettiartige Flecke um die Haarfollikel und konkave Begrenzungslinien.

\section{!}

Progrediente Herde sind nach außen konvex, regrediente konkav.

Histologie. In befallenen Arealen fehlen Melanozyten. Im Randbereich meist milde lymphozytäre Infiltrate; ultrastrukturell pyknotische Melanozyten.

Assoziierte Symptome und Krankheiten. Diese können sein:

- Haut: Die Haare sind in ca. $30 \%$ mitbefallen, entweder in Form fokaler Depigmentierung (Poliosis) oder vorzeitigen Ergrauens (Kanities). Halo-Nävi sind häufig; eine Assoziation mit Melanom ist eindeutig (nach Schätzungen 180 fache Inzidenz bei Vitiligo). Alopecia areata in ca. $20 \%$;

- Augen: Mitbefall nicht selten (ca. 10\%), aber meist klinisch stumm: Hypo- und Depigmentationen sowie Närbchen von Iris und Chorioidea; floride Uveitis ist selten, noch seltener Retinitis pigmentosa;

- Innenohr: Assoziation von Hörproblemen mit klassischer Vitiligo ist unsicher, jedenfalls nicht häufig;

- Autoimmunkrankheiten: Assoziation mit (Autoimmun)Thyreoiditis (bzw. Thyreotoxikose, Myxödem, toxische Struma etc.) besteht in ca. $30 \%$. Seltener assoziiert sind Alopecia areata, Diabetes mellitus (5\%), ausnahmsweise Autoimmunhypoparathyreoidismus, perniziöse Anämie, M. Addison und multiglanduläre hormonelle Insuffizienz.

Bei letzteren Assoziationen wird diskutiert, ob sie nicht zufällig sind. Dem widerspricht, daß bei allen diesen die Inzidenz von Vitiligo überzufällig häufig ist. Es ist wahrscheinlich, aber nicht generell akzeptiert, daß Vitiligo in Assoziation mit Autoimmunkrankheiten aggressiver abläuft. 
Komplikationen. Systemische Komplikationen ergeben sich aus den genannten Begleitkrankheiten. Die vitiliginösen Hautareale sind durch den fehlenden Lichtschutz besonders UV-empfindlich (Sonnenbrände!). Aktinische Keratosen und Plattenepithelkarzinome bei chronischer Vitiligo sind jedoch paradoxerweise selten.

Labor. Die Routinetests sind unauffällig, doch können in bis zu 20 \% Autoantikörper gegen verschiedene Körperzellen bzw. Zellstrukturen nachgewiesen werden: Schilddrüsen-, glatte Muskel-, Belegzellen, Melanozyten; Mitochondrien, Mikrosomen; antinukleäre Antikörper. Melanozytotoxische Autoantikörper finden sich nur in einem Teil (wenn auch nach isolierten Literaturberichten bis $80 \%$ ), oft auch bei Normalpersonen.

Pathogenese. Eine Autoimmungenese wird durch die Assoziation mit den genannten Autoantikörpern und -immunkrankheiten, die häufige Nachweisbarkeit (in vitro) melanozytotoxischer Antikörper sowie die Anwesenheit aktivierter CD4 + und CD8 + Lymphozyten im aktiven Randsaum nahegelegt. Alternative Erklärungen: die Selbstmord- (Fehlen eines Schutzmechanismus, der normale Melanozyten gegen toxische Melaninsyntheseprodukte bewahrt) und die neurogene Hypothese (Freisetzung melanozytotoxischer Substanzen aus Nervenendigungen).

Therapie. Lokale Kortikosteroide sind wenig wirksam und kommen nur zur Behandlung kleiner Läsionen in Betracht; systemische sind nicht angezeigt. Mittel der Wahl ist die Photochemotherapie; als phototoxische Substanz eignen sich besonders Trisoralen, 5-Methoxypsoralen und Khellin. Die Therapie ist langwierig; erst nach Monaten wird eine meist nur inkomplette Repigmentierung erzielt (die Läsionen an den freigetragenen Körperstellen sprechen häufig besonders schlecht an).

Eine noch nicht ausgereifte Methode ist die Autotransplantation isolierter Melanozyten (Problem: wegen des Köbnerphänomens kann an der Entnahmestelle ein neuer Vitiligoherd entstehen). Eine ultima ratio an besonders auffälligen Regionen (z. B. Lippen) kann die Tätowierung mit Eisenoxyd sein (bleibt kosmetisch oft unbefriedigend). Eine keinesfalls unvernünftige Lösung ist die Verwendung wasserstabiler Schminken (die auch nach dem jeweiligen Pigmentierungszustand der Haut gemischt werden können). Restherde normaler Haut können durch permanente Bleichung mit der für Melanozyten toxischen Substanz Hydrochinonmonobenzyläther entfernt werden.

Differentialdiagnose. Narben, ausgebrannter CDLE, Vinylchloridkrankheit, Piebaldismus, Pityriasis versicolor alba.

Vogt-Koyanagi-Harada-Syndrom. Eine seltene Systemkrankheit, die mit einer transienten, oft milden meningoenzephalitischen Vorphase beginnt und bald in das Vollbild übergeht: Uveitis anterior und posterior (nicht selten mit Ablatio retinae), bilaterale Dysakusis (ca. 50\%) sowie ausgedehnte Vitiligo und Poliosis. Manche ZNS-Symptome können permanent erhalten bleiben (Paresen, Persönlichkeitsveränderungen).

Pathogenese. Vermutlich eine Maximalvariante der Vitiligo.Virale Auslösung wird erwogen.

Therapie. Systemische Kortikosteroide sind zur Behandlung der Augenveränderungen erforderlich, die Vitiligo spricht darauf nur gering an.

\section{Weitere erworbene umschriebene Hypomelanosen}

Postinflammatorische Hypopigmentierung. Eine häufige Folge verschiedener entzündlicher Dermatosen: Psoriasis, Ekzeme (atopische Dermatitis; Pityriasis alba), Cutis vagantium, Sarkoidose, Sklerodermie, Lymphome etc. Eine eigene Kategorie mit oft besonderer Morphologie sind Hypopigmentierungen bei oder nach Infektionskrankheiten: Pityriasis versicolor, Treponematosen (Syphilis, Pinta, Frambösie), Lepra, Kala Azar. Pathogenese: direkte Schädigung der Melanozyten durch Entzündungsmediatoren und/oder Störung des Pigmenttransfer.

Postinflammatorische Depigmentierung ist seltener (z.B. Herpes simplex und zoster).

Toxische Hypo- und Depigmentierung. Eine Reihe von Chemikalien der Arbeitswelt können bei Kontakt zur vorübergehenden oder bleibenden Schädigung der Melanozyten führen (Tabelle 19.3). Zur irreversiblen Zerstörung führt der Monobenzyläther des Hydrochinon (s.oben). Hydrochinon ist Bestandteil vieler Bleichcremen.

Aktinisch bedingte Hypomelanose. Die idiopathische Hypomelanosis guttata ist eine diskrete, perifollikuläre (?) kleinfleckige Hypopigmentierung, die vorwiegend an den Unterschenkeln von Frauen in der 2.Lebenshälfte mit chronischem UV-Schaden auftritt (Abb.19.16). Pro-

Tabelle 19.3. Hypo-/Depigmentierung induzierende Chemikalien

\begin{tabular}{|c|c|}
\hline $\begin{array}{l}\text { Aromatische } \\
\text { Verbindungen }\end{array}$ & $\begin{array}{l}\text { Phenol und Analoge } \\
\text { (Alkyl-, Amyl-, Butyl-) } \\
\text { Hydroxytoluol und Analoge } \\
\text { Katechol und Analoge } \\
\text { (Methyl-, Isopropyl-, Butyl-) } \\
\text { Hydrochinon und Analoge } \\
\text { (Methyl-, Äthyl-, Benzyläther) }\end{array}$ \\
\hline Sulfhydryle & $\begin{array}{l}\text { diverse Mercaptoamine } \\
\text { (Äthyl-,Propyl-) }\end{array}$ \\
\hline Medikamente & $\begin{array}{l}\text { Benzoyl-Peroxid } \\
\text { 5-Fluorouracil } \\
\text { Thiotepa } \\
\text { Carmustin } \\
\text { Vitamin-A-Säure } \\
\text { Kortikosteroide }\end{array}$ \\
\hline
\end{tabular}




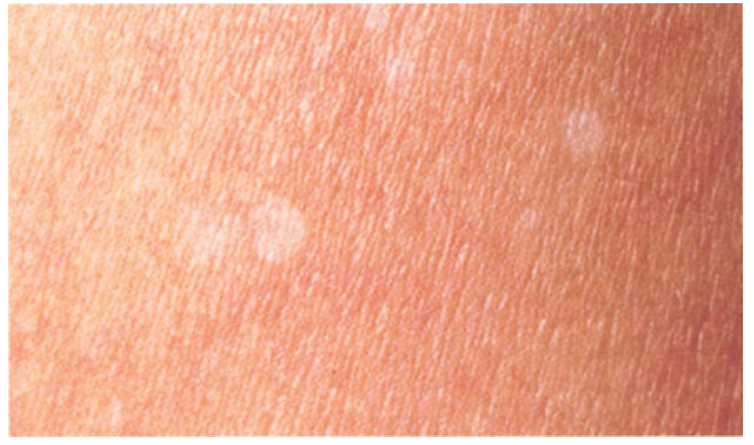

Abb. 19.16. Hypomelanosis guttata. Konfettigroße, runde, scharf begrenzte hypopigmentierte Areale vorwiegend der unteren Extremitäten

gredienter Verlauf. Möglicher zusätzlicher kausaler Faktor ist Rasieren bzw. Epilation der Körperhaare. Eine maximale Erscheinungsform sind bizarre, atrophe narbenähnliche Depigmentationen der UV-geschädigten Unterarme im hohen Alter („stellate pseudoscars“).

\section{Erworbener Pigmentverlust der Haare}

Ergrauen der Haare als Teil des physiologischen Alterungsprozesses wird als Canities bezeichnet, beruht auf langsamer Reduktion der Melanosomenproduktion und schließlich Zugrundegehen der Melanozyten des Haarfollikels. Typisches Verteilungsmuster (Beginn: Schläfen, Scheitel, dann Rest), irreversibel (Ausnahme: Wiederdunkelwerden der Haare bei Porphyria cutanea tarda). Die Haare ergrauen individuell (gefärbte Haare erkannt man am monotonen Farbton des Kapillitiums).Setzt mit etwa 25 Jahren ein, und ist mit etwa 70 abgeschlossen; erhebliche individuelle Schwankungen. Afrikaner ergrauen später als Weiße. Prämature Canities tritt entweder als (autosomal-dominant) vererbte Anlage oder als Begleitsymptom progerieähnlicher Fehlbildungssyndrome auf.

\subsection{Krankheiten des Fettgewebes}

Das Fettgewebe ist zwar bei tiefen Prozessen oft mit betroffen (z. B. Phlegmonen, infektiöse oder nicht-infektiöse Granulome), selbst jedoch nur selten Manifestationsort von Krankheiten. Noxen können auf das Fettgewebe sowohl durch die Zirkulation (z. B. Erythema nodosum) oder direkt lokal einwirken (Trauma, Injektion). Sie werden, eher monoton und genormt, mit Entstehung einer Pannikulitis beantwortet: tiefsitzende, rote bis livide Knoten, häufig an den Beinen loalisiert. Geht im Rahmen der Pannikulitis Fettgewebe zugrunde, entstehen gravierendere Läsionen wie Einschmelzung, Fisteln, Fibrosierung, Sklerose und
Schrumpfung. Eine andere, seltenere Reaktionsweise ist die ohne vorhergehende Entzündung auftretende Atrophie.

Das Fettgewebe ist - entsprechend seiner Funktion als mechanisches Schutzpolster-gegen mechanische Traumen wenig empfindlich, um so empfindlicher jedoch gegenüber chemischen, entzündlichen und auch Kältetraumen. Die Reaktionsweisen des Fettgewebes sind in ihrer Zahl beschränkt; unterschiedliche Krankheiten laufen daher unter ähnlichen Bildern ab und werden unter dem Begriff, Pannikulitis" subsummiert.

Klassifikation der Pannikulitis (Tabelle 19.4). Grundlage ist die Unterscheidung zwischen septaler und lobulärer Pannikulitis: bei der septalen sind die entzündlichen Veränderungen auf die (die Gefäße tragenden) Septen zwischen den Fettläppchen beschränkt, bei der lobulären Pannikulitis sind die Fettläppchen in ihrer Gesamtheit ergriffen.

Alle Formen der Pannikulitis, deren primärer Ausgangspunkt eine Schädigung der Fettzellen ist, sind lobulär; alle Formen, deren primäre Noxe am Gefäß-Bindegewebssystem ansetzt, sind (zumindest anfangs) septal.Eine septale Pannikulitis kann sich jedoch in eine lobuläre fortentwickeln. Die Gefässe sind bei der Pannikulitis entweder Mittler der Entzündungsreaktion oder selbst deren Ziel (Vaskulitis). Lobuläre Pannikulitis ist der gravierendere Befund, da er mit Nekrose des Fettgewebes einhergeht und zur unten beschriebenen pathophysiologischen Kettenreaktion führt.

Pathologische Reaktionen bei lobulärer Pannikulitis. Untergang von Fettzellen ist Endresultat vieler Traumen, das selbst wieder eine Kaskade pathophysiologischer Vorgänge auslöst: Das frei ins Gewebe gelangende Fett, zum überwiegenden Teil Triglyzeride, wird durch Blut- oder Gewebelipasen gespalten. Die entstehenden freien Fettsäuren führen zu einer heftigen entzündlichen Reaktion, durch die im Sinn eines Circulus vitiosus weiteres Fettgewebe zugrunde geht. Makrophagen wandern ein, die das Fett phagozytieren (Lipophagen) und Granulome ausbilden (Lipogranulom). Letztere führen zu Fibrosierung und Sklerosierung.

Stehen bei lobulärer Pannikulitis Zelluntergang und Entzündung im Vordergrund, kommt es zur Einschmelzung des Fettgewebes - von nur histologisch erkennbaren „Mikroölzysten“ bis zu fluktuierenden Knoten mit Fistelbildung und Absonderung eines öligviskösen Exsudats. Überwiegen hingegen die produktiven Veränderungen, entstehen torpide, knotige oder plattenartige Lipogranulome. Endzustand ist in beiden Fällen eine intensive Fibrosierung und narbige Schrumpfung der Pannikulitisherde, die zu charakteri- 


\begin{tabular}{|c|c|c|}
\hline & lobuläre Pannikulitis & septale Pannikulitis \\
\hline OHNE Vaskulitis & $\begin{array}{l}\text { idiopathische Pannikulitis } \\
\text { (Pfeifer-Weber-Christian) } \\
\alpha_{1} \text {-Antitrypsin-Defizienz } \\
\text { physikalische Pannikulitis } \\
\text { (Kälte, traumatische, chemisch) } \\
\text { neonatale Pannikulitis } \\
\text { (Sklerema neonatorum, neonatale } \\
\text { Fettgewebsnekrose) } \\
\text { bei Systemkrankheiten } \\
\text { (LE, Sarkoidose, Pankreaskrankheiten, } \\
\text { Lymphome) }\end{array}$ & $\begin{array}{l}\text { E. nodosum } \\
\text { eosinophile Fasziitis } \\
\text { Eosinophilie-Myalgie-Syndrom } \\
\text { systemische Sklerodermie }\end{array}$ \\
\hline MIT Vaskulitis & Nodulärvaskulitis & $\begin{array}{l}\text { bei Thrombophlebitis } \\
\text { bei Arteriitis }\end{array}$ \\
\hline
\end{tabular}

stischen Einziehungen und dadurch zu erheblichen Reliefveränderungen der Haut, zu Sklerosierung und Adhärenz der Haut an den tiefen Faszien führt.

Diagnostik. Wegen der Ähnlichkeit vieler Krankheitsbilder ist eine histologische Sicherung meist angezeigt. Hierfür ist die korrekte Durchführung der Biopsie Voraussetzung: Diese muß nicht nur ausreichend groß sein, sondern auch das Fettgewebe miterfassen (häufiger Fehler: Biopsien zu oberflächlich).

\subsubsection{Septale Pannikulitis}

Der häufigste Vertreter dieser Kategorie ist das Erythema nodosum (s. S. 204). Eine septale Pannikulitis ist ferner Begleitsymptom aller Formen der Sklerodermie (s.S. 466) und mancher tiefer vaskulitischer Prozesse (Thrombophlebitis, Systemvaskulitiden).

\subsubsection{Lobuläre Pannikulitis}

Lobuläre Pannikulitis kann entweder als umschriebener oder als Systemprozeß auftreten; in letzterem Fall kann es sich um Krankheiten sui generis oder Begleitsymptome anderer Systemkrankheiten handeln.

\section{Umschriebene lobuläre Pannikulitis}

Diese ist die häufigste Form der lobulären Pannikulitis; sie entsteht durch direkte Einwirkung von physikochemischen Traumen.

Mechanisch-traumatische Pannikulitis (traumatische Fettgewebsnekrose). Relativ selten, gewöhnlich bei sehr adipösen Personen. Prädilektionsstellen: Brüste, Hinterbacken. Klinik: schmerzhafte knotige und plattenartige derb-fibrotische Infiltrate. Ausheilung mit Atrophie.
Kältepannikulitis. Eine seltene, nach langdauernder Kälteexposition auftretende knotige Form der Pannikulitis vorwiegend bei Säuglingen und Kleinkindern. Sie verläuft selbstlimitiert, Einschmelzung bleibt aus. Prädilektionsstellen: der kalten Luft oder kalten Gegenständen (Eis!) exponierte Regionen (Wangen, seltener Extremitäten, Skrotum). Bedrohliche Formen der kälteinduzierten lobulären Pannikulitis im Neugeborenenalter sind das Sklerema neonatorum und die neonatale subkutane Fettnekrose (s. S. 708).

Kleinkinder sind deswegen besonders empfindlich, weil ihr Fett einen höheren Anteil gesättigter Fettsäuren besitzt und daher leicht in der Kälte erstarrt. Der Gehalt an gesättigten Fettsäuren normalisiert sich im ersten Lebensjahr.

Pannikulitis nach Injektion von Fremdsubstanzen. Zahlreiche intramuskulär zu verabreichende Medikamente führen, wenn fälschlich in die Subkutis injiziert, zur Fettgewebsnekrose und, in deren Folge, zum sog. „Spritzenabszeß“. Auslösend sind entweder primär irritierende Substanzen (Beispiel: Pentazocin) oder ölige Lösungsmittel. Nicht selten entstehen solche Formen der Pannikulitis durch Selbstinjektion (Suchtgifte, Artefakte).

Klinisch zeigen sich schmerzhafte, häufig einschmelzende und fistulierende Knoten an der Injektionsstelle von oft erheblicher Größe, die mit unregelmäßig eingezogenen Narben ausheilen.

Differentialdiagnose. Embolia cutis medicamentosa, eine unregelmäßig begrenzte, extrem schmerzhafte Nekrose nach versehentlicher intraarterieller Injektion von (viskösen oder schlecht aufgelösten) Medikamenten.

Eine Sonderform stellen Silikongranulome dar. Früher wurden aus kosmetischen Gründen Paraffinoder Silikonpräparate frei in das Fettgewebe injiziert. Das unausbleibliche (wenngleich auch oft erst nach Monaten auftretende) Resultat waren extrem chronische, fistulierende und fibrosierende Veränderungen und daher Entstellung der so behandelten Körperteile (Brüste, Gesicht, gelegentlich auch männliche Genitalien). Das Silikon wird nicht von Makrophagen abtransportiert! Die Verabreichung von freiem Silikon ist heu- 
te kontraindiziert, eine solche von abgepacktem Silikon wird jedoch geübt.

\section{Systemische lobuläre Pannikulitis}

Eine Gruppe von Krankheitsbildern, die durch multiple knotige Läsionen von Pannikulitis an der Haut, oft auch im Fettgewebe innerer Organe und Systemzeichen gekennzeichnet sind.

Diese Krankheitsgruppe bestand ursprünglich aus einer einzigen Krankheit unbekannter Ursache, der „febrilen non-suppurativen Pannikulitis“ (Pfeifer-Weber-Christian). Aus dieser wurden zunehmend einzelne Einheiten ausgegliedert, für die eine Ursache gefunden wurde (s. unten). Es ist zu vermuten, daß der verbleibende Rest ätiologisch gleichfalls heterogen ist.

Idiopathische lobuläre Pannikulitis (Pfeifer-WeberChristian). Eine seltene systemische lobuläre Pannikulitis unbekannter Ursache, die selten ist und vorwiegend bei Frauen mittleren Lebensalters auftritt

Klinik. Eine schubartig verlaufende chronische Krankheit, die mit Fieber, Arthralgien und Krankheitsgefühl einhergeht. An der Haut, hauptsächlich an Beinen und im Beckenbereich (Gesicht ist nie befallen), erscheinen meist symmetrisch verteilte, schmerzhafte, entzündliche knotige Herde von einigen Zentimetern Durchmesser, die sich in der Regel nach einigen Wochen spontan mit Fibrose zurückbilden. Selten kommt es zur Exulzeration, Entleerung serös-öligen Exsudats und Ausbildung von Fisteln. In den meisten Fällen beschränken sich die Läsionen auf das subkutane Fettgewebe. An inneren Organen können sie zu unterschiedlichen Symptomen führen: Perikarditis, Pleuritis, akute Abdominalsymptomatik, Hepatomegalie; selten auch Befall des Knochenmarks mit Thrombo- und Leukopenie.

Histologie. Lobuläre Pannikulitis mit gemischtzelligem Infiltrat, im späteren Verlauf Lipophagie und Fibrose.

Labor. Unspezifische Entzündungszeichen und eine hohe Senkung. Bestimmung des Pankreasenzyme und des $\alpha 1$-Antitrypsin erforderlich!

Therapie. Allgemein akzeptierte Therapierichtlinien existieren nicht. Ansprechen auf systemische Kortikoide ist wechselhaft, milde Wirkung von Tetrazyklinen. Chloroquin und Dapson sind häufig gut wirksam.

Prognose. Letale Ausgänge für schwer verlaufende Fälle mit Systembeteiligung wurden berichtet. In der Regel kommt es nach jahrelangem rezidivierenden Verlauf zum Sistieren der Symptomatik.

Idiopathische Lipogranulomatose (Rothman-Makai-Syndrom). Eine seltene Variante der Pfeifer-Weber-ChristianKrankheit, die hauptsächlich bei Kindern vorkommt und durch multiple derbe, knotige oder plattenartige Infiltrate v.a. der Extremitäten gekennzeichnet ist. Die Erscheinungen bilden sich meist innerhalb eines Jahres spontan zurück. Keine Systembeteiligung. Histologie: Lipogranulome und ausgeprägte Fibrose.
Lobuläre Pannikulitis bei $\boldsymbol{\alpha} 1$-Antitrypsinmangel. Eine vermutlich nur selten diagnostizierte Form der systemischen lobulären Pannikulitis. Das klinische (und histologische) Bild ist analog, jedoch durch größere Knoten, Prädilektion des Rumpfes und stärkere Neigung zur Exulzeration und Fistelbildung gekennzeichnet.

a1-Antitrypsin ist die hauptsächliche Antiproteinase des zirkulierenden Blutes. Sie wird in der Leber gebildet, ist ein Akutphasenprotein und Hemmer zahlreicher Enzyme, u.a. der Leukozytenelastase. Bei homozygotem Mangel (Prävalenz 1/7.000) sind die Plasmaspiegel auf 0-20\% reduziert; es resultiert ein Ungleichgewicht zwischen Leukozytenproteinasen und -antiproteinasen, das an der Lunge zu früh auftretendem schwerem Emphysem führt (in ca. $80 \%$; Elastase der durch z.B. Rauchen in die Bronchien gelockten Leukozyten wird nicht ausreichend inaktiviert). Der Mangel ist auch mit früher, progredienter Leberzirrhose assoziiert (Akkumulation durch Ausschleusungsdefizit aus Leberzellen). Heterozygote (Plasmaspiegel $50 \%$ ) scheinen nicht gefährdet zu sein.

Pathogenese. Vermutlicher Auslöser sind Traumen, die durch mangelnde Inaktivierung der Leukozytenproteinasen zur Fettzelldestruktion führen.

Diagnose. Nachweis des Enzymmangels aus dem Serum.

Therapie wie oben; kontinuierliche Substitution mit gereinigtem $\alpha 1$-Antitrypsininhibitor kann Erscheinungsfreiheit bewirken. Die Langzeitprognose hängt von den assoziierten inneren Manifestationen ab.

Lobuläre Pannikulitis bei Pankreatitis und Pankreaskarzinom. Eine seltene Form systemischer lobulärer Pannikulitis, die mit Freisetzung von Pankreasfermenten aus dem krankhaft veränderten Pankreas assoziiert ist. Männer sind viel häufiger betroffen als Frauen. Das klinische Bild ähnelt wieder der idiopathischen Form, neigt jedoch mehr zur Einschmelzung. Histologisch sind basophile nekrotische Fettzellen charakteristisch ("ghost cells"). Systemzeichen sind Fieber, Arthralgien, Polyserositis.

Zugrunde liegen kann sowohl eine Pankreatitis (traumatisch, bei Gallensteinkrankheit, meist jedoch bei Alkoholismus) oder ein Pankreaskarzinom (meist vom azinären Typ). Pankreasenzyme (Lipase, Amylase) sind in Blut und Harn, aber auch in den Herden der Pannikulitis erhöht; durch Spaltung der Neutralfette werden freie Fettsäuren freigesetzt.

\section{Manifestationen von Systemkrankheiten unter der Form von lobulärer Pannikulitis}

Klinisch einer lobulären Pannikulitis entsprechende und von ihr nicht oder nur schwer unterscheidbare Infiltrate des Fettgewebes können bei einer Reihe von Systemkrankheiten auftreten. Systemischer Lupus erythematodes (Lupuspannikulitis), Sarkoidose, Lymphome und Leukämien, sowie die kalzifizierende Pannikulitis bei metastatischer Kalzinose (s. die jeweiligen Kapitel). 


\section{Lobuläre Pannikulitis mit Vaskulitis: \\ Nodulärvaskulitis \\ (syn. Erythema induratum Bazin)}

Ein durch chronische, teils exulzerierende subkutane Knoten an den Unterschenkeln meist von Frauen gekennzeichnetes Krankheitsbild, das auf Vaskulitis mittelgroßer Gefäße, Pannikulitis und granulomatöser Entzündung beruht.

Epidemiologie. Nodulärvaskulitis ist nicht ganz selten und anscheinend an bestimmte Bedingungen geknüpft: Befallen sind fast ausschließlich Frauen mittleren Alters, an der Dorsalseite der Unterschenkel. Diese Frauen sind meist adipös („schwammige“, „säulenartige" Beine), besonders kälteempfindlich und haben oft Zeichen eines chronischen Frostschadens. Die Nodulärvaskulitis galt früher als Tuberkulid; die heute beobachteten Fälle werden jedoch überwiegend nicht mit Tuberkulose assoziiert. Neuerdings wurde allerdings mittels PCR in einem hohem Prozentsatz DNS von M. tuberculosis nachgewiesen.

Klinik. Meist bilateral an den Unterschenkeln (selten auch Oberschenkeln) finden sich mehrere derbe, unscharf abgegrenzte, indolente tiefsitzende Knoten, die an der deckenden Haut fixiert sind; manche dieser Knoten bilden sich spontan zurück, andere schmelzen ein und bilden Fistelgänge. Es kommt zu atropher Narbenbildung und Neueruption solcher Knoten; schließlich wandelt sich der Unterschenkel in eine höckrige, derb infiltrierte, von Fisteln, Ulzera und Einziehungen durchsetzte derbe Platte um. Der Prozeß ist auf die Region beschränkt; keine Systemzeichen.

Histologie. Leukozytär-granulomatöse Vaskulitis der kleineren und mittelgroßen Arterien und Venen, ausgedehnte fibrinoide Nekrosen des Fettgewebes mit lobulärer, zuerst unspezifischer, dann tuberkuloid-granulomatöser, schließlich fibrosierender Entzündung. Hierdurch Zugrundegehen des Fettgewebes und Ersatz durch Fibrose („Wucheratrophie“).

Pathogenese. Ursache unbekannt; abnorme Kältereaktionen der Gefäße sind wahrscheinlich, Immunreaktionen auf bakterielle bzw. mykobakterielle Antigene möglich.

Diagnose. In nicht wenigen Fällen hochpositiver TineTest. Ausschluß einer Organtuberkulose ist angezeigt.

Prognose und Therapie. Auch bei Tine-Test-negativen Patienten sollte ein Versuch mit INH erfolgen. Bei Wirkungslosigkeit nichtsteroidale Antiphlogistika, Tetrazykline, Dapson. Unbehandelt besteht der Prozeß durch viele Jahre weiter.

Differentialdiagnose. Erythema nodosum, kutane Polyarteritis nodosa.

\subsubsection{Fettgewebsatrophien}

Atrophien des Fettgewebes. Diese treten regelmäßig nach lobulärer Pannikulitis verschiedener Genese auf (s.oben), aber auch nach Sklerodermie (Atrophoderma Pasini, Hemiatrophia faciei), Sarkoidose etc. Auf nicht-entzündlicher Basis beruht die umschriebene Fettgewebsatrophie nach subkutaner Injektion von Depotkortikoiden und Insulin. Letztere Herde sind in der Regel rückbildungsfähig.

Lipodystrophien. Sehr seltene Krankheitsbilder unbekannter Ursache, bei denen es zum progredienten Verlust des Fettgewebes von umschriebenen Körperteilen oder des gesamten Körpers (auch des extrakutanen Fetts) kommt.

Die partielle Lipodystrophie ergreift fast ausschließlich präpubertäre Mädchen, beginnt im Gesicht und breitet sich langsam nach kaudal fort, ergreift aber meist die unteren Extremitäten nicht. Die Haut selbst bleibt unverändert. Assoziation mit Diabetes, Komplement-C 3 -Defizienz und Glomerulonephritis.

Die generalisierte Lipodystrophie kommt familiär gehäuft vor und ist mit insulinresistentem Diabetes und dessen Komplikationen (Retinopathie, Nierenveränderungen etc.), aber auch mit Hepatomegalie, Akanthosis nigricans und disseminierten Xanthomen assoziiert.

Von den Lipodystrophien zu unterscheiden sind die harmlosen umschriebenen fokalen Lipoatrophien: erworbene fokale, meist zu mehrt an Rumpf und Extremitäten auftretende Herde von Fettgewebsatrophie unbekannter Ursache (postpannikulitisch?). Eine Sonderform ist die Lipatrophia semicircularis: beidseits symmetrisch an der Vorderseite der Oberschenkel auftretende Schnürfurchen-ähnliche Eindellungen. Dieses seltene klinische Bild ist unbekannter Ursache und tritt vornehmlich bei jungen Frauen auf (Abb. 19.17).

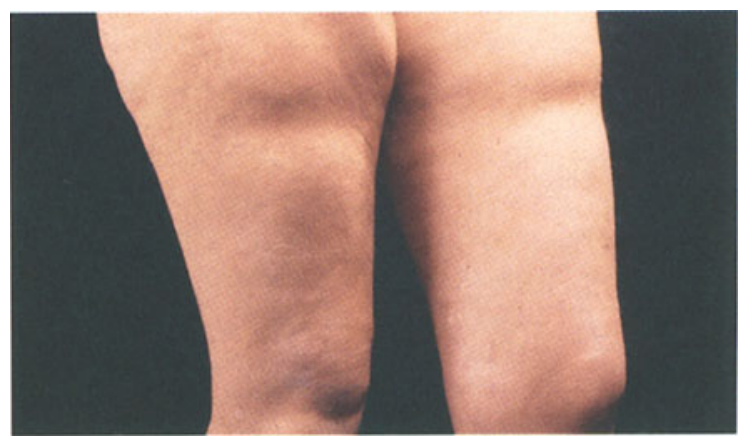

Abb. 19.17. Lipoatrophia semicircularis. Horizontale, an beiden Oberschenkeln in gleicher Höhe befindliche, lineäre Mulden 


\subsection{Krankheiten des Haarapparats}

... Das Haar ist eine bestimmende Komponente der äußeren Erscheinung. Seine Krankheiten und Anomalien sind für den Betroffenen daher oft weit über ihre medizinische Relevanz bedeutsam. Haarprobleme werden in der kosmetikbewußten Gegenwart zunehmend an den Dermatologen herangetragen und sind im allgemeinen schwierig zu lösen.

Die Krankheiten bzw. Anomalien des Haarapparats werden konventionell nach dem jeweiligen Leitsymptom in drei Gruppen eingeteilt:

- Mangel an Haaren: Effluvien, Alopezien, Atrichien;

- Überschuß an Haaren: Hypertrichosen, Hirsutismus;

- Strukturdefekte von Haaren: Haarschaftsanomalien, Pigmentstörungen.

\subsubsection{Effluvien und Alopezien}

Definitionen. Effluvium bezeichnet (Kopf-)Haarausfall, also einen Vorgang. Alopezie ist das Resultat dieses Vorgangs: die erworbene Haarlosigkeit (Glatze), also ein Zustand. Ein Effluvium mündet häufig, aber nicht immer in eine Alopezie. Angeborene partielle oder totale Haarlosigkeit wird Atrichie bzw. Hypotrichie genannt.

Der Begriff „Alopezie“ (ethymologisch eine Anspielung auf die „Räude des Fuchses“) wird oft unscharf auch für andere Zustände als jene gebraucht, wo die Haare tatsächlich fehlen. Der klinische Eindruck einer "Glatze“ entsteht etwa auch, wenn statt normaler Langhaare unscheinbare Lanugohärchen wachsen (androgenetisches Effluvium), die Haare dünn und spärlich sind (z. B. ektodermale Dysplasien) oder vorzeitig abbrechen (z. B. Mikrosporie).

Pathophysiologische Wege zum Haarverlust. Haarausfall kann auf zwei Hauptwegen zustandekommen: durch Verstärkung der physiologischen Haarmauserung oder durch Schädigungen der Haarmatrix. Solche Schädigungen können vorübergehend oder permanent sein und durch systemische oder lokale Noxen verursacht werden.

- Störungen des physiologischen Haarzyklus: Der Haarbestand ist der sichtbare Ausdruck eines Fließgleichgewichts zwischen ausfallenden („Mauserung") und nachwachsenden Haaren; seine Konstanz ist Folge des asynchronen Ablaufs des Haarzyklus in den individuellen Haarfollikeln (s.,,Allgemeiner Teil"). Physiologische Faktoren (s.unten), aber auch milde systemische Noxen (z.B. Fieber) können durch Auslösung der Apoptose in den Haarmatrices zum synchronen, oft vorzeitigen Wachstumsstop und Übertritt in die Telogenphase führen. Da Telogenhaare nach etwa 2-3 Monaten spontan ausfallen, ergibt sich $\mathrm{zu}$ diesem Zeitpunkt ein Wellenberg der natürlichen Haarmauserung, das Telogeneffluvium.

Das Telogeneffluvium ist der häufigste Typ des Haarausfalls. Es ist ein polyätiologisches Reaktionsmuster des Haarapparats, betrifft das gesamte Kapillitium, ist reversibel und durch ein langes Intervall zwischen Noxe und Haarausfall gekennzeichnet. Es kann durch eine Erhöhung der Telogenhaarrate im Trichogramm nachgewiesen werden. Die ausfallenden Haare sind normale Telogenhaare.

Trichogramm: mit einer Klemme werden aus der Stirn-, Scheitel- und Hinterkopfregion beidseits je ein Büschel von 20-30 Haaren ausgezupft, die Haarwurzeln im Mikroskop untersucht und der Anteil der Telogenhaare bestimmt. Liegt dieser über 15-20\%, liegt ein Telogeneffluvium vor.

Es ist unumgänglich, ausgezupfte Haare zu untersuchen, da ausgefallene klarerweise stets Telogenhaare sind. Untersuchung mitgebrachter Haare ist daher wertlos (wie auch die von manchen wenig seriösen Firmen angebotene Befundung postalisch eingesandter Haare).

- Schädigungen der Haarmatrix können durch systemische Noxen oder im Rahmen von Krankheiten des Haarfollikels oder der umgebenden Haut entstehen:

Schwere systemische (z. B. Vergiftungen) oder lokale (z. B. Röntgenbestrahlung) Noxen führen zu Degeneration bis Nekrose von Haarmatrix und Wurzelscheiden und zum Ausfall der Haare noch im Anagenstadium (das Telogenstadium wird nicht erreicht - Anageneffluvium). Das Intervall zwischen Noxe und Haarausfall ist kurz (Tage bis Wochen), die ausfallenden Haare sind geschädigte (dystrophe) Anagenhaare; letztere prägen auch das Trichogramm (bei normaler Telogenhaarrate). Anageneffluvien sind erheblich seltener als Telogeneffluvien, gleichfalls polyätiologische Reaktionsmuster und gleichfalls häufig reversibel; sie können jedoch in schweren Fällen zum Verlust der Follikel und damit zum bleibenden Haarverlust führen.

Telogen- und Anageneffluvien sind theoretisch säuberlich trennbar, praktisch sind die Grenzen jedoch fließend. Bei beiden ist die Kopfhaut selbst unauffällig.

Haarausfall als Folge (klinisch manifester) Dermatosen: Hautläsionen im Follikelbereich können zu vorübergehender oder permanenter Schädigung der Haarmatrix führen. Oberflächliche bakterielle oder mykotische Follikulitis etwa kann vorübergehenden Haarausfall bewirken, eine tiefe abszedierende Entzün- 
dung des Follikels führt zu dessen Zerstörung. Atrophie und Verödung des Follikels tritt ferner bei chronisch entzündlichen (z.B. CDLE) oder ulzerierenden Prozessen, Hauttumoren u. a. m. auf.

Reversibilität von Haarausfällen. Alle Formen von Haarausfall sind reversibel, solange es nicht zur Zerstörung bzw. Atrophie des Follikels kommt. Manche Formen führen schnell bzw. unbehandelt stets hierzu; diese werden als „vernarbende“ (zikatrizierende) Alopezien bezeichnet (z. B. CDLE, tiefe abszedierende Follikulitis). Andere, die „nicht-vernarbenden“ Alopezien, führen seltener oder nur nach längerem Bestand zum Follikelverlust (Beispiele: Alopecia areata, mechanische Alopezien). Es sind daher auch die Grenzen zwischen reversiblem und irreversiblem Haarausfall fließend.

Der Begriff „vernarbend“ ist irreführend, da klinische Narbenbildung kaum je vorkommt. Es handelt sich vielmehr um ein Verschwinden des Follikels durch Atrophie und Fibrose, was klinisch durch Fehlen der Follikelostien („Poren“ der Haut) feststellbar ist.

Klassifikation der Effluvien und Alopezien. Die zahlreichen Formen von Haarausfall werden auch heute noch nach morphologischen Gesichtspunkten eingeteilt (Tabelle 19.5): man unterscheidet grundsätzlich diffuse (das gesamte Kapillitium betreffende) und umschriebene (scheibenförmige), nicht-vernarbende und vernarbende Effluvien und Alopezien.

\subsubsection{Diffuse Effluvien}

Diese sind das häufigste Haarproblem, mit dem Dermatologen konfrontiert werden. Zumeist handelt es sich um physiologische bzw. altersbedingte oder androgenetische, seltener um toxische bzw. metabolische Telogeneffluvien. Anageneffluvien begegnet man nur ausnahmsweise. Klinisch sind alle diffusen Effluvien durch Haarausfall am ganzen Kapillitium bei völlig erscheinungsfreier Kopfhaut charakterisiert; bei sanftem Durchstreichen bleiben zahlreiche Haare hängen.

Die Unterscheidung zwischen normaler Mauserung und mildem Telogeneffluvium ist oft schwierig. Anamnestische Angaben sind mit Vorsicht aufzunehmen; einerseits, weil eine Verminderung der Haare erst ab $30 \%$ objektiv auffällig wird, andererseits weil die Haare als bedeutsames Prädikat oft einer übergenauen Eigenbeobachtung unterzogen werden. Von Effluvium spricht man erst, wenn pro Tag mehr als 100 Haare ausfallen.

Nur noch locker im Follikel steckende Kolbenhaare werden natürlich bei geringer mechanischer Belastung leicht ausgezogen; dies wird vom Patient oft als krankhaft mißinterpretiert (typische Aussage: „Ich trau mich schon gar nicht mehr kämmen und Haare waschen").

Die Ursache diffuser Effluvien kann durch Anamnese, Klinik und entsprechende Laboruntersuchungen geklärt werden. Das Trichogramm erlaubt die Unterscheidung zwischen Telogen- und Anageneffluvium.

\section{Telogeneffluvien}

Eine Gruppe von diffusen Effluvien, die im Trichogramm durch vermehrt Telogenhaare gekennzeichnet sind. Sie verlaufen bei punktuellen Ursachen als Episode (allerdings von einigen Monaten Dauer) und reversibel, be i dauerhaften Ursachen chronisch und können daher $\mathrm{z}$ I bleibender Rarefizierung der Haare führen. Man un erscheidet physiologische und toxisch-metabolische T:logeneffluvien; ein Sonderfall ist das Androgenefflu vium.

\section{Physiolıgische Effluvien. Man unterscheidet:}

- Effluvium des Neugeborenen: In utero sind alle Haarfollikel in der Anagenphase; mit der Geburt treten sie synchron in die Telogenphase ein. Dies führt nach 6-8 Wochen zum meist restlosen Haarausfall; in den folgenden Monaten treten die Haarfollikel wieder sukzessive asynchron in die Anagenphase ein, es kommt zur Ausbildung von Langhaaren;

- postpartales Effluvium: Während der Gravidität werden viele (bis 95\%) Haarfollikel in der Anagenphase

\begin{tabular}{|c|c|c|}
\hline Diffuse Effluvien & $\begin{array}{l}\text { - nicht-vernarbende } \\
\text { - vernarbende }\end{array}$ & $\begin{array}{l}\text { Telogen } \\
\text { Anagen } \\
\text { androgenetisches } \\
\text { Keratosis follicularis atrophicans } \\
\text { M.Darier, manche Ichthyosen }\end{array}$ \\
\hline Umschriebene Effluvien & $\begin{array}{l}\text { - nicht-vernarbende } \\
\text { - vernarbende }\end{array}$ & $\begin{array}{l}\text { Alopecia areata } \\
\text { mechanische Alopezien } \\
\text { Pseudopelade Brocq } \\
\text { Folliculitis decalvans } \\
\text { Epidermolysis bullosa } \\
\text { weitere entzündliche, infektiöse, granu- } \\
\text { lomatöse und neoplastische Prozesse, } \\
\text { Geburtstrauma, physikochemisches } \\
\text { Trauma }\end{array}$ \\
\hline
\end{tabular}

Tabelle 19.5. Klassifikation der Effluvien und Alopezien 
festgehalten und treten postpartal synchron in die Telogenphase. Es resultiert ein diffuses Effluvium etwa ab der 8. Woche post partum, das sich nach einigen Monaten wieder normalisiert. Das Effluvium ist meist mild, manchmal klinisch auffällig (zusätzlicher Faktor: Geburtsstreß?), in Ausnahmefällen kommt es zur irreversiblen Rarefizierung des Haares. Therapie: In schwereren Fällen hormonelle Kontrazeptiva.

Ein ähnliches Phänomen tritt nicht selten nach dem Absetzen von hormonellen Kontrazeptiva auf.

- postpubertäres Effluvium: ein meist mildes Telogeneffluvium; meist bei Mädchen zwischen 16 und 20 Jahren;

Das postpubertale Effluvium wird auch als Erstmanifestation des androgenetischen Effluviums interpretiert; Auslöser: Beginn der Androgenproduktion.

Die Haarfülle kulminiert etwa zur Zeit der Pubertät; anschließend setzt der physiologische Alterungsprozess ein, der langsam sowohl zur Rarefikation als auch zum Dünnerwerden der Haare führt. Dieser Prozeß verläuft nicht gleichförmig, sondern eher stufenweise, wobei jede Stufe als Effluvium und damit oft als krankhaft wahrgenommen wird (während die maximale Haarfülle der Jugend als ,normal“ in Erinnerung bleibt). Die erste dieser Stufen ist das postpubertäre Effluvium. Obwohl durchaus vorstellbar, daß die einzelnen Stufen durch äußere Trigger ausgelöst werden (z. B. Androgenproduktion, Infektionskrankheiten etc.; am häufigsten werden von den Patienten psychische Ursachen vermutet), läßt sich kaum je eine entsprechende organische Ursache nachweisen.

Typische Anamnese: Eine 65jährige Patientin mit völlig normal wirkendem Haarbestand gibt an: „Mir gehen seit 5 Jahren die Haare so stark aus, Sie können sich gar nicht vorstellen!“

- seniles Effluvium: Durch progrediente Atrophie der Haarfollikel werden im fortgeschrittenem Alter die Haare zunehmend spärlicher und dünner; die individuelle Variation ist groß, die Abgrenzung zum androgenetischen Effluvium oft schwierig.

Toxische und metabolische Telogeneffluvien. Haarfollikel haben in der Anagenphase eine hohe metaboli- sche Aktivität; Stoffwechselstörungen und toxische Einflüsse verschiedener Art können sich leicht in Minderung der Syntheseleistung (Verdünnung der Haare) und vorzeitigem Ende der Anagenphase (Telogeneffluvium) auswirken. Die auslösenden Prozesse können episodischer (z. B. fieberhafte Krankheit) oder chronischer Natur sein (z.B. Eisenmangelanämie, Mangelernährung). Bei episodischem Telogeneffluvium dauert es bis zu einem Jahr (bei Frauen), bis das Haarvolumen voll ersetzt ist. Chronische Telogeneffluvien können durch Follikelatrophie zu dauernder Verdünnung und Rarefizierung der Haare führen.

Häufige Ursachen eines episodischen Telogeneffluviums sind schwerer Blutverlust, hohes Fieber, akute schwere Infektionskrankheiten (Grippe, Typhus, Syphilis etc.), Operations- oder traumatischer Schock, Schübe von Systemkrankheiten (z.B. Kollagenosen), forcierte Diäten, manche Medikamente (Tabelle 19.6). Pathogenese: systemische Ausschüttung von IL-1?

Häufige Ursachen eines chronischen Telogeneffluviums sind Eisenmangel (Hypermenorrhö!), Zinkmangel, Proteinmangelernährung, Malabsorptionssyndrome (glutensensitive Enteropathie), inadäquate parenterale Ernährung, konsumierende Krankheiten, Vitaminmangel (Folsäure, Vitamin B12). Mangelhafte Syntheseleistung liegt bei genetisch determinierten Stoffwechselstörungen, namentlich Aminoazidurien vor (Homozysteinurie, Orotazidurie, Phenylketonurie; bei letzterer sind die Haare nicht nur verdünnt, brüchig und kräuselig, sondern auch blond). Klassische Ursachen sind ferner endokrine Störungen, insbesondere Hyperund Hypothyreoidismus, Hyperparathyreoidismus und Hypopituitarismus.

Bei Hypothyreoidismus sind typischerweise die lateralen Augenbrauen besonders betroffen (dieses Symptom findet sich auch beim syphilitischen Effluvium und bei der Neurodermitis - Hertoghe-Zeichen).

Therapie. Außer dem Versuch, die zugrundeliegende Störung zu beheben, sind keine wirksamen Therapiemöglichkeiten gegen Telogeneffluvien bekannt. Die Wirksamkeit früher in großem Umfang verabreichter Vitamin-B-Mischpräparate ist zweifelhaft.

\begin{tabular}{|c|c|c|}
\hline Klasse & Beispiele & \\
\hline Zytostatika & $\begin{array}{l}\text { Cyclophosphamid, } \\
\text { MTX, Doxorubicin u.v.a.m. }\end{array}$ & $\begin{array}{l}\text { bei niedrigen Dosen Telogeneffluvien, } \\
\text { bei höheren Anageneffluvien }\end{array}$ \\
\hline Retinoide & Etretinat, Accutan & Telogeneffluvien \\
\hline ZNS-Mittel & L-DOPA, Trimethadion & \\
\hline Lipidsenker & Triparanol & \\
\hline Betablocker & Propanolol & \\
\hline Antikoagulantien & $\begin{array}{l}\text { Heparin } \\
\text { Dicumarol }\end{array}$ & \\
\hline Hormonblocker & Thiouracil, Bromocriptin & \\
\hline
\end{tabular}

Tabelle 19.6. Medikamente als Ursache von Effluvien 


\section{Androgeneffluvium \\ (Syn. Androgenetische bzw. Andro- \\ Genetische Alopezie, Haarausfall vom \\ männlichen Typ, „male pattern alopecia“)}

Epidemiologie. Die Prävalenz der androgenetischen Alopezie bei postpuberalen Personen wird - je nach gewählten Parametern - zwischen 30 und $80 \%$ geschätzt. Im Gegensatz zur Volksmeinung ist sie bei beiden Geschlechtern gleich häufig auf, tritt bei Frauen jedoch später in Erscheinung (oft erst nach dem Klimakterium), verläuft viel milder und führt nur selten zur Kahlköpfigkeit. Die Anlage zum Androgeneffluvium wird polygen vererbt (,,autosomal-dominant mit unregelmäßiger Penetranz").

In Anbetracht ihrer Häufigkeit kann auch argumentiert werden, daß es sich um eine universell vorhandene, nur in ihrer Ausprägung unterschiedliche Anlage handelt. Daß Kahlköpfigkeit der Väter eine solche der Söhne begünstigt, ist Volkswissen; ebenso aber, daß diese Regel oft schlecht erfüllt scheint. Genauere Prognosen sind möglich, wenn man die gesamte Aszendenz inklusive der Frauen einbezieht. Das Risiko einer signifikanten androgenetischen Alopezie korreliert dann gut mit dem Anteil der Aszendenz, der gleichfalls ein solche hatte (wobei bei Frauen und Männern natürlich die unterschiedliche Expression berücksichtigt werden muß).

Klinik (Abb. 19.18). Ein mit Einsetzen der Pubertät beginnendes und sehr unterschiedlich schnell und regelhaft verlaufendes Effluvium. Die Lichtung des Haars beginnt bei Männern an bestimmten Prädilektionsstellen: den seitlichen Stirnregionen (Hofratsecken) und

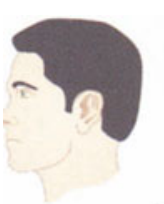

I

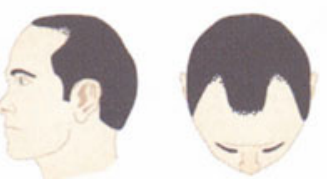

III
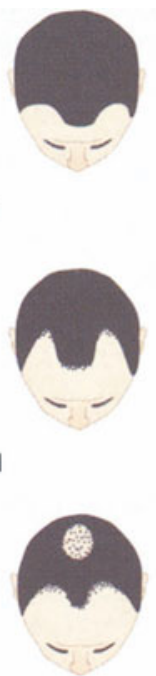

IV

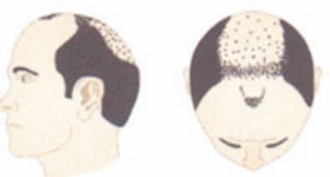

VI

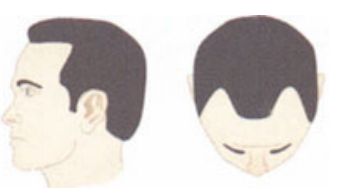

II

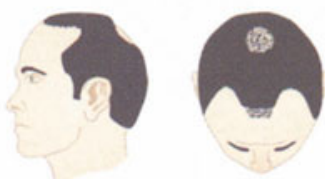

III vertex

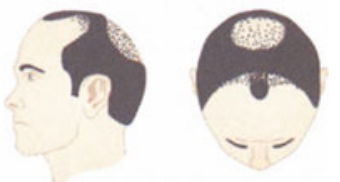

V

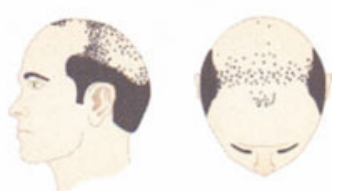

VII
Abb. 19.18. Norwood-Hamilton-Stadieneinteilung der androgenetischen Alopezie

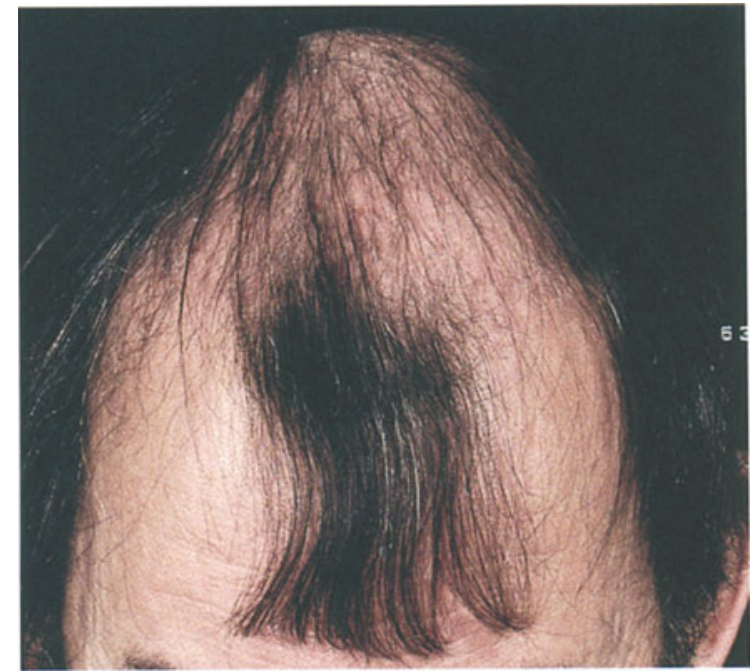

Abb. 19.19. Androgenetisches Effluvium beim Mann

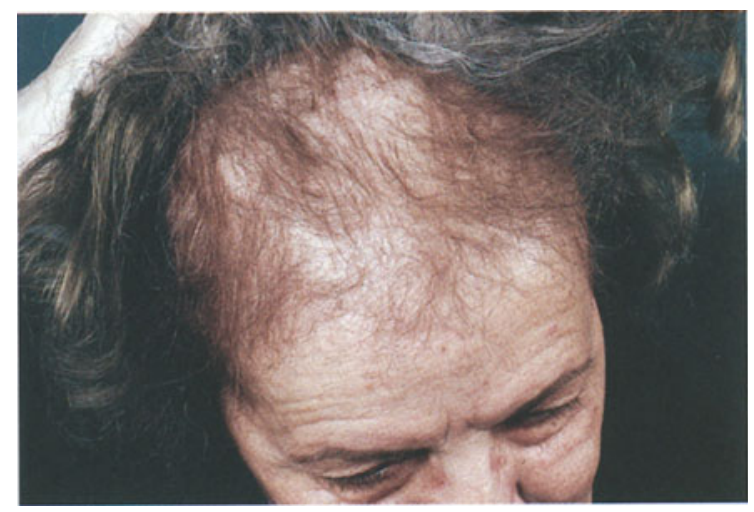

Abb. 19.20. Androgenetisches Effluvium bei der Frau. Beachte, daß bei der Frau die frontale Haaransatzlinie zumindest angedeutet erhalten bleibt

der Scheitelplatte; meist im 4. Lebensjahrzehnt werden diese Bereiche kahl. Durch Ausdehnung und Konfluenz derselben reduziert sich der Haarbestand auf einen charakteristischen Kranz von Schläfen- und Okzipitalhaaren, der im Lauf der Jahre zwar weiter schmilzt, aber doch in der Regel erhalten bleibt. Über der Glabella (zwischen den Hofratsecken) bleibt oft lange eine solitäre Haarlocke bestehen (Abb.19.19). Aktive Phasen des Haarverlusts sind häufig (auch ohne begleitendes seborrhoisches Ekzem) mit Juckreiz und unangenehmem Organgefühl verbunden. Das androgenetische Effluvium wird häufig von den übrigen androgenabhängigen Dermatosen begleitet: Seborrhoe, seborrhoisches Ekzem, Akne vulgaris und Hirsutismus. Eine Verschärfung des Effluviums durch die Entzündung beim seborrhoischen Ekzem wird vermutet.

Bei Frauen (Abb.19.20) unterscheidet sich das Bild nicht nur durch geringere Intensität (Kahlheit tritt selten ein), sondern auch morphologisch: Die Lichtung der Haare beschränkt sich auf die Scheitelplatte, der frontale Haaransatz bleibt erhalten. Das Androgeneffluvium der Frauen kommt während des geschlechts- 
fähigen Alters lediglich bei Virilisierung oder medikamentös bedingt (bei Einnahme eines Kontrazeptivums mit starker Progesteronkomponente) vor, nach dem Klimakterium in Folge eines relativen Androgenüberschusses.

Pathogenese. Zugrunde liegt der androgenetischen Alopezie eine Akzeleration des Haarzyklus durch Verkürzung der Anagenphase; Haare und Haarfollikel werden bei jedem Haarwechsel dünner bzw. kleiner („Miniaturisierung“). Schließlich werden nur mehr Lanugohaare produziert. Bei langer Dauer atrophisiert der Haarfollikel gänzlich und verschwindet, die Glatze ist dann tatsächlich völlig haarlos. Diese Vorgänge werden durch Androgene mediiert.

Für die essentielle Rolle der Androgene gibt es überzeugende „klassische“ Beweise: Androgeneffluvium kommt bei Eunuchen nicht vor (selbst bei starker genetischer Belastung); ein bestehendes Androgeneffluvium wird durch Kastration unterbrochen und setzt sich bei Androgensubstitution wieder fort.

Androgene bewirken eine Verkürzung der Anagenphase, während Östrogene sie verlängern. Das hauptwirksame Prinzip, Dehydrotestosteron (DHT), wird durch periphere Konversion in der dermalen Papille aus den Präkursoren synthetisiert: freiem Testosteron ( $\mathrm{T}$ ) beim Mann, bei der Frau Dehydroepiandrosteron (DHEA). Der Androgeneffekt am Follikel kommt in der Regel nicht durch vermehrtes Angebot von Präkursoren aus dem Blut, sondern durch erhöhte Aktivität jener Enzyme zustande, die diese periphere Konversion vollziehen: $5 \alpha$-Reduktase bei $\mathrm{T}$ und zwei spezifische Dehydrogenasen bei DHEA. Die erhöhte Aktivität dieser Enzyme kann in befallenen Follikeln nachgewiesen werden, in gesunden ist sie normal.

Frauen scheinen durch eine (im Vergleich zu Männern) höhere Aktivität von Aromatase im Langhaarfollikel einen Schutzmechanismus gegen die androgenetische Alopezie zu besitzen: Aromatase baut den (aus DHEA entstandenen) Metaboliten Androstendion schneller zu Östron um als die oben genannten spezifischen Dehydrogenasen zu T bzw. DHT. In Follikeln, die von androgenetischer Alopezie ergriffen sind, findet sich diese Erhöhung nicht.

Diagnostik. Die Erkennung der androgenetischen Alopezie ist bei voller Ausprägung einfach, im Beginnstadium kommen die übrigen Telogeneffluvien in Differentialdiagnose. Die Hormonwerte im Blut sind in der Regel unauffällig; eine bedeutsame Ausnahme sind Androgenisierungssyndrome der Frau (s. S. 385).

Therapie. Bis heute stehen keine gänzlich befriedigenden Maßnahmen zur Therapie des Androgeneffluviums zur Verfügung. Von mehreren prinzipiell erfolgreich scheinenden Wegen (Antiandrogene, Apoptosehemmer) ist bislang keiner sowohl sicher als auch wirksam. Erfolgversprechend ist hingegen ein spezifischer Hemmer der $5 \alpha$-Reduktase (Typ II - nur in Haarfollikeln und in der Prostata vorhanden), Finasterid. Dieses Medikament, seit langem zur Therapie der benignen Prostatahypertrophie zugelassen, führt zum Wiederwuchs der Haare im frühen Stadium der androgenetischen Alopezie. Das Androgeneffluvium der Frau

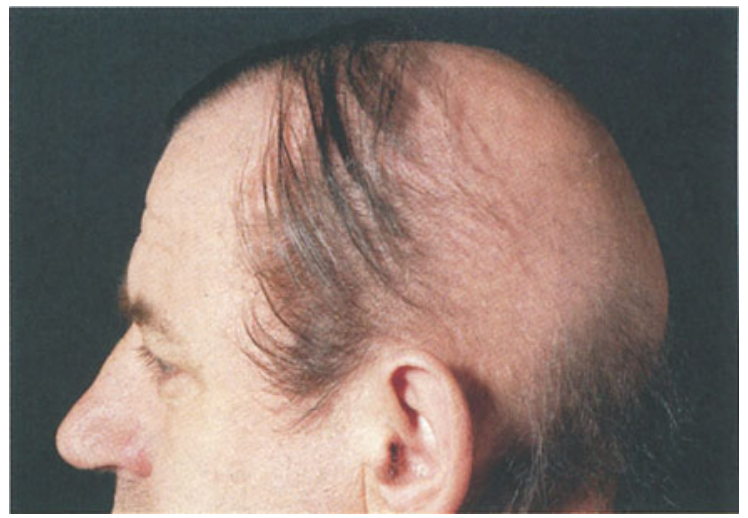

Abb. 19.21. Anageneffluvium nach Röntgenbestrahlung eines Hirntumors. Beachte die für jede andere Art von Haarausfall untypische Lokalisation

bei Androgenisierung kann durch entsprechende hormonelle Therapie stabilisiert werden.

In den letzten Jahren wurde Minoxidil zur Lokalbehandlung eingeführt (ein Antihypertensivum, das als Nebenwirkung zu Hypertrichose führt). Minoxidil bewirkt tatsächlich bei manchen Patienten (mit nicht weit fortgeschrittener Alopezie) mäßigen Wiederwuchs der Haare, muß aber lebenslang verabreicht werden; bei Absetzen oder Unterbrechung kommt es zu baldigem Wiederausfall. Minoxidil wird nicht unbeträchtlich resorbiert, systemische Nebenwirkungen werden nicht beobachtet.

Sorgsame Behandlung des oft koexistenten seborrhoischen Kopfhautekzems schaltet einen das Androgeneffluvium beschleunigenden Faktor aus.

Diffuse Anageneffluvien (dystrophische Effluvien). Dieses seltene Art von Effluvien kommt zumeist bei schweren Vergiftungen oder als Nebenwirkung medikamentöser Therapie zustande und wird durch Schädigung der in Mitose befindlichen Zellen des Anagenfollikels bewirkt. Ist der Schaden nur gering, wird die Proliferationstätigkeit des Haarfollikels nach kurzer Zeit wieder aufgenommen. Folge ist eine ringartige Einschnürung des Haars (bei Verabreichung mehrerer Zytostatikazyklen kommt es nicht selten zu intermittierenden Schnürfurchen). Bei starkem Schaden kommt es $\mathrm{zu}$ Degeneration und Zelltod der sich teilenden Haarfollikelzellen und nach 1-3 Wochen zum diffusen und meist fast vollständigen Haarausfall (Unterschied zum Telogeneffluvium!).

Typische auslösende Ursachen: Thallium (früher als Rattengift verwendet), Colchizin, Röntgenbestrahlung (Abb.19.21). Die ausfallenden Haare zeichnen sich durch unregelmäßig verjüngte, nekrotische Haarwurzeln aus (dystrophische Haare). Das Anageneffluvium ist, wenn die Ursache eliminiert wird, nur in seltenen Fällen (bei gänzlicher Nekrose der Haarfollikel) irreversibel.

Differentialdiagnose. Telogeneffluvium.

Therapie. Keine. Unterkühlung des Kapillitiums (Eishaube) während der Zytostatikatherapie kann dem Haarausfall teilweise vorbeugen. 


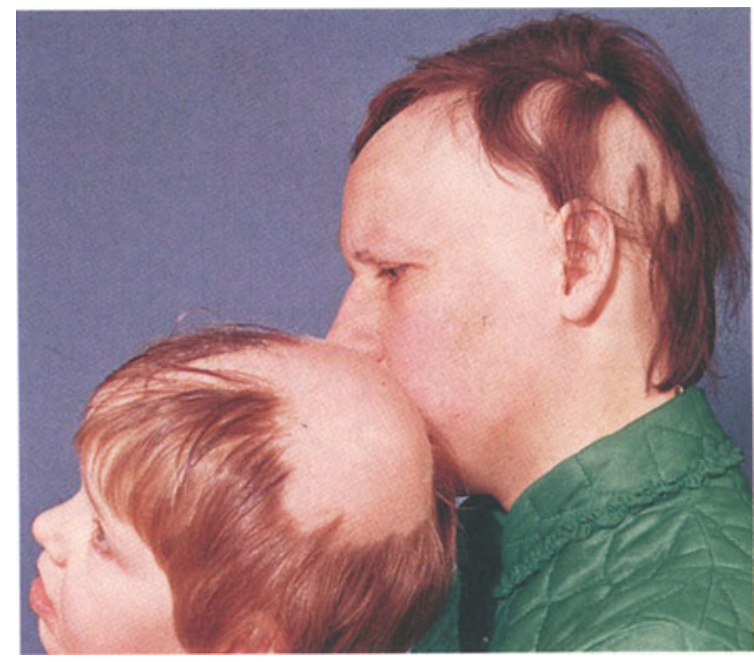

Abb. 19.22. Alopecia areata bei Mutter und Tochter (bei der Mutter vom Ophiasis-Typ)

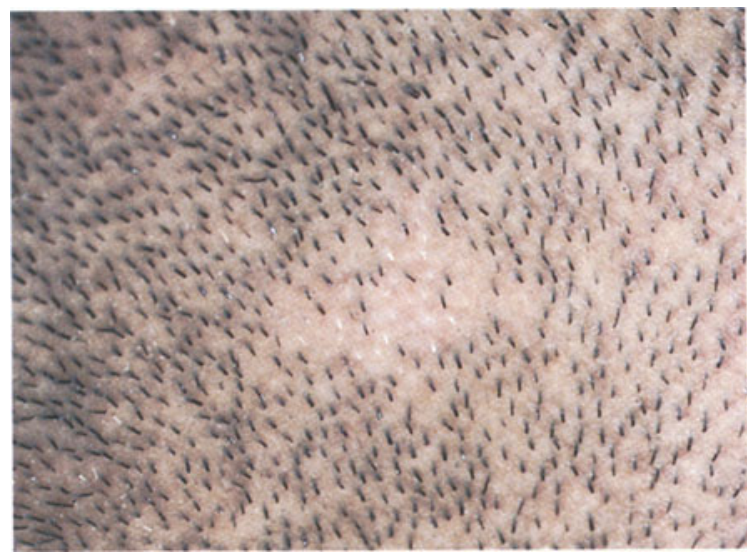

Abb. 19.23. Alopecia areata barbae. Inmitten dieses kleinen alopezischen Herdes (alle Haarfollikel erhalten!) finden sich noch isolierte Resthaare (Telogenhaare). Graue Haare sind anfangs resistenter als pigmentierte (das alopezische Areal hat daher viel mehr graue Haare als die Umgebung. Dieses Phänomen ist die Ursache des sprichwörtlichen „Ergrauens über Nacht")

\subsubsection{Umschriebene Alopezien}

\section{Alopecia areata}

Eine relativ häufige, wahrscheinlich autoimmunologisch bedingte nicht-vernarbende Alopezie, die pathologisch einem Anageneffluvium entspricht, durch schubartigen, scheibenförmigen, oft ausgedehnten Haarausfall gekennzeichnet ist und bei einem Teil der Fälle in eine permanente Alopezie mündet.

Epidemiologie. Alopecia areata kann in jedem Lebensalter auftreten, meist jedoch in der Lebensmitte. Es besteht keine Geschlechtsdisposition. In etwa $30 \%$ findet sich familiäre Häufung. Die Lebensinzidenz beträgt etwa $1 \%$.
Klinik (Abb. 19.22 u. 19.23). Die Krankheit beginnt meist mit plötzlichem Haarausfall in einem oder mehreren münzgroßen Bereichen am Haupt- oder Barthaar; subjektive Beschwerden fehlen. Selten sind foudroyante Verläufe - „Kahlwerden über Nacht“. Die kahle Hautstelle ist unauffällig (keine Entzündung, keine Schuppung, Follikelostien erhalten), gegenüber der Umgebung allerdings etwas eingesunken (keine Atrophie, sondern Folge des Fehlens der Haarschäfte). Einzelne Haare bleiben innerhalb der kahlen Stelle zurück (Telogenhaare, die vom Krankheitsprozeß unberührt bleiben, jedoch bald ohnehin ausfallen). Auffallend ist, daß weiße Haare resistenter zu sein scheinen als pigmentierte (Abb.19.23).

Die alte Volksweisheit, daß das Haar vor Schrecken „über Nacht weiß" werden kann, hat seine Wurzel vielleicht in diesem Phänomen. Bei einer akut einsetzenden ausgedehnten Alopecia areata können tatsächlich die meisten dunklen Haare ausfallen und nur die weißen übrigbleiben.

Die Herde breiten sich zentrifugal aus; am aktiven Rand lassen sich die Haare leicht büschelweise ausziehen. Nach einiger Zeit setzt in variabler Weise ein Wiederwuchs, oft von der Peripherie her, ein. In den meisten Fällen bilden sich nur einzelne oder mehrere bis handgroße alopezische Herde aus, wobei auch Augenbrauen und Wimpern befallen sein können. Selten ist der Befall großflächig; ist das gesamte Kapillitium betroffen, spricht man von Alopecia areata totalis, bei Befall auch der Körperhaare von Alopecia areata universalis.

Häufig assoziierte Zeichen sind Läsionen der Nägel (Tüpfelnägel, Längsrillen, Atrophie), selten Katarakte. Nicht selten kombiniert sind ferner andere organspezifische Autoimmunkrankheiten (perniziöse Anämie, Autoimmunthyreoiditis, Vitiligo, M.Addison, chronisch aktive Hepatitis), das Down-Syndrom und atopische Dermatitis.

Histologie. Dichte lymphozytäre Infiltrate, vorwiegend $\mathrm{CD} 8+$, um die tiefen Portionen der Haarfollikel.

Pathogenese. Alopecia areata ist nach heutiger Meinung ein von zytotoxischen Lymphozyten mediierter Autoimmunprozeß gegen die Zellen des Follikelapparats. In der Anagenphase kommt es zum abrupten Absinken oder Stillstand von Proteinsynthese und Mitosen sowie zur Apoptose. Als Folge wird mechanisch minderwertiges Keratin produziert, in der keratogenen Zone entsteht eine mechanische Schwachstelle, an der das Haar abbricht. Die Keratinproduktion setzt meist nicht gänzlich aus: Es wird ein abortiver krümeliger Stummel produziert, der nach einiger Zeit als sog. „mumifiziertes" bzw. "Ausrufungszeichenhaar" aus dem leeren Follikel austritt (typisches Zeichen der Alopecia areata). In schweren Fällen oder bei längerem Bestand führt die Schädigung der Matrix zur irreversiblen Follikelatrophie.

Die Schädigung betrifft auch die Melanozyten des Haarfollikels; „mumifizierte“ Haare sind demnach 
meist unpigmentiert. Nicht selten sind dies auch die bei Spontanremission nachwachsenden, normal gestalteten Haare („Poliosis circumscripta“).

Verlauf und Prognose. Alopecia areata schwankt meist Monate oder Jahre zwischen partiellen Remissionen und schubartigen Rezidiven. Das Schicksal der Patienten kann grundsätzlich 3 Wege gehen (wobei nach einer alten Regel jeder etwa gleich wahrscheinlich ist):

- Spontanheilung;

- chronisch-rezidivierender Verlauf, der schließlich mit einigen bleibenden alopezischen Herden zum Stillstand kommt;

- progredienter Verlauf, der in eine permanente totale oder universelle Alopezie einmündet.

Die Voraussage, zu welcher dieser 3 Gruppen ein Patient zählt, ist kaum möglich, doch gibt es einige grobe Regeln:

- Auf gute Prognose deuten einzelne oder wenige Herde, Befall des Bartbereichs, langsames Wachstum, kurzer Bestand, Beginn im Erwachsenenalter, Fehlen familiärer Häufung und assoziierter Systemkrankheiten.

- Auf schlechte Prognose deuten die gegenteiligen Merkmale; darüber hinaus mehrere Rezidive und Befall an der Haargrenze im Bereich des Hinterkopfes („Ophiasis“).

Diagnose. Bei typischer Ausprägung ist die Alopezia areata leicht klinisch zu erkennen. Akut verlaufende Fälle können (vor der Ausbildung scheibenförmiger Herde!) mit diffusen Effluvien, insbesondere Anageneffluvien verwechselt werden. Scheibenförmige Herde müssen von der Pseudopelade Brocq unterschieden werden (letztere eine vernarbende Alopezie). Patienten mit Alopecia areata müssen auf das Vorliegen der genannten assoziierten Autoimmunkrankheiten untersucht werden.

Therapie. Topische Kortikoide sind wenig wirksam, können jedoch versuchsweise bei kleinen Herden eingesetzt werden. Systemische Kortikosteroide bewirken einen augenblicklicher Stopp des Haarausfalls, doch sind die erforderlichen Dosen relativ hoch, und nach Absetzen kommt es sofort zum Rezidiv - diese Behandlung ist daher abzulehnen. Von fraglichem Nutzen ist die Behandlung mit Irritantien (Anthralin, Tinctura capsici) und Photochemotherapie.

Therapie der ersten Wahl bei schwereren Fällen ist die Immunotherapie: Induktion einer allergischen Kontaktdermatitis in den alopezischen Herden mit Diphencypron (DPCP) oder Quadratsäure; diese Therapie ist bei frischeren Fällen meist wirksam und bei älteren des Versuches wert. Ihr Nachteil ist die unbestimmt lange Dauer (Jahre; Abbruch, bevor die Alopecia areata „ausgebrannt“ ist, führt zum Rezidiv) und die Belästigung durch die chronische (milde) Ekzemreaktion.
Beide Substanzen sind starke Sensibilisatoren, weder kanzerogen noch mutagen (wie das früher verwendete $\mathrm{DNCB}$ ) und kommen in der normalen Privat- und Arbeitswelt nicht vor. Das vermutete Wirkprinzip ist die Verdrängung des spezifischen zytotoxischen Infiltrats aus dem Follikelbereich durch die provozierte entzündliche Reaktion.

Durchführung: Der Patient wird epikutan mit $2 \%$ DPCP in Vaseline sensibilisiert. Nach 2 Wochen beginnt man mittels Patchtest, die niedrigste Konzentration von DPCP zu bestimmen, die noch eine allergische Kontaktdermatitis erzeugt. Diese Konzentration wird zu wöchentlichen Applikationen an den alopezischen Herden verwendet.

Während die kurzfristige Wirksamkeit der DPCP-Therapie unbestritten ist (Wiederwuchs in $>70 \%$ ), wurden Zweifel geäußert, ob damit auch das langfristige Schicksal der Alopezie beeinflußt werden kann. Es ist wahrscheinlich, daß die Alopecia areata, wie viele andere Immunkrankheiten, „ausbrennen" kann; wird die DPCP-Therapie bis zu diesem Zeitpunkt durchgeführt, bleibt nach Absetzen ein Rezidiv aus.

\section{Weitere, nicht vernarbende, umschriebene Alopezien}

Alopecia areolaris specifica. Kleinfleckiger Haarausfall in der späteren Lues II mit Maximum an Schläfen und Hinterkopf. Treffender Vergleich: „wie von Motten zerfressen“. Ursache: Die alopezischen Herde entstehen am Ort zurückgebildeter lokalisierter Papeln durch lokale Toxinwirkung aus den Treponemen. Reversibel.

Frühe Lues II führt zu einem toxischen Telogeneffluvium. Beide Formen sind heute selten, doch sollte die alte Regel nicht vergessen werden, bei allen ätiologisch nicht völlig klaren Effluvien und Alopezien Blut zur Syphilisserologie abzunehmen.

Mechanisch bedingte Haarausfälle. Obwohl ein gesundes Anagenhaar erstaunlich fest im Bulbus haftet und seine gewaltsame Entnahme schmerzhaft ist, sind Haare gegenüber chronisch reibender, ziehender oder drückender mechanischer Traumatisierung relativ empfindlich. Folge: Abbrechen des Haarschafts oder Herausreißen aus der Matrix; in beiden Fällen kommt es zur Alopezie, die meist reversibel ist, aber bei zu starker oder chronischer Traumatisierung zur irreversiblen Verödung des Haarfollikels führt. Folgende charakteristische Situationen führen $\mathrm{zu}$ mechanisch bedingten Alopezien:

- Traktionsalopezie beispielsweise durch forcierte Friseuraktionen, etwa bei Ausrichten gekräuselter oder bei Eindrehen gerader Haare; gewisse Frisurtypen (z.B. Pony-Frisur), die dauernden Zug an der Haarwurzel verursachen (Gummiband!);

- dauerndes Tragen von Kopfbedeckungen, Perücken etc.;

- Aufliegestellen des Hinterkopfes am Polster (bei Kleinkindern und Bettlägerigen) (Abb.19.24);

- Trichotillomanie (Abb.19.25), ein durchaus nicht seltenes Zustandsbild, das durch gewohnheitsmäßiges Ziehen, Reißen, Reiben, Zupfen und Eindrehen von 


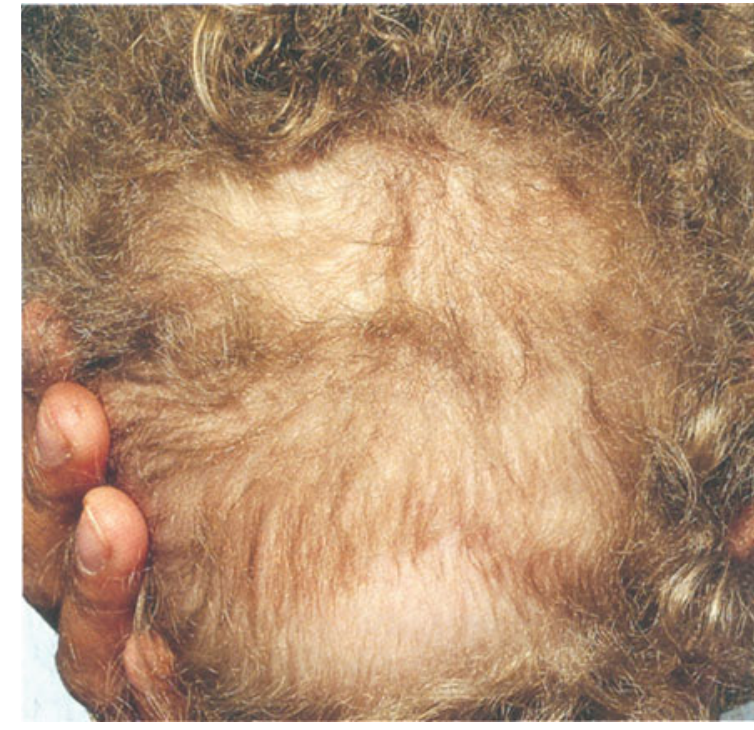

Abb. 19.24. Mechanisch bedingte Effluvien. Rarefikation der Haare des Hinterkopfes bei Kleinkind durch chronisches Reibetrauma

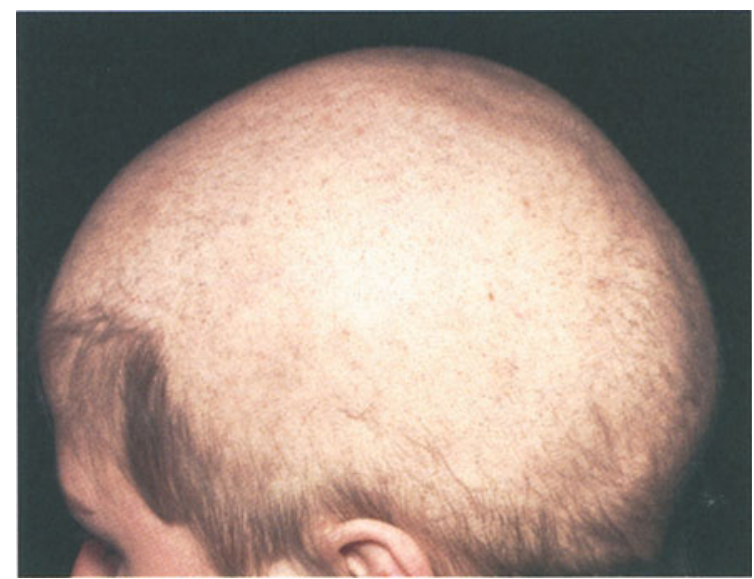

Abb. 19.25. Mechanisch bedingte Effluvien. Trichotillomanie mit typischer tonsurartiger Konfiguration. Beachte die durchwegs erhaltenen Haarfollikel mit Haarstummeln

Haarsträhnen zustande kommt. Klinisch findet sich meist ein eher unscharf begrenzter, scheibenförmiger alopezischer Herd, an dem alle Haarfollikel sichtbar sind und verschieden lange Haarstummel tragen („schlecht gemähte Wiese“). Trichotillomanie tritt meist bei neurotischen Kindern auf und wird gewöhnlich für eine Pilzkrankheit gehalten. Da die Dissimulierungstendenz groß ist, stößt die Diagnose nicht selten auf Unglauben.

Auch Körperhaare werden durch jahrelanges Tragen von engen Strümpfen, Hosen („Wadenglatze“), Gürteln etc. vernichtet.

\section{Vernarbende Alopezien}

Unter dieser Bezeichnung werden alle jene verschiedenartigen Krankheiten zusammengefaßt, die durch

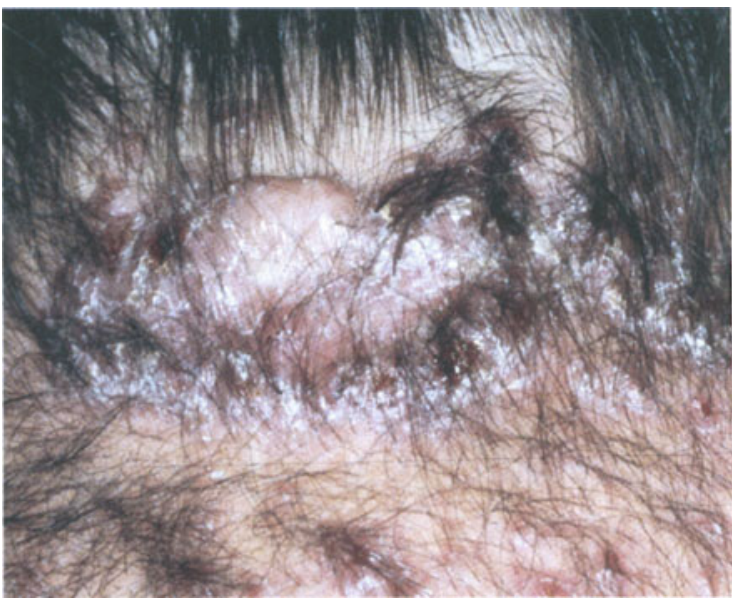

Abb. 19.26. Akne keloidalis nuchae. Mischbild hyperkeratotischer follikulärer Papeln, Keloidnarben, entzündlicher follikulärer Infiltrate und zikazitrierender Alopezie

Atrophie oder entzündliche Zerstörung der Haarfollikel („Vernarbung“) zur irreversiblen Alopezie führen. Es handelt sich meist um umschriebene entzündliche Prozesse des Follikelapparats selbst bzw. der Kopfhaut.

Vernarbende Alopezien bei Genodermatosen. Solche finden sich klarerweise bei hereditären Verhornungsstörungen der Haarfollikel: der Gruppe der atrophisierenden Keratosis follicularis (Maximalform: Keratosis follicularis spinulosa decalvans Siemens, s. Abb.17.13) und bei M. Darier; ferner bei manchen Ichthyosen (Xrezessive, epidermolytische, Conradi-Syndrom), manchen Formen der Epidermolysis bullosa hereditaria, Incontinentia pigmenti u.a.m., aber auch bei umschriebenen Läsionen (epidermale Nävi) und Defekten.

Aplasia cutis idiopathica ist ein fast stets median gelegener kongenitaler Bildungsdefekt der Skalphaut, der in den ersten Lebensmonaten narbig abheilt und ein haarloses atrophes Areal hinterläßt. Differentialdiagnose: traumatische Skalpdefekte anläßlich der Geburt (Vakuumextraktion).

Nach physikochemischen Traumen. Mechanisches Trauma (Geburtstrauma, Dekubitus), Verbrennungen, Verätzungen, ionisierende Strahlen sind typische Ursachen für vernarbende Alopezien.

Als Folge infektiöser Prozesse. Die häufigste Ursache vernarbender Alopezien. Ein fast trivialer Befund sind kleine narbige Herde nach Furunkeln der Kopfhaut, meist im Rahmen eines seborrhoischen Ekzems. Gravierender ist die Folliculitis decalvans, eine herdförmige (meist am Scheitel), enorm chronische und therapieresistente pyogene tiefe Follikulitis; außerdem die seltene Folliculitis et perifolliculitis capitis abscedens et suffodiens, eine gleichfalls enorm chronische pyogene Infektion - diese ist durch multiple tiefe Abszesse und Fisteln gekennzeichnet und gilt als (seltenes) Teilsymptom der sog. Acne conglobata (s. diese). 
Nicht selten ist schließlich die sog. Acne keloidalis nuchae (Abb.19.26), eine durch derbe Knötchen gekennzeichnete, sehr chronische pustulierende Follikulitis der Nackengegend (wichtiger auslösender bzw. perpetuierender Faktor: Kratzen!). Weitere infektiöse Ursachen umschriebener vernarbender Alopezien: tiefe Mykosen, Lupus vulgaris, Leishmaniose, Varizellen etc.

Im Rahmen diverser entzündlicher Dermatosen. Mehrere klassische entzündliche Hautkrankheiten sind häufig mit vernarbender Alopezie assoziiert: CDLE, Lichen ruber (follicularis), systemische und zirkumskripte (Coup-de-sabre-Typ) Sklerodermie, Hemiatrophia faciei, vernarbendes Pemphigoid, hepatoerythrozytäre Porphyrie, systemische Amyloidose u.a.m. Die meisten dieser Krankheiten sind im frischen Zustand klinisch und mit den entsprechenden Laboruntersuchungen leicht $\mathrm{zu}$ diagnostizieren. Im „ausgebrannten“ Zustand kann dies schwierig oder auch unmöglich sein. Aus diesem Grund hat sich ein historischer Sammelbegriff für den Endzustand vieler derartiger Dermatosen bis heute erhalten: die „Pseudopelade Brocq".

„Pelade“ ist der französische Begriff für Alopecia areata. Brocq (einer der Begründer der französischen Dermatologie) hielt seine Pseudopelade allerdings für eine Krankheit sui generis.

Das „typische“ Bild der Pseudopelade Brocq ist ein meist einzelner (oder nur oder wenige), größerer, scheibenförmiger, eingesunkener, relativ unregelmäßig begrenzter alopezischer Herd, häufig in der Scheitelgegend von Personen mittleren Lebensalters. Die Haut erscheint atroph und ohne Entzündungszeichen, manchmal mit zarten narbigen Zügen; Haarfollikel fehlen. Die häufigsten zugrundeliegenden, meist schon ausgeheilten Krankheiten sind Lichen ruber („Lichen planopilaris", s. Abb. 13.25), der chronisch-diskoide Lupus erythematodes (CDLE) und seltener die zirkumskripte Sklerodermie („Coup-de-sabre-Form“).

Anhaltspunkte zur klinischen Differentialdiagnose: Beim Lichen ruber ist der Rand oft kleinfleckig strukturiert, dazwischen einzelne Büschel normaler Haare. CDLE zeigt großzügigere polyzyklische Begrenzung, die lineare Sklerodermie oft noch die charakteristische Induration. In Zusammenschau mit der Histologie kann die Diagnose meist gestellt werden.

Bei Mucinosis follicularis (s. Abb.14.33). Ein seltenes, aber wichtiges Krankheitssymptom mit typischem klinischem und histologischem Bild, jedoch unbekannter Pathogenese: plaqueartige elevierte erythematöse, oft hypopigmentierte, mäßig derbe Läsionen mit etwas vorragenden Haarfollikeln („Gänsehaut"), in denen nach einiger Zeit die Haare ausfallen. Prädilektionsstellen sind Skalp und Gesicht, weniger häufig der übrige Körper. Die Histologie zeigt muzinöse Degeneration der äußeren Haarwurzelscheide.
Man unterscheidet eine idiopathische und eine symptomatische Mucinosis follicularis. Erstere tritt meist bei jungen Erwachsenen auf; die Läsionen sind selbstlimitiert (Spontanheilung nach Monaten bis Jahren). Klinisch bestehen fließende Grenzen zur sogenannten Pityriasis alba (s.S.174). Die symptomatische Mucinosis follicularis ist mit Lymphomen, meist Mycosis fungoides, assoziiert: Hier sind die Plaques meist generalisiert; histologisch finden sich auch die Infiltrate des Lymphoms. Oft heftiger Juckreiz!

Bei Tumoren. Basaliome der Kopfhaut („Ulcus rodens"); Melanom, Angiosarkom.

Bei granulomatösen Entzündungen der Kopfhaut. Diese eher seltene Ursache von herdförmigen vernarbenden Alopezien ist bei Granuloma anulare, Nekrobiosis lipoidica, Sarkoidose gegeben.

\subsubsection{Strukturdefekte des Haarschafts}

Strukturdefekte des Haarschafts sind meist genetisch determiniert und treten entweder isoliert oder im Rahmen übergeordneter Störungen auf.Viele gehen mit erhöhter Brüchigkeit einher.

\section{Atrichien und Hypotrichien}

Eine Reihe seltener Erbsyndrome, bei denen die Langhaare nur spärlich (verringerte Follikelzahl), dünn und kurz ausgebildet werden, aber meist keine deutlichen Haarschaftsanomalien aufweisen. Bei vielen dieser Syndrome entsteht der (nicht ganz richtige) Eindruck der Kahlköpfigkeit.

Bei der autosomal rezessiven Atrichia congenita universalis werden die Kinder zwar mit den fetalen Lanugohaaren geboren, es entwickelt sich aber kein Terminalhaarkleid. Bei der autosomal-dominanten hereditären Hypotrichie (Abb.19.27) entsteht zwar schütteres Terminalhaar, verschwindet jedoch nach der Pubertät durch progressive Follikelatrophie. Bei beiden Syndromen handelt es sich um isolierte Haardefekte.

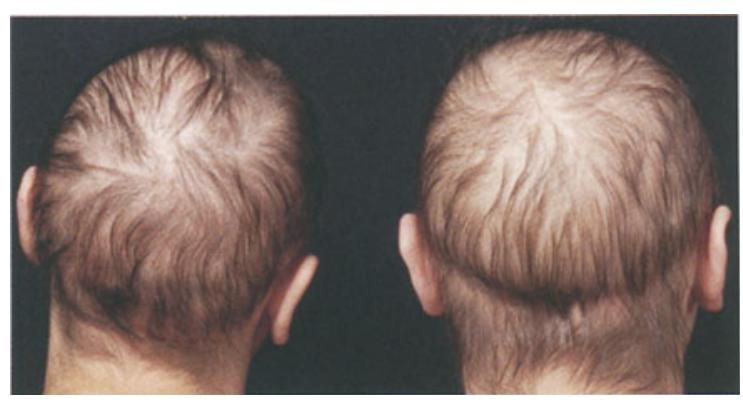

Abb. 19.27. Hypotrichia congenita (Zwillingspaar) 

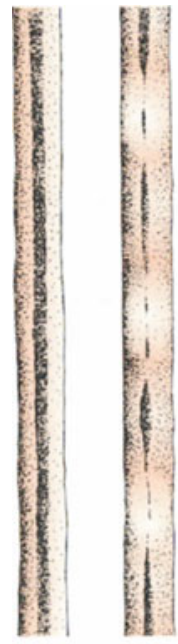

1
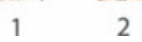

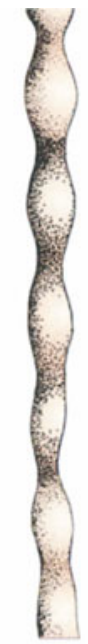

3

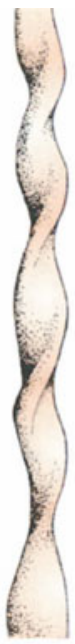

4

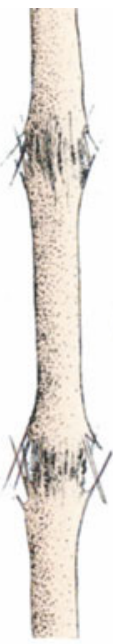

5

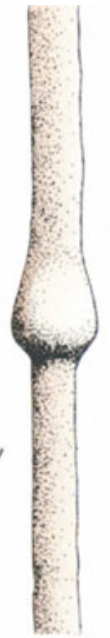

6

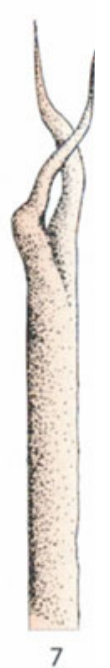

Abb. 19.28. Einige Haarschaftanomalien (in Anlehnung an Braun-Falco, 1984) Von links nach rechts: normales Haar (1), Pilus anulatus (2), Monilethrix (3), Pilus tortus (4), Trichorrhexis nodosa (5), Trichorrhexis invaginata (6), Trichoschisis (7)

Bei zahlreichen anderen Syndromen ist Hypotrichie nur Teilsymptom ausgedehnterer Entwicklungsstörungen. Wichtigste Gruppe sind die ektodermalen Dysplasien. Zumindest vier Vertreter sind bekannt; alle sind neben Hypotrichie (Skalp, Gesicht, manchmal auch Körper) durch verschiedene Entwicklungsanomalien gekennzeichnet: Dystrophie der Nägel, Palmoplantarkeratosen, Zahn- und Skelettanomalien, retardierte Entwicklung u.a.m. Bei der seltenen, X-chromosomal oder autosomal-rezessiv vererbten anhidrotischen Form besteht zusätzlich eine Aplasie der Schweißdrüsen (Hitzeintoleranz!). Die hidrotische und die hypohidrotische ektodermale Dysplasie sind autosomal dominant vererbt.

Hypotrichie ist ferner ein Merkmal verschiedener Progerie- und Fehlbildungssyndromen, seltener der Dyskeratosis congenita, der Pachyonychia congenita u.a.m.

\section{Haarschaftanomalien (Abb. 19.28)}

Diese sind charakteristische, meist genetisch determinierte Bildungsstörungen des Haarschafts bei normaler Follikelzahl. Sie können isoliert oder als Teilsymptom übergeordneter Störungen auftreten.

\section{Haarschaftsanomalien mit erhöhter Haarbrüchig-} keit. Viele Haarschaftsanomalien führen zur mechanischen Minderwertigkeit und damit zu abnorm kurzem (oft nur einige Zentimeter), oft auch scheinbar schütterem Haar. Trotz ihrer Verschiedenheit ähneln sich die klinischen Bilder, die Diagnose kann nur durch mikroskopische Untersuchung erfolgen. Die Strukturdefekte sind unbekannt.

Typische anamnestische Angabe: „Ich war bis zur Matura nie beim Friseur".

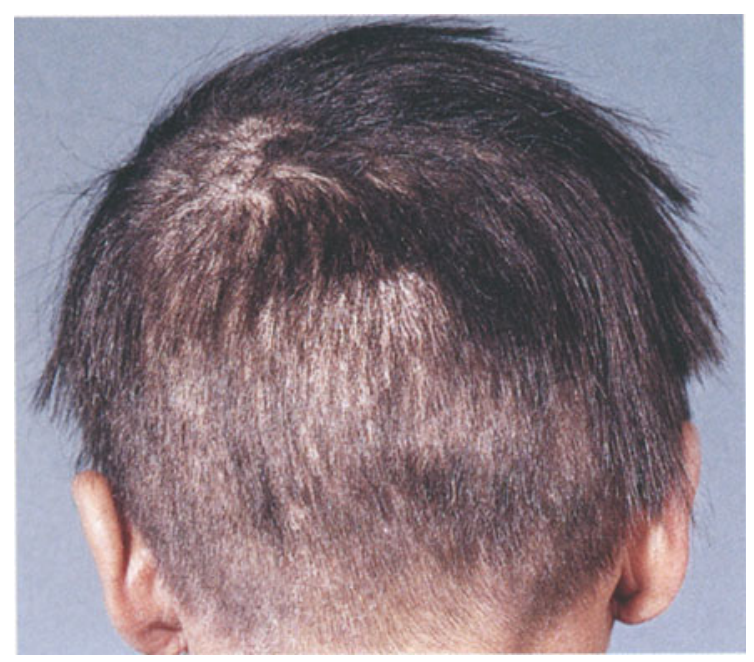

Abb. 19.29. Trichorrhexis nodosa bei einem Knaben mit Netherton-Syndrom. Kurze, glanzlose, brüchige Haare

- Monilethrix ist ein autosomal-dominant vererbtes Zustandsbild mit inkompletter Penetranz, das durch intermittierende, knotige Verdickungen des Haares charakterisiert ist (Monile: lat. (Perlen)halsband). Krankheitsbeginn in den ersten Lebensmonaten, manchmal bis zur späten Kindheit. Betroffen sind sowohl Haupt- als auch (seltener) Körperhaar. Keine sicher assoziierten Symptome.

- Trichorrhexis nodosa ist gleichfalls durch knotige Auftreibungen der Haare gekennzeichnet; in diesen kommt es jedoch zu einer partiellen Fraktur mit charakteristischer Aufsplitterung der Bruchenden ( „zwei mit der Borstenseite aufeinandergesteckte Besen“). Trichorrhexis nodosa ist die häufigste Haarschaftsanomalie und ist meist erworben (wohl $\mathrm{Zu}$ sammenspiel einer dispositionellen Haarschwäche und mechanischer Traumatisierung - forciertes Kämmen!). Assoziation mit Stoffwechselstörungen und Ichthyosen wurde berichtet.

- Trichorrhexis invaginata (Abb.19.29) ist ebenso ein intermittierender Haardefekt, der durch Plastizität des Haarkeratins gekennzeichnet ist. Folge: Der distale Anteil des Haarschaftes wird an der Schadstelle teleskopartig ein Stück in den proximalen hineingeschoben („Bambushaare“). Auftreten isoliert oder als Teilsymptom des Netherton-Syndroms.

- Pili torti. Die Haare sind abgeflacht und in der Längsrichtung eingedreht; Ursache: Biegung der Haarfollikel. Selten erworben (z.B. Bazex-Syndrom), meist autosomal-dominant ererbt. Assoziation mit Menke-Syndrom (s.S.381), Trichothiodystrophie u. a.m.

Trichothiodystrophie: ein autosomal rezessives Fehlbildungssyndrom, das durch physischen und intellektuellen Entwicklungsrückstand, verringerte Fertilität, häufig Ichthyose, Nageldystrophie und Lichtempfindlichkeit gekennzeichnet ist. Die Haare zeigen im polarisierten Licht eine Bänderung, im Lichtmikroskop Pili torti und Trichorrhexis nodosa. Stark reduzierter Schwefelgehalt. 


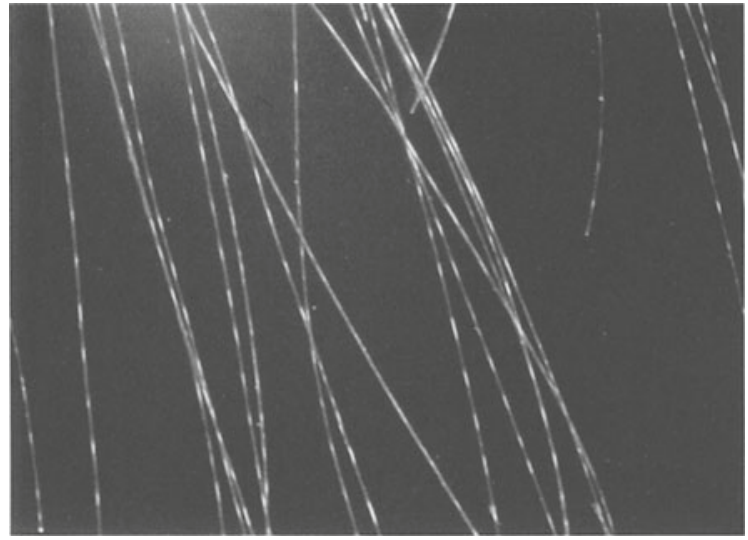

Abb. 19.30. Pili anulati. Die Haare erscheinen gebändert (pigmentierte und unpigmentierte Abschnitte)

Durch chronisch-mechanisches Frisiertrauma bedingte erworbene Haarschaftsanomalien sind ferner Trichoschisis (Spaltung der Haare vom freien Ende in der Längsrichtung; Ursache: Defekte der Kutikula), Trichomalazie (Bruchstellen durch Zug) und Trichonodosis (Knotenbildung - vornehmlich bei gekräuseltem Haar).

Haarschaftanomalien ohne erhöhte Brüchigkeit. Typische Manifestationen sind:

- Pili anulati (Abb.19.30). Eine periodische ringartige Dunkel- und Hellfärbung der Haare. Ursache: Lichtreflexion durch Luftbläschen im Haarkortex; Vererbung autosomal-dominant.

- Kräuselhaare. Negroide Kräuselung der Haare bei Weißen. Häufig mit anderen Haarschaftanomalien und Pigmentanomalien kombiniert; autosomal-dominant. Kann auch als nävusartige Bildung inmitten ansonsten normalen Terminalhaars auftreten.

- Pili trianguli et canaliculati (Cheveux incoiffables). Unkämmbar verfilztes Haar. Ursache: dreieckiger Querschnitt mit Längsrillen macht Gerade- und Parallelrichtung der Haare unmöglich. Autosomal-dominant.

Eine Therapie der Haarschaftsanomalien ist nicht möglich. Systemische Retinoidtherapie kann zur Besserung führen (z. B. Monilethrix), Dauerbehandlung ist jedoch nicht indiziert. Prophylaxe: Vermeidung von Trauma.

\section{Pigmentstörungen des Haares}

Häufigste Pigmentstörung ist das physiologische Ergrauen der Haare (Canities) (s. S. 659).

Obwohl weiße Haare sich nur durch den Pigmentmangel von den pigmentierten unterscheiden, besitzen sie dennoch andere physikalische Eigenschaften: Sie sind borstiger, lassen sich daher schlechter kämmen („graue Wirrköpfe") und stehen weiter vor. Ein frisch getrimmter gemischt grauer Bart erscheint daher dunkler als ein wuchernder.
Weiße oder gelblichweiße Haare finden sich bei Albinismus, auffallend helle ferner beim Menke-Syndrom, der Phenylketonurie, Mangelernährung, Eisenmangelanämie u.a.m. Unter Poliose versteht man isolierte Strähnen weißen Haares. Solche finden sich angeboren etwa beim Piebaldismus, beim M. Pringle und der Neurofibromatose, erworben z.B. bei Nachwuchs von Alopecia areata oder beim Vogt-Koyanagi-Syndrom. Auch Haare in Nävi pilosi ergrauen oft früher als normale Haare.

Fallbericht: Ein 30 jähriger Studentenfunktionär (heute keine Seltenheit) hat seit Geburt einen streifigen Pigmentnävus an der linken Kinnseite, in dem borstige dunkle Haare wuchsen. Kurz nach der Pubertät ließ er sich einen Bart wachsen, der Nävus stach in diesem weiterhin durch seine schwärzlichen Haare hervor. Mit ca. 25 Jahren ergrauten die Haare ausschließlich im Nävusbereich und bildeten einen auffälligen, schlohweißen Streifen.

\subsubsection{Hypertrichosen}

Unter diesem Begriff versteht man Zustände, die durch ein „Zuviel“ an (Körper)haaren gekennzeichnet sind. Eine Hypertrichose der androgenabhängigen Haarfollikel (außerhalb des Kapillitiums) bei Frauen wird als Hirsutismus bezeichnet.

Bei Hypertrichose und Hirsutismus sind nicht zuviele Haarfollikel angelegt, sondern die Haare länger und dicker als der Norm entspricht.

\section{Angeborene Hypertrichosen}

Bei der autosomal-dominanten kongenitalen generalisierten Hypertrichose (Abb.19.31) ist das Gesicht und der gesamte Körper, abgesehen von Handflächen und Fußsohlen, schon bei Geburt oder bald danach mit wolligem Lanugohaar bedeckt, das sich später in Langhaar umwandeln kann. Es bestehen keine anderen Abnormalitäten.

Generalisierte Hypertrichose ist ferner Teilsymptom bei einer Reihe von angeborenen Stoffwechselstörungen (z.B. Mukopolysaccharidosen - Hurler-, Morquio-Syndrom, Leprechaunismus, Porphyrien) und Fehlbildungssyndromen (Cornelia-de-LangeSyndrom u.a.m.).

Umschriebene kongenitale Hypertrichose kann als eigene nävoide Fehlbildung oder in Form komplexer Nävi (z. B. „Tierfellnävus“, Becker-Nävus etc.) auftreten. Eine wichtige Signalfunktion hat die umschriebene Hypertrichose bei Dysraphien des Achsenskeletts (Spina bifida) (Abb. 19.32). 


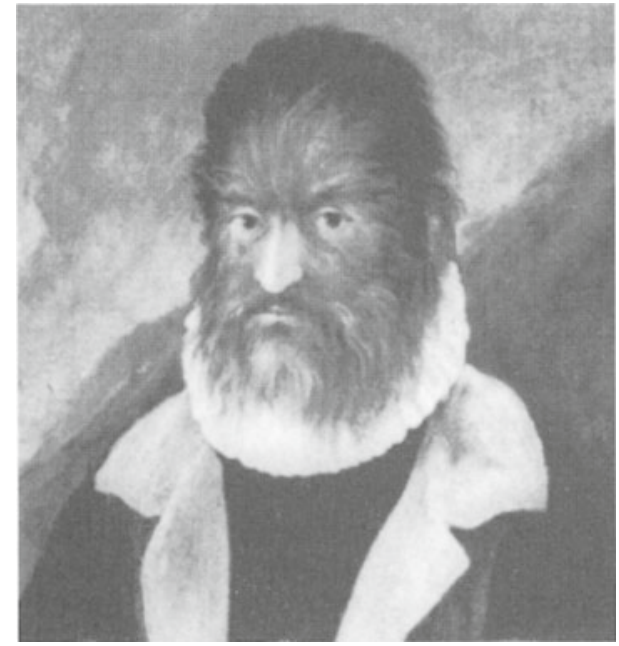

Abb. 19.31. Historisches Beispiel einer hereditätren Hypertrichosis lanuginosa: "Haarmensch" (deutsch, um 1580, Gemäldesammlung Schloß Ambras, Tirol). Im Katalog der Sammlung finden sich folgende Angaben: „Petrus Gonsalvus, geboren 1556 auf Teneriffa, kam noch als Kind an den Hof König Heinrich II. in Frankreich, der ihn erziehen und unterrichten ließ. Er lebte später in Flandern am Hof der Margarethe von Parma, Statthalterin der Niederlande, nach 1583 in Parma. Auf der Reise nach Italien wurden der Haarmensch und seine Familie von dem Basler Arzt Felix Plater und in Italien selbst von dem Bologneser Naturforscher Ulysses Aldrovandi untersucht. Die Ergebnisse sind in ausführlichen Berichten festgehalten... Petrus Gonsalvus verheiratete sich wahrscheinlich noch in den Niederlanden und hatte 2, nach anderen Beschreibungen 4 Kinder". 2 Kinder des Haarmenschen waren mit derselben Anomalie behaftet.

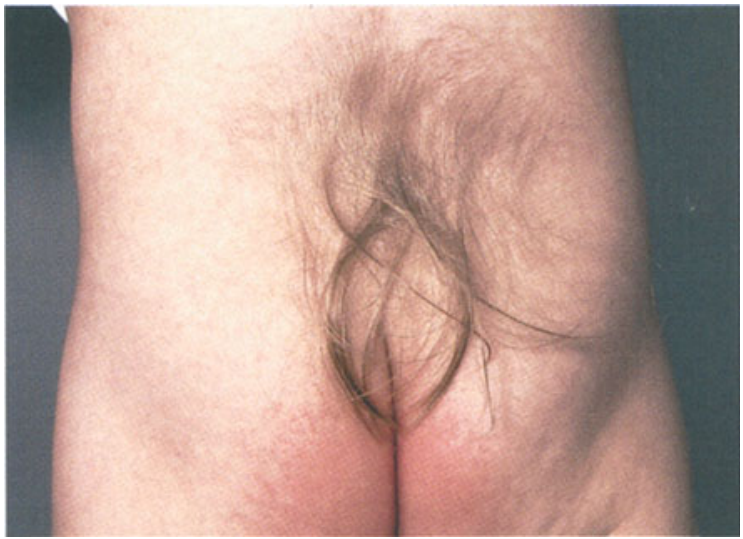

Abb. 19.32. Umschriebene Hypertrichose der Sakralgegend ein wichtiger Hinweis auf eine Spina bifida, wie auch im Fall dieses 2 jährigen Mädchens

\section{Erworbene Hypertrichosen}

Die akquirierte Hypertrichosis lanuginosa ist ein seltenes, dramatisches Zustandsbild, bei dem beim Erwachsenen plötzlich lange Lanugohaare im Gesicht und oft am ganzen Körper auftreten. Es handelt sich um eine (fast) obligate Paraneoplasie, wobei die Hauterscheinungen dem Auftreten des Tumors oft Jahre vorausgehen können.

Generalisierte Hypertrichose kann ferner als Symptom schwerer Systemkrankheiten (Marasmus, mul-

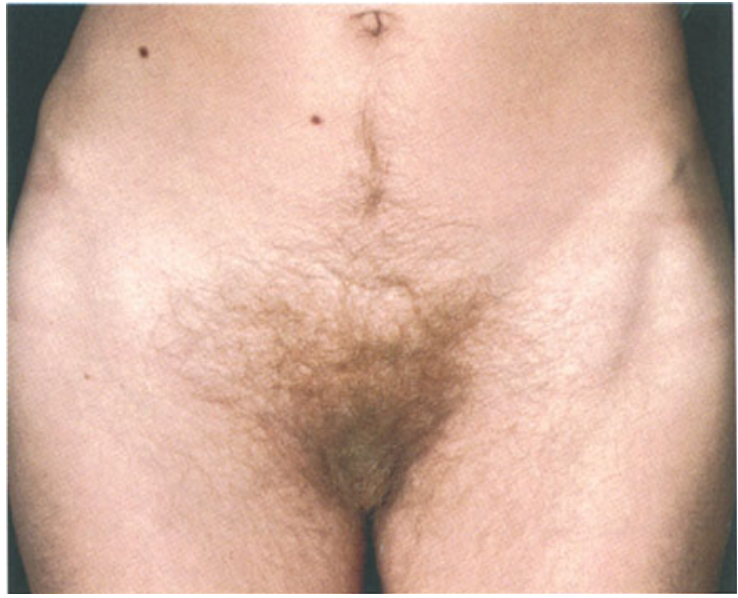

Abb. 19.33. Hirsutismus. Männliches Verteilungsmuster der Pu bes bei einer jungen Frau mit Hyperandrogenisierungssyndrom

tipler Sklerose, nach Schädelhirntraumen), Stoffwechselkrankheiten (Cushing-Syndrom) auftreten. Ursächlich können auch Medikamente sein: Steroide, Cyclosporin A, Minoxidil, Penicillamin, Phenytoin.

Lokalisierte erworbene Hypertrichosen sind nicht selten. Man findet sie am häufigsten als Folge langdauernder lokaler Kortikoidtherapie, regelmäßig bei Porphyria cutanea tarda an lichtexponierten Körperstellen, seltener an Stellen chronischer Hyperämie (z.B. über Angiomen, chronischen Entzündungen, postthrombotischem Syndrom, prätibialem Myxödem etc.) und ausnahmsweise bei Läsionen peripherer Nerven.

\section{Hirsutismus}

Hirsutismus bedeutet ein männliches Haarwachstumsmuster bei Frauen. Er ist entweder anlagemäßig bedingt (in solchen Fällen auch erblich) oder beruht auf Androgenisierung.

Epidemiologie. Hirsutismus liegt bei 5-10\% der Frauen in den Industrieländer vor; die Zahlen schwanken, da die Grenze zum Normalzustand schwer zu ziehen ist und große Unterschiede nach dem ethnischen Hintergrund bestehen (was z.B. bei Frauen mediterraner Herkunft der Norm entspricht, müßte etwa bei ostasiatischen als Hirsutismus gelten).

Klinik (Abb.19.33). Langhaare anstelle unscheinbarer Lanugohaare an Kinn, submental, Kotelettenbereich, Oberlippe (lateral > medial); am Körper über dem Sternum, im Mamillarbereich und am medianen Unterbauch (zwickelförmiges Auslaufen der Schambehaarung zum Nabel).Die Ausprägung des Hirsutismus kann von kaum wahrnehmbar bis schwer reichen. Er kann ein isolierter Befund oder von anderen Zeichen der Androgenisierung (androgenetisches Effluvium, Akne vulgaris (bes. Akne tarda), Menstruationsstörungen, Seborrhö) oder der Virilisierung begleitet sein (männlicher Habitus, Vergrößerung der Klitoris, tiefere Stimme etc). 
Obwohl hirsute Frauen häufig auch einen überdurchschnittlichen Wuchs der Körperhaare haben, ist weder dieser noch buschiges Haupt-, Scham- und Achselhaar ein Zeichen von Hirsutismus.

Pathogenese. Idiopathischer Hirsutismus ist oft durch familiäres Vorkommen, einschleichenden Beginn nach der Pubertät mit voller Ausprägung im 3. Lebensjahrzehnt, Fehlen weiterer Androgenisierungszeichen und normale Hormonspiegel gekennzeichnet. Der idiopathische Hirsutismus beruht auf erhöhter Ansprechharkeit des Endorgans (Ausschluß der symptomatischen Formen erforderlich!). Hirsutismus durch ovarielle, adrenale und andere hormonelle Störungen (s. S. 385).

Therapie. Die systemische Behandlung allfälliger Hormonstörungen ist Aufgabe des Endokrinologen. Antiandrogene (z.B. Cyproteronacetat) bewirken durch Kompetition um den Rezeptor in mehr als $50 \%$ eine Besserung des Hirsutismus (allerdings erst nach Monaten; Nebenwirkungen sind depressive Verstimmung und Verlust der Libido). Topisch wirksame Antiandrogene existieren noch nicht. Milde Formen des Hirsutismus können durch Bleichung unauffälliger gemacht werden. Rasieren und chemische Entfernung bringen nur zeitweilige Besserung; sachgerechte Epilation ist schmerz-, aber dauerhaft.

\subsection{Krankheiten der Talgdrüsen}

\subsubsection{Seborrhoe}

Der Begriff Seborrhoea oleosa bezeichnet die Neigung zu fettiger (Gesichts)haut und fetten Haaren durch übermäßige Talgproduktion ohne weitere klinische Symptome. Dieser Zustand steht am Rande des Physiologischen, tritt nach der Pubertät auf und bildet sich gewöhnlich im dritten Lebensjahrzehnt weitgehend zurück. Er ist meist Ausdruck der individuellen Reaktionsweise auf die endogene androgene Stimulation und Objekt oft eher subjektiver Beurteilung. Er ist häufig, jedoch nicht zwangsläufig, mit Akne vulgaris und seborrhischem Ekzem verbunden. Männer haben häufiger Seborrhoea oleosa als Frauen (deren Talgdrüsen physiologisch nicht voll stimuliert sind), diese suchen jedoch häufiger Abhilfe.

Vermehrter Talgfluß kann auch Zeichen innerer Krankheiten sein: So ist z. B. Akromegalie fast stets von Seborrhoe begleitet (Wirkung eines hypothetischen sebotropen Hypohysenhormons?), ebenso M.Parkinson („Salbengesicht"). Bei letzterem sind die zugrundeliegenden Regulationsstörungen unbekannt, doch führt Therapie mit L-DOPA zur Normalisierung. Weitere, weniger sicher mit Seborrhoe assoziierte Krankheiten sind Phenylketonurie und Thyreotoxikose (Hypothyreose führt hingegen zur Drosselung der Talgproduktion). Manche Medikamente besitzen eine talgflußfördernde Wirkung: Anabolika, ACTH und Kortikosteroide.

Die Möglichkeiten der Therapie sind gering. In extremen Fällen kann der Einsatz von Isotretinoin gerechtfertigt sein.

\subsubsection{Akneiforme Krankheiten}

Unter solchen werden Dermatosen verstanden, die durch entzündliche Knötchen und/oder Pusteln an den Haarfollikeln gekennzeichnet sind. Die meisten entstehen durch Okklusion des Follikelinfundibulum.

\section{Acne vulgaris}

Eine androgenabhängige, selbstlimitierte entzündliche Dermatose der Adoleszenz und des frühen Erwachsenenalters. Ihre Primärläsion ist der Komedo, ihr Erscheinungsbild ist durch einen gesetzmäßigen Ablauf entzündlicher Veränderungen am Komedo gekennzeichnet, ihr Endzustand ist narbige Abheilung.

Epidemiologie. Acne vulgaris ist außerordentlich häufig und tritt wahrscheinlich bei jedem Individuum in bzw. nach der Pubertät zumindest in Minimalform in Erscheinung. Die Geschlechter sind etwa gleich häufig betroffen, doch ist der Verlauf bei Knaben meist schwerer. Der Beginn fällt gewöhnlich in das 12. Lebensjahr oder noch früher (bei Mädchen häufig vor der Menarche). Die Intensität der Akne ist sehr unterschiedlich; schwere Akneformen sind familiär gehäuft (genetischer Faktor?). Faustregel: Je früher der Beginn, desto schwerer der Verlauf und desto später das (spontane) Ende der Akne. Letzteres fällt im günstigsten Fall mit dem Ende der Pubertät zusammen, kann sich jedoch (insbesondere bei Frauen) bis zum 30. Lebensjahr hin erstrecken; hierbei spielen hormonelle und Sekundärfaktoren (Kosmetika, Manipulation) bedeutende Rollen.

Primäreffloreszenz. Der Komedo (Mitesser) ist eine auf Hyperkeratose des Follikelostiums beruhende Talgretentionszyste. Man unterscheidet sog. offene und geschlossene Komedonen. Bei den offenen (schwarzen) Komedonen klafft die Follikelöffnung, darinnen sieht man den am oberen Pol schwarzen Horn-Lipid-Pfropf (Ursache: Schmutz, Melanin). Bei den geschlossenen Komedonen ist das Follikelostium vollständig oder weitgehend obliteriert; der weißliche Talg scheint durch (weiße Komedonen). Geschlossene Komedomen neigen mehr als die offenen zur Entzündung und eitri- 


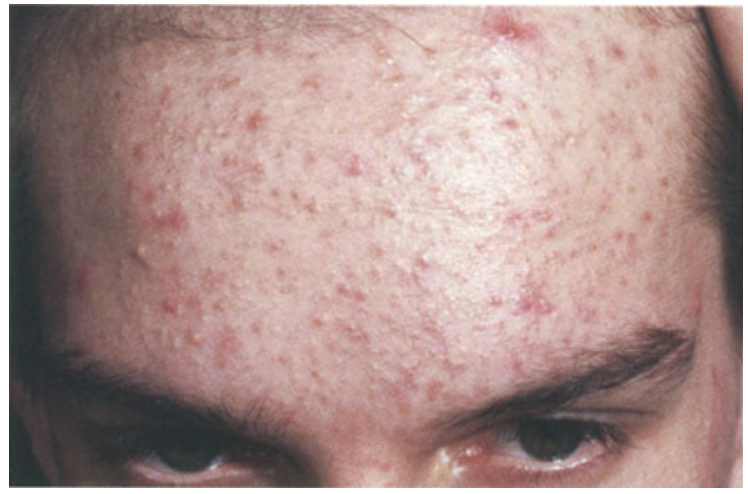

Abb. 19.34. Akne vulgaris comedonica. Vorwiegend geschlossene (weiße) Komedonen der Stirn

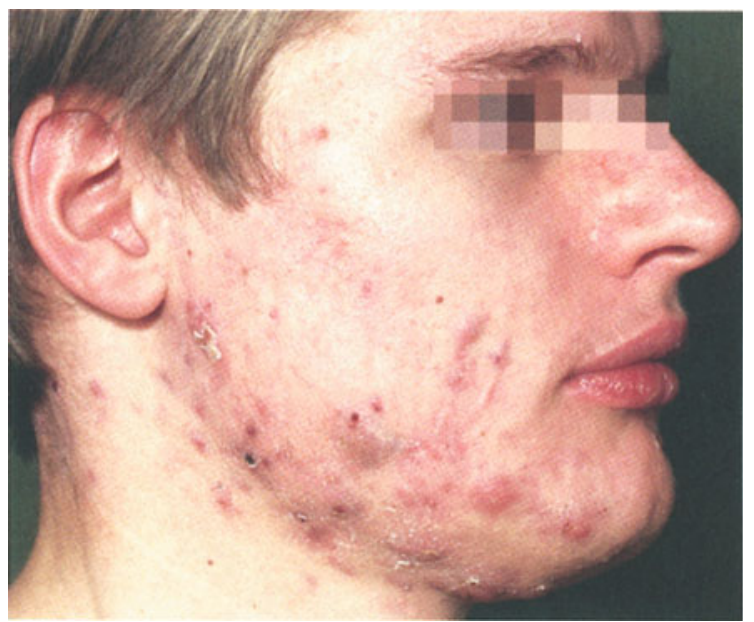

Abb. 19.35. Übergang von Akne papulopustulosa zu Akne conglobata

gen Einschmelzung. Beide Arten von Komedonen treten zumeist gemeinsam auf.

Klinik (Abb.19.34 u. 19.35). Je nach dem Entwicklungsstadium unterscheidet man folgende Erscheinungstypen (bzw. Stadien) der Acne vulgaris:

- Erstmanifestation ist die Acne comedonica, die durch mehr oder minder zahlreiche Komedonen vorwiegend an Stirn, Nase, nasolabial und im Kinnbereich gekennzeichnet ist. Dieses Stadium kann monate- bis jahrelang andauern und wird vom Betroffenen häufig wenig beachtet.
- Im weiteren Verlauf kommt es zu entzündlichen Veränderungen an den Komedonen, die vorerst ohne, später mit Pustelbildung ablaufen (Acne papulopustulosa). Die Pusteln entsprechen zumeist einer oberflächlichen Follikulitis, können sich jedoch gelegentlich zu tiefen, Furunkel-ähnlichen Läsionen weiterentwicklen. In diesem Stadium bleiben Fälle mit durchschnittlich schwerem Verlauf stehen; es dauert einige Jahre an und heilt dann spontan ab. Jede tiefe Follikulitis hinterläßt eine meist eingezogene, seltener hypertrophe Narbe, deren Größe der Massivität der vorangegangenen Entzündung entspricht; meist sind sie wenig auffällig.

- Bei weiterem Fortschreiten entstehen multiple knotige perifollikuläre abszedierende Infiltrate (z.T. durch Platzen follikulärer Pusteln), die dadurch zu ausgedehnten Abszessen mit multiplen Fistelöffnungen konfluieren und im Extremfall weite Teile der Haut von Gesicht, Brust und Rücken fuchsbauartig unterminieren können (Acne nodulocystica bzw. Acne vulgaris conglobata). Gerade in solchen ausgedehnten Fällen ist die Schmerzhaftigkeit oft geringer als erwartet.

Bei schwerer nodulozystischer Akne entleert sich bei Druck an einer Hautstelle Eiter aus mehreren, oft weit entfernten Fistelöffnungen.

Extrem ausgeprägte Fälle der Akne vulgaris sind durch ein buntes Nebeneinander von allen bisher beschriebenen Läsionen und zusätzlich sehr auffälligen, wie gestrickt aussehenden atrophen und hypertrophen Narben (Aknekeloid) gekennzeichnet. Auch im Abheilungsstadium bleiben die Narben weiterhin auffällig („pockennarbig“).

Der Schweregrad der Akne vulgaris wird entsprechend einer Einteilung nach Pocchi klassifiziert (Tab. 19.7).

Ätiologie und Pathogenese. Die Akne wird durch das gleichzeitige bzw. sukzessive Wirken mehrerer Faktoren ausgelöst.

- Als erster Schritt der Genese kommt es in der Pubertät unter dem Einfluß der Androgene zur Volumenzunahme der Talgdrüsen und zur Steigerung der Lipidsynthese. Diese Reaktion wird durch Androgenrezeptoren in den Talgdrüsen mediiert. Die Talgdrü-

Tabelle 19.7. Gradeinteilung der Akne (nach Pocchi et al, 1991)

\begin{tabular}{|c|c|c|c|c|}
\hline & mild & mäßig & schwer & sehr schwer \\
\hline Komedonen & wenige $(<20)$ & zahlreich $(>20)$ & zahlreich (> 20) & Fistelkomedonen \\
\hline Papeln/Pusteln & $\begin{array}{l}\text { keine oder wenige } \\
(<10)\end{array}$ & $\begin{array}{l}\text { wenige bis zahlreich } \\
(10-20)\end{array}$ & $\begin{array}{l}\text { zahlreich bis sehr } \\
\text { zahlreich }(>20)\end{array}$ & sehr zahlreich $(>30)$ \\
\hline knotige Infiltrate & keine & keine & wenige $(<5)$ & wenige bis zahlreich $(>5$ ) \\
\hline „Zysten" & keine & keine & wenige $(<5)$ & wenige bis zahlreich $(>5$ ) \\
\hline Fisteln & keine & keine & wenige $(<5)$ & wenige bis zahlreich $(>5$ ) \\
\hline Narben & keine & keine & vorhanden & zahlreich \\
\hline
\end{tabular}


sen sind in ähnlicher Weise androgen-sensitiv wie die Haarfollikel der Bartregion; Kastraten entwickeln keine oder nur geringfügige Akne. Bei Frauen kommt es zur charakteristischen prämenstruellen Verschlechterung der Akne durch die höheren Progesteronspiegel (androgenähnliche Wirksamkeit).

- Gleichzeitig mit der Steigerung des Talgflusses kommt es im tieferen Anteil des Follikelinfundibulums zur Proliferationssteigerung des Epithels und zur Umstellung auf einen epidermalen Verhornungstyp (Ausbildung eines Stratum granulosum, "cornified envelopes" und Stratifizierung); das Resultat ist ein aus orthohyperkeratotischen Hornmassen bestehender Pfropf, der den Haarfollikel in der Gegend des Infundibulums ausfüllt und auftreibt. Proximal davon kommt es zum Stau der intensiv weiterproduzierten Lipidmassen. Es entsteht ein mit Lipid-Keratin gefüllter Sack, der Komedo.

Die Ursache der follikulären Hyperkeratose ist nicht genau bekannt; entweder ist auch sie eine direkte Folge der Hormoneinwirkung, oder sie wird sekundär durch die Talghyperproduktion hervorgerufen (Mangel an Linolensäure?). Daß Talg "komedogen“ wirkt, kann am Kaninchenohr (Tiermodell zur Akneentstehung) nachgewiesen werden: Lokale Applikation von Talg führt zur Ausbildung von follikulären Hornpfröpfen und damit zu Komedonen.

- Gleichzeitig zur Komedobildung kommt es auch zur sprunghaften Keimproliferation der sonst kaum pathogenen aeroben, lipophilen und lipolytischen Begleitkeime Corynebacterium acnes und granulosum. Diese Keime bewohnen physiologischerweise den Grund des Haarfollikels; im Komedo finden sie ideale Lebensbedingungen vor und spalten mit Lipasen die reichlich vorhandenen Neutralfette auf. Die Corynebakterien sind zur Komplementaktivierung befähigt; im Serum von Aknepatienten sind häufig Antikörper gegen sie nachweisbar.

Die entstehenden freien Fettsäuren wirken stark inflammatorisch und führen zu Leukotaxis und weiterem Druckanstieg im Komedo (entzündliche Papel, oberflächliche Pustel). Letzterer platzt entweder spontan oder durch Nachhelfen des Patienten (Ausdrücken!) und ergießt seinen Inhalt in das umgebende Bindegewebe. Dies führt zur heftig entzündlichen, tiefen abszedierenden Reaktion.

Klarerweise neigen geschlossene Komedonen mehr zur Ruptur als offene, da sich hier der Druckanstieg nach außen entladen kann. Geschlossene Komedonen gleichen hingegen „Zeitbomben, die durch das Hinzutreten von C. acnes gezündet werden“.

Bei Tieren (auch bei Primaten) tritt Acne vulgaris nicht oder nur unter sehr speziellen Bedingungen auf (Kaninchenohr). Auch beim Menschen ist die Akne auf jene Bezirke beschränkt, wo große Talgdrüsen mit Lanugohaaren gekoppelt sind. Dicke Terminalhaare verhindern demnach vermutlich auch bei starker Talgproduktion die Bildung von Komedonen.
Androgene und Akne. Die Stimulierung der Talgdrüse durch Androgene erfolgt wieder über Bildung von DHT im Endorgan (aus freiem T, mittels der $5 \alpha$-Reduktase) und Bindung eines DHT-Rezeptorkomplexes im Zellkern. Die überschießende Androgenwirkung bei Akne beruht bei beiden Geschlechtern in aller Regel nicht auf erhöhten Androgenspiegeln sondern auf dispositionell überhöhter Enzymaktivität des Endorgans. Hiefür sprechen experimentelle Daten, aber auch die klinische Beobachtung, daß die Akne im späteren Verlauf trotz etwa gleichbleibender T-Spiegel spontan rückläufig ist (Gewöhnungseffekt?).

Selbstverständlich können auch erhöhte Androgenspiegel zur Akne führen. Dies ist bei einer Minorität von Frauen der Fall, bei denen die (meist schwere, früh einsetzende und lang andauernde) Akne von anderen Zeichen der Androgenisierung (s. S. 385) begleitet ist. Zugrunde liegt in solchen Fällen häufiger ein ovarieller (polycystisches Ovarsyndrom) als ein adrenaler (LO$\mathrm{CAH}$ ) Androgenismus. Seltener sind erniedrigte Spiegel des SHBG (sex hormone binding globulin) verantwortlich, bei denen mehr T zur Konversion in DHT verfügbar ist (bei Hypothyreoidismus, Adipositas, Akromegalie, Corticoidmedikation).

In manchen Serien wurden in selektierten Kollektiven (Spätakne) in bis zu $30 \%$ zumindest geringfügige Zeichen des polycystischen Ovarsyndroms gefunden.

Therapie. Ein Spektrum sehr wirksamer Therapiemöglichkeiten steht zur Verfügung; diese setzen an verschiedenen Gliedern der pathogenetischen Kette an.

- Komedolytische Therapie. Diese wesentlichste Säule der Aknetherapie erfolgt lokal durch Applikation von Vitamin-A-Säure (Trans-Retinsäure); diese wirkt stark antikeratinisierend, löst bestehende follikuläre Hornpfröpfe auf, ermöglicht damit die Entleerung des gestauten Talgs und verhindert die Ausbildung neuer Komedonen. Sie ist bei Acne comedonica und papulopustulosa indiziert und ist langwierig: ihre Wirkung wird erst nach etwa 3 Wochen deutlich, und sie muß im Prinzip solange weitergeführt werden wie die Neigung zur Akne besteht (Jahre!).

Vitamin-A-Säure wirkt leicht irritierend (Brennen, Rötung, Schuppung) und muß daher sorgsam dosiert werden. Viele Patienten mißinterpretieren die Irritation als "Allergie“ („Das habe ich schon gehabt, das vertrage ich nicht"). Sie kann auch zu Therapiebeginn durch synchrones „Reifen“ der Komedonen zur scheinbaren Verschlechterung der Akne führen. Außerdem bewirkt sie erhöhte UV-Lichtempfindlichkeit (Vorsicht bei Badeaufenthalten, GletscherSchilauf etc.).

- Antibiotische Therapie. Intensiver entzündliche Fälle von Acne papulopustulosa bedürfen vor und während der Vitamin-A-Säure-Therapie einer antibiotischen Behandlung. Diese kann, je nach Intensität, lokal (Erythromycin, Clindamycin, Benzoyl- 
peroxyd) oder systemisch erfolgen (orale Tetrazykline bzw. Minozyklin). Tetrazykline drängen (natürlich nur vorübergehend) die bakterielle Komponente der Akne zurück und werden solange angewendet als abszedierende Veränderungen vorhanden sind (kaum länger als 1-2 Monate), kann bei Rezidiven aber jederzeit wieder angesetzt werden. Langzeittherapie ohne komedolytische Begleitbehandlung ist nicht sinnvoll.

C. acnes ist außerordentlich empfindlich gegenüber diesen Antibiotika (schon geringe Dosen sind wirksam, z. B. 50-100 mg Minocyclin/Tag); zusätzlich werden die von C. acnes erzeugten Lipasen gehemmt. Lokale Antibiotika dringen in tiefe Infiltrate jedoch nicht ein!

Komedolytische und antibakterielle Wirksamkeit vereinigt Benzoyl-Peroxyd; allerdings stellt es keine Alternative zu Tetrazyklinen bei tiefen Entzündungen dar und ist der Vitamin-A-Säure unterlegen.

- Unterdrückung der Talgproduktion. Ausschließlich bei Frauen können Antiandrogene (Cyproteronacetat) eingesetzt werden, die durch Rezeptorblockade die Wirkung der körpereigenen Androgene weitgehend ausschalten.

Nachteil: nur milde Wirksamkeit, oft nicht sehr gute Verträglichkeit. Auch hier gilt, daß eine Systemtherapie ohne Lokalbehandlung wenig Sinn hat.

Adrenale Androgenproduktion (bei LOCAH) kann durch niedrig dosiertes Dexamethason gebremst werden.

Das stärkste gegen Akne wirksame Mittel ist Isotretinoin (cis-Retinsäure, Accutan), ein orales synthetisches Retinoid, das die Talgdrüsen zur langdauernden, aber reversiblen Involution und die Akne zum Stillstand bringt. Isotretinoin ist das Mittel der Wahl bei schwerer nodulozystischer Akne. Es wird meist in Dosen von 1,0 mg/kg durch 1-3 Monate verabreicht, anschließend wird - je nach Verlauf - entweder abgesetzt oder mit Erhaltungsdosen von 0,2 bis $0,5 \mathrm{mg} / \mathrm{kg}$ weiterbehandelt. Nach Abschluß der Therapie kommt es zur langsamen Wiederkehr der Talgproduktion, meist aber nur zu milden (oder keinen) Aknerezidiven. Nebenwirkungen und Kontraindikationen sind ähnlich wie bei Etretinat (Teratogenität, Transaminasen- und Lipidanstieg, Notwendigkeit hormoneller Kontrazeption). Isotretinoin und Tetrazykline sollten nicht gleichzeitig gegeben werden (Gefahr des Pseudotumor cerebri).

In seltenen Fällen tritt nach Isotretinoin eine paradoxe Verschlechterung auf: Fieber, multiple neue Läsionen, schmerzhafte Granuloma pyogenicum-ähnliche Granulationen.

Ein für sehr stark entzündliche Fälle von Akne geeignetes Chemotherapeuticum ist schließlich Dapson. Leider wenig wirksam ist die Azelainsäure: Diese ist ein Stoffwechselprodukt von Malassezia furfur, einem Saprophyt des Haarfollikels, der eine wachstumshemmende Wirkung auf $\mathrm{C}$. acnes besitzt.
Zur Behandlung der Acne vulgaris wurden früher (und werden noch heute) verschiedene Diäten, Schälkuren und andere Maßnahmen, insbesondere die manuelle Entfernung der Komedonen,empfohlen. Keinerlei Diät beeinflußt den Verlauf der Akne und erhöht nur die Belastung des ohnehin meist sensiblen Aknepatienten. Maßnahmen, die ausschließlich auf Entfernung der Komedonen ausgerichtet ist (manuell oder Schälkuren), haben nur vorübergehende Wirkung, Manipulationen bringen das Risiko der Follikelruptur mit sich. Allerdings sind Bemühungen, Patient/innen vom Ausdrücken von Komedonen und Pusteln abzubringen, meist wenig erfolgreich.

Wenig bzw. nicht wirksam sind einige viel geübte Praktiken:

- lokale Desinfektion und Säuberung mit Seifen. Die oberflächliche Entfernung von Hautfett bzw. Hautkeimen haben keinen Einfluß auf den Verlauf der Akne;

- kommerziell erhältliche „Peeling“-Präparate. Eine Ausnahme davon sind möglicherweise die derzeit „aktuellen“ Fruchtsäurepräparate;

- UV-Bestrahlungen.

\section{Komplikationen der Acne vulgaris.}

Superinfektion mit Staphylokokken ist ein nicht seltenes Ereignis, das sich klinisch als den typischen Veränderungen der Acne vulgaris aufgepfropfte Furunkulose manifestiert. Therapie: penicillaseresistentes Penicillin.

„Gramnegative Follikulitis“. Eine Superinfektion meist mit Klebsiellen oder Enterobakterien. Die gramnegative Follikulitis äußert sich als akute Episode multipler oberflächlicher Pusteln mit heftiger entzündlicher Reaktion im Rahmen einer Acne vulgaris; auch tiefer liegende nodös-zystische Läsionen durch gramnegative Keime (meist Proteus) kommen vor. Therapie: Aminoglykoside, Quinolone.

\section{Sonderformen der Acne vulgaris}

Acne cosmetica. Meistens mäßig entzündliche Akneform, die sich durch reichlich Komedonen und relativ tief sitzende entzündliche fibrotische Knötchen auszeichnet. Ursache: komedogene Substanzen in Kosmetikartikeln. Diese Akneform wird in besonderem Maße durch Manipulation (Drücken, Kratzen) genährt; ihre Hauptlokalisation sind die beiden Kinnseiten. Bevorzugung über 20 jähriger Frauen.

Bis ins Erwachsenenalter persistierende Akne bei Frauen ist häufig durch milden Hyperandrogenismus bedingt (meist bei polyzystischem Ovarsyndrom). Diese Spätakne ist durch fibrosierte Akneeffloreszenzen am Kinn (Kinnakne), Kratzzwang, milde Zeichen der Hormondysregulation (Menstruationsunregelmäßigkeiten, milder Hirsutismus) sowie prämenstruelle Exazerbation gekennzeichnet (Abb. 19.36).

Acne excoriée des jeunes filles. Psychogen überlagerte Akne, reichlich Kratzeffekte.

Acne tropica. Eine wegen Superinfektion mit Staph. aureus besonders intensiv verlaufende Acne vulgaris 


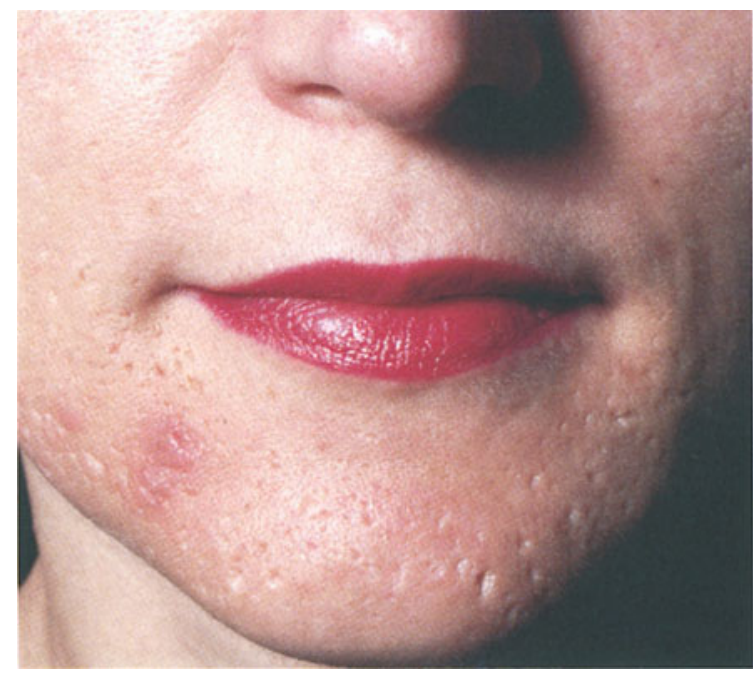

Abb. 19.36. Aknenarben. Atrophe eingezogene Narben nach Kinnakne (artefizielle Komponente)

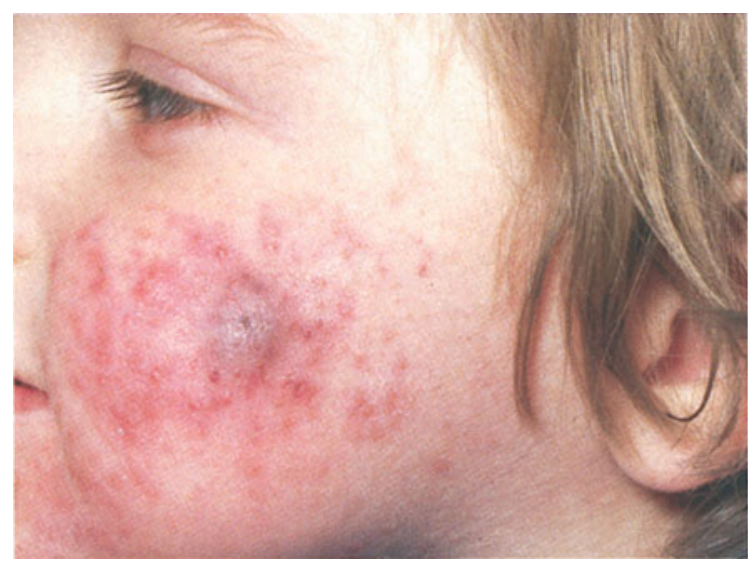

Abb. 19.37. Akne infantilis bei 5 jährigem Knaben

(starkes Schwitzen fördert die Proliferation der Hautflora).

Acne neonatorum. In der Postpartalperiode (seltener im Kleinkindesalter) auftretende Acne papulopustulosa (Abb.19.37). Genese: restierende mütterliche Androgene. Heilt spontan ab.

\section{Akneähnliche Dermatosen}

Medikamenteninduzierte Akne. Manche Medikamente rufen nach systemischer Gabe akneiforme Exantheme hervor. Die Ähnlichkeit beschränkt sich allerdings auf die Follikelobstruktion durch Hornpfröpfe mit entzündlicher Begleitreaktion (Abb. 19.38); echte Komedonen werden kaum gebildet. Prädisponiert sind junge Patienten, die gleichzeitig eine echte Acne vulgaris haben.

Klassisches Beispiel ist die Steroidakne: vorwiegend am oberen Rumpf und den proximalen Extremitäten schütter disseminierte entzündliche Papeln um kleine follikuläre Hornpfröpfe. Die Steroidakne hat ein charakteristisches Bild (Blickdiagnose) und tritt meist

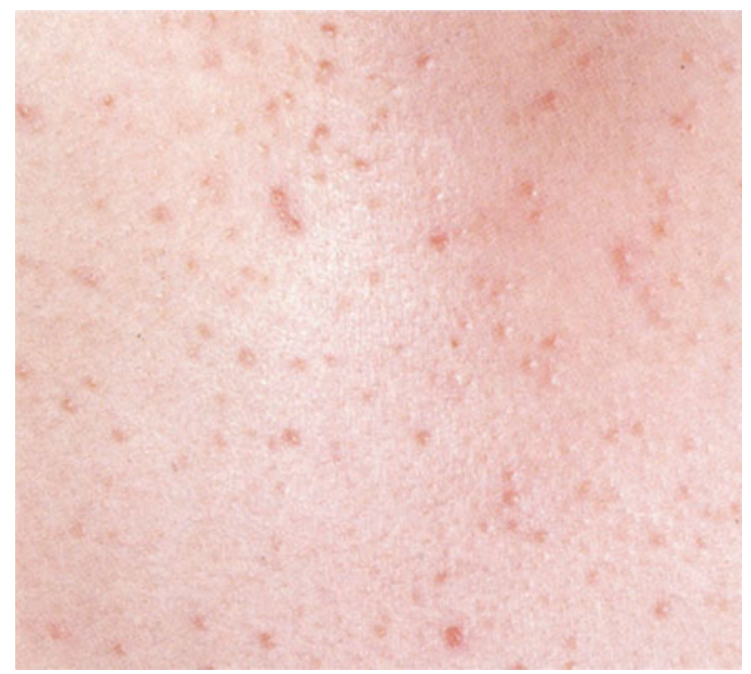

Abb. 19.38. INH-Akne. Zahlreiche am Rumpf lokalisierte hyperkeratotische, pustulierende Papeln

schon kurze Zeit (etwa 2 Wochen) nach hochdosierten Kortikoidstößen auf. Ähnliche Exantheme kommen oft bei INH und nahezu stets bei Kombination dieser beiden Medikamente zustande (Behandlungsmodus bei bestimmten Formen der Tuberkulose). Akneartige Bilder können ferner Hydantoine sowie Halogene (Jod, Brom) hervorrufen; bei letzteren ist das Bild allerdings durch starke Entzündung gekennzeichnet.

Exogen bedingte Akne (Öl-, Teerakne). Verschiedene industriell verwendete Substanzen können akneähnliche Bilder erzeugen; die häufigsten Beispiele sind Öle und Teer. Öle kommen entweder als feine Tröpfchen in der Luft mit der Gesichtshaut in Kontakt (etwa in Webereien, Schleifereien etc.) und verursachen dort oft ungemein reichlich Komedonen (Prädilektionsstellen: Schläfen und Jochbeingegend). Direkter Kontakt mit Öl, beispielsweise durch Öl verschmutzte Arbeitskleider, kann Akneerscheinungen an den betroffenen Körperstellen hervorrufen.

Acne fulminans. Dieses akute Krankheitsbild ist sehr selten, tritt fast nur bei Knaben in der Pubertät und oft ohne vorhergehende Akneläsionen auf. Es ist ähnlich der nodulozystischen Akne, doch exulzerieren die sehr schmerzhaften Läsionen und heilen mit starker Narbenbildung ab; es bestehen ausgeprägte Systemzeichen (Fieber, Leukozytose, Polyarthralgien).

Acne conglobata (follikuläres Okklusionssyndrom, Aknetetrade, chronische Hidroadenitis suppurativa) (Abb. 19.39).

Zur Nomenklatur: Acne conglobata ist nicht dasselbe wie Acne vulgaris conglobata, ist aber häufig von dieser begleitet.

Ein seltenes charakteristisches und schweres Krankheitsbild, das durch exzessiv chronische, unbeherrschbar fortschreitende, nodulozystische akneartige Verän- 


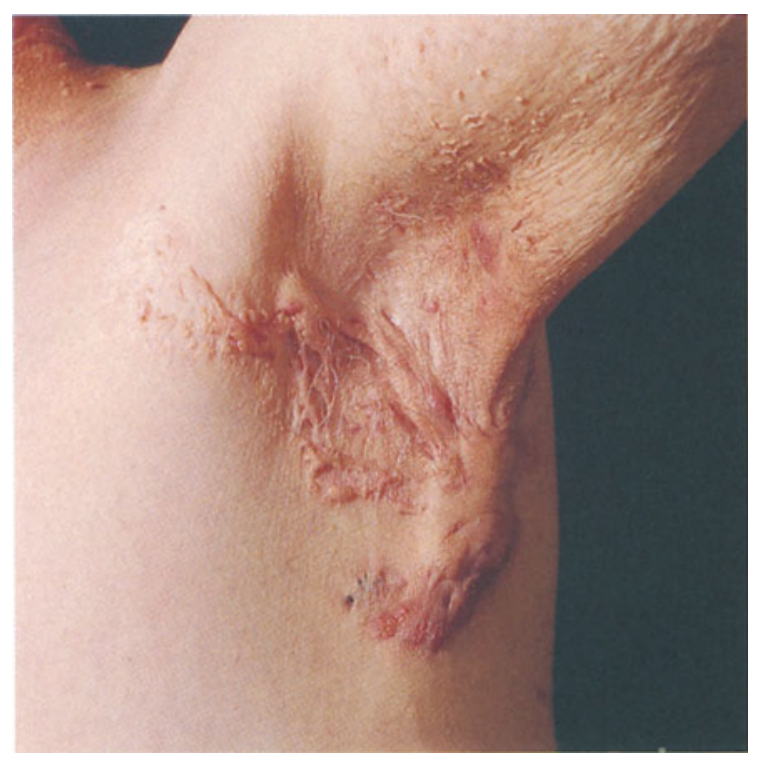

Abb. 19.39. Follikuläres Okklusionssyndrom (chronische Hidradenitis suppurativa). Wie gestrickt aussehende Narben nach Infiltraten und Fisteln; ein frisch entzündlicher Knoten am unteren Bildrand

derungen mit multipler Fistelbildung in den Regionen der Acne vulgaris, im Nacken sowie den Regionen apokriner Schweißdrüsen (axillär, inguinal, perianal) gekennzeichnet ist. Der Krankheitsbeginn liegt meistens im frühen Erwachsenenalter, Männer sind viel häufiger befallen. Konservative Maßnahmen (Antibiotika, Stichinzisionen) bringen nur vorübergehend Abhilfe, auch Isotretinoin ist weniger wirksam als ursprünglich angenommen. Einzige zielführende Therapie ist oft die radikale Exzision der betroffenen Areale und plastische Deckung. Ursache, insbesondere die Rolle der apokrinen Schweißdrüsen sind unklar.

\subsubsection{Formenkreis der Rosazea}

\section{Rosazea}

Eine morphologisch charakteristische akneähnliche entzündliche Krankheit der Gesichtshaut von unbekannter Ätiologie, die in der zweiten Lebenshälfte auftritt und nicht von Komedonen begleitet ist.

Epidemiologie. Rosazea ist eine häufige, harmlose, auf die Haut beschränkte Krankheit der zweiten Lebenshälfte, die bei beiden Geschlechtern etwa gleich häufig vorkommt, bei Männern jedoch intensiver abläuft. Bei Patienten mit Alkoholabusus, gastrointestinalen Störungen und solchen, die sich häufig Wind und Wetter aussetzen, ist die Inzidenz höher.

Klinik. Die Rosazea kann sich morphologisch variabel präsentieren. Sie verläuft in 3 bzw. 4 Stadien, doch kann sie in jedem derselben stehenbleiben, dieses exzessiv ausbilden oder andere überspringen. Der Beginn ist meist langsam und wird vom Patienten zunächst nicht registriert.

- Stadium teleangiektaticum (Abb.19.40): Als erstes stellt sich eine Neigung zu Flush-artiger Rötung des Gesichts ein. Die Anfälle stellen übersteigerte Reaktionen auf Reize dar, die auch physiologisch zur Gesichtsröte führen: Temperaturschwankungen, Wind und Wetter sowie Anstrengung, Kaffee und Alkohol. Im Lauf der Zeit entstehen zarte, fleckig verdichtete Teleangiektasien an Nase und Wangen, die sich in Monaten und Jahren ausbreiten und dem Gesicht einen charakteristischen dunkellividroten Ausdruck verleihen (daher der wenig geglückte deutsche Name „Kupferfinne“);

- Stadium papulosum und papulopustulosum (Abb. 19.41): Auf den Erythemen entwickeln sich zunehmend entzündliche Knötchen v.a. an Wangen und Nase: das nunmehr persistent lividrote Gesicht wirkt höckerig. Bei weiterem Fortschreiten Umwandlung der Knötchen in oberflächliche Pusteln;

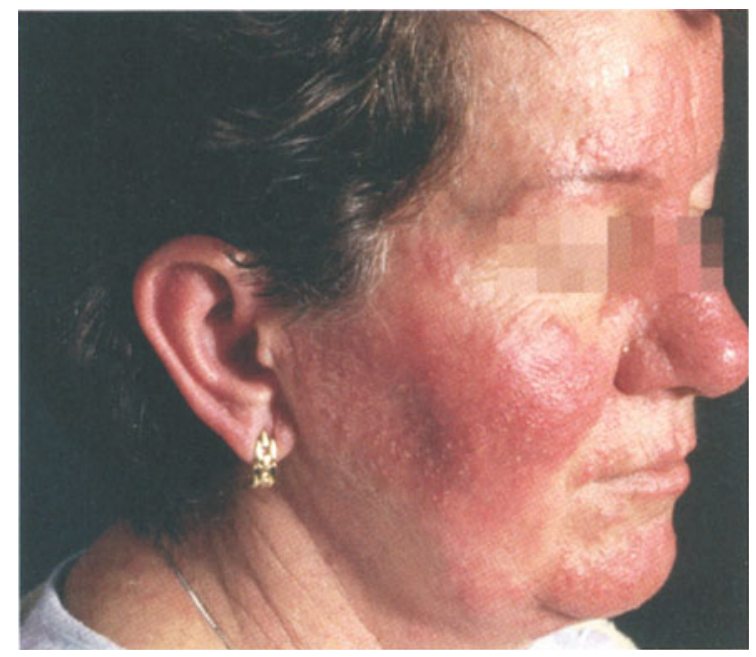

Abb. 19.40. Rosacea. Teleangiektatisches Stadium

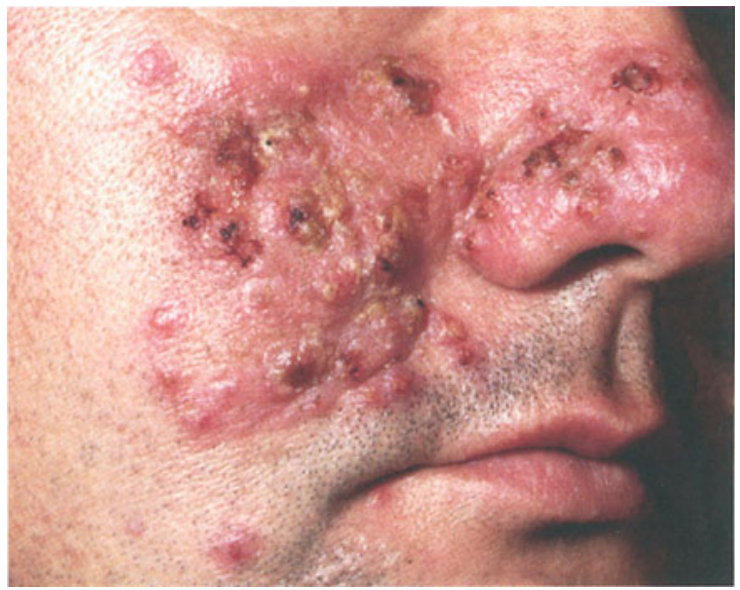

Abb. 19.41. Rosacea. Papulopustulöses Stadium 
- Rhinophym: Schließlich kommt es - fast ausschließlich bei Männern - zu oft mächtiger Hypertrophie der Talgdrüsen, die zur bizarren Vergrößerung der Nase führen kann: Diese ist riesenhaft, unregelmäßig höckrig, unförmig, von schwammig-wabiger Beschaffenheit und wegen klaffender, eingezogener Follikelöffnungungen von „wurmstichiger“ Oberfläche.

Variabilität der Morphologie. Das Spektrum der Rosazea reicht von zarter Rötung der Wangen über umschriebene, auffällige Rötungen (z. B. „Rubor nasi“ „Schnapsnase“) und solide knotige Läsionen („sarkoidale Rosazea") zu ausgedehnten entzündlichen, eitrigen Formen. Das Rhinophym entsteht etwa gleich häufig als Krönung einer vollausgeprägten Rosazea wie als nahezu isoliertes Phänomen.

Der Verlauf ist chronisch, schubartig, Exazerbationen häufig nach Alkoholzufuhr oder Kälteexposition. Die Rosazea heilt spontan meist nicht ab, doch sind vorübergehende Remissionen nicht selten. Keine Narbenbildung.

Histologie. In frühen Stadien lediglich lympho-leukozytäre perifollikuläre Infiltrate, später meist wenig intensive, manchmal beträchtliche sarkoidale Begleitkomponente (in solchen Fällen sprach man früher von „Lupus miliaris disseminatus faciei“ bzw. sarkoidaler Rosazea).

Ätiologie und Pathogenese. Die Ätiologie ist unbekannt. Es bestehen zwei grundlegende Störungen, deren Konnex unklar ist: einerseits die pathologische Gefäßdilatation der Gesichtsregion auf physiologische Stimuli; andererseits die Entzündung der Haarfollikel, die wahrscheinlich bakterieller Genese ist, da sie auf Antibiotika anspricht (übermäßige Wucherung der residenten Flora des Haarfollikels?).

Differentialdiagnose. Acne vulgaris; außer der verschiedenen Altersprädilektion (die jedoch nicht immer ein verläßliches Kriterium ist) unterscheidet sich die Rosazea durch das Fehlen von Komedonen und den charakteristischen kupfer- bis lividroten Farbton. Systemischer Lupus erythematodes.

Therapie. Breitbandantibiotika können die Rosazea vorübergehend komplett unterdrücken. Da die Rosazea jedoch auf einer erworbenen Disposition beruht, kommt über kurz oder lang ein Rezidiv zustande (worauf der Patient aufmerksam gemacht werden muß). Bei milden Formen ist Lokaltherapie (Erythromycin-, Clindamycinpräparationen) ausreichend, bei schwereren orale Tetrazykline bzw. Minozyklin. Unter systemischer Therapie gewöhnlich schon nach einigen Wochen fast völlige Rückbildung. Bei schlecht ansprechenden Fällen ist ein Versuch mit Metronidazol (lokal oder systemisch) angezeigt.

Wenig oder nicht spricht hingegen das Rhinophym auf alles Genannte an. Behandlungsversuche mit Iso-

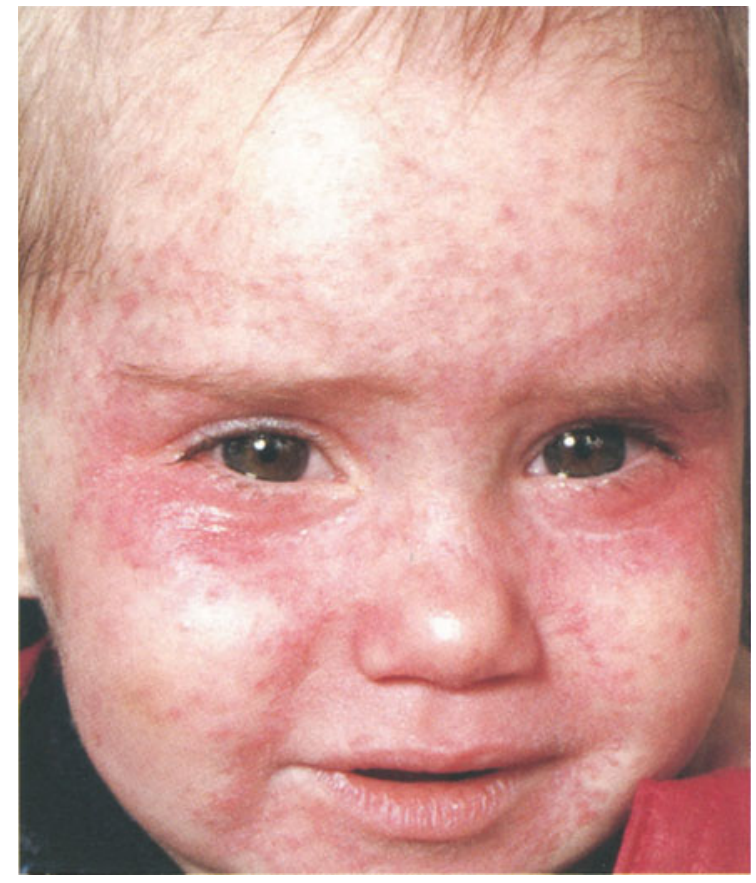

Abb. 19.42. Periorale Dermatitis bei 3jährigem Knaben. Ursache: routinemäßige Gesichtspflege mit Feuchtigkeitscreme

tretinoin (systemisch) sind oft erfolgreich; bei ausgeprägten Formen ist nur die operative Therapie (Dekortikation) sinnvoll.

\section{Periorale Dermatitis \\ (syn. Rosazeaartige Dermatitis)}

Eine auf die Gesichtshaut beschränkte, entzündliche Dermatose vorwiegend bei Frauen jüngeren und mittleren Alters oft mit milder atopischer Disposition. Ihre wahrscheinliche Ursache ist chronische Quellung und Überfeuchtung durch kosmetische Cremes. Sie ist eine zwar harmlose, kosmetisch jedoch sehr störende Krankheit, die auf geeignete Behandlung (Entzug der Cremes) ausgezeichnet anspricht.

Epidemiologie. Dieses der Rosazea ähnliche Krankheitsbild hat sich erst vor ca. 35 Jahren fast epidemisch in den westlichen Ländern ausgebreitet, parallel zum Wohlstand und dem Gebrauch von Kosmetika auch in breiteren Schichten. Betroffen sind ausschließlich Personen, die regelmäßig Feuchtigkeitscremes applizieren („Tages-, Nachtcremes“). Dies sind weit überwiegend Frauen ab dem Nachschulalter; die seltenen Männer bzw. Kleinkinder mit perioraler Dermatitis hängen derselben Gewohnheit an bzw. werden von ihren Müttern mit Feuchtigkeitscremes "gepflegt" (Abb.19.42). Disponierend ist ein trockener Hauttyp; oft besteht eine Anamnese milder Neurodermitis.

Klinik (Abb. 19.43). Die Gesichtshaut ist diffus milde geschwollen, matt (wenn nicht gerade von Creme bedeckt), zeigt verwaschene, manchmal strichförmige 


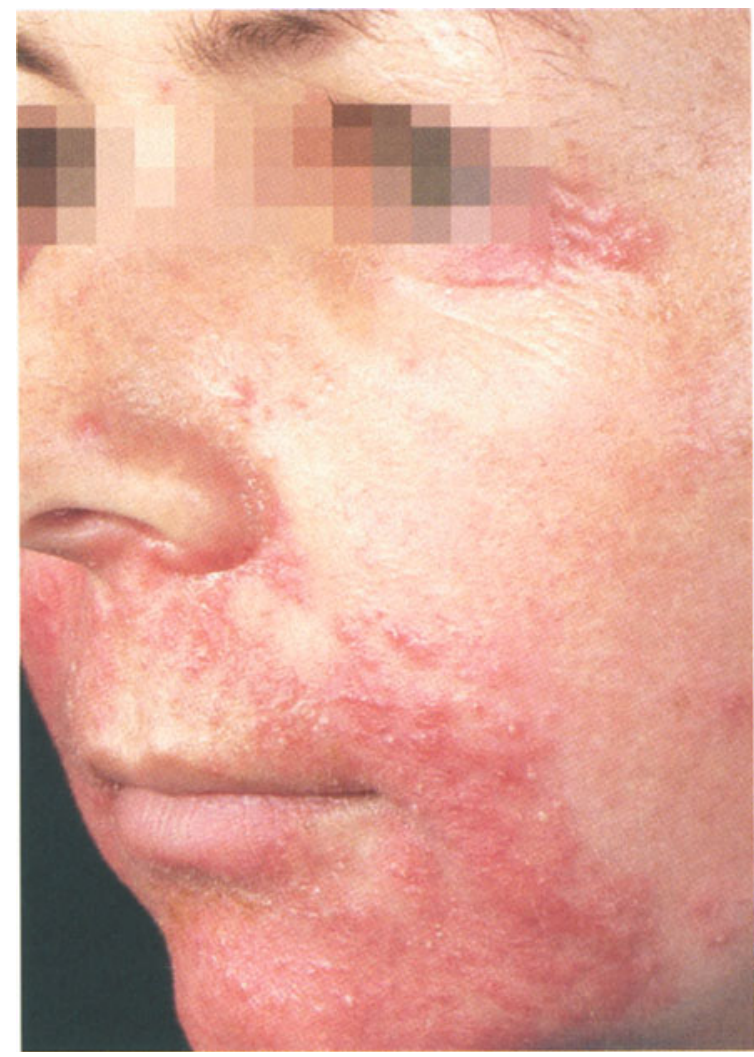

Abb. 19.43. Periorale Dermatitis. Erythem und Papeln perioral und periokulär

Erytheme (Dermographismus) und hat eine durch zahlreiche kleine Papeln unebene („grießelige“) Oberfläche. Die Papeln sind anfangs hautfarben, später hell- bis dunkelrot und teils konfluierend. Sie sind an typischen Hautstellen verdichtet: der seitlichen Perioralgegend, an den Augenlidern und seitlich dieser (Regionen der Fältchenbildung, wo Cremes vorwiegend aufgetragen werden), können jedoch das ganze Gesicht ergreifen.

Die Patientin klagt über ein trockenes, brennendes Organgefühl der Gesichtshaut, das nur durch Applikation der Creme gemildert werden kann. In ausgeprägten Fällen kommt es zu intensiver Rötung und Schwellung, Ausbildung multipler oberflächlicher Pusteln und starkem Brennen, weniger Jucken. Die periorale Dermatitis hat einen schubartigen, unbehandelt eminent chronischen Verlauf, ist jedoch im Grunde selbstlimitiert. Prämenstruelle Exazerbationen sind typisch.

Histologie. Ähnlich der Rosazea. Keine Spongiose.

Typischer Entwicklungsgang. Aus der Anamnese läßt sich fast stets eruieren, daß die ersten klinischen Symptome erst nach Beginn der routinemäßigen Applikation von Gesichtscremen entstehen. Erstes Symptom ist ein Gefühl der Trockenheit und des Spannens, das als primär „empfindliche“ Haut interpretiert wird. Tatsächlich läßt die Trockenheit nach, wenn die Creme appliziert wird und kehrt wieder, wenn dies unterlassen wird: es stellt sich eine Abhängigkeit ein („Wenn ich meine Creme nicht verwende, ist die Haut ganz trocken und spannt").
Die Feuchtigkeitscremen werden nun umso systematischer verwendet, die „Empfindlichkeit“ nimmt jedoch weiter zu. Die Patientin meint nun, daß sie diese spezielle Creme nicht vertrüge und beginnt die Suche nach geeigneteren. Oft werden Dutzende Präparate ausprobiert, die sich jedoch bald alle als unbrauchbar erweisen („Ich vertrage gar nichts mehr“). Häufig sind sich die Betroffenen der überschießenden Kosmetikaapplikation nicht bewußt („Ich habe sowieso nur eine ganz normale Creme verwendet"). Es wird nun ein Arzt aufgesucht, der die „richtige“ Creme empfehlen oder eine Salbe verschreiben soll, die sie ihre Cremen wieder vertragen macht. Dies ist häufig eine Kortikosteroidsalbe, die zwar die Beschwerden sehr schnell mildert, jedoch zur langfristigen Verschlechterung führt (Circulus vitiosus). Alle exzessiven Fälle von perioraler Dermatitis sind solche, die von kutanen Kortikoidnebenwirkungen überlagert sind („Tomatengesicht").

Ätiologie und Pathogenese. Quellung der Hornschicht führt zur Verschlechterung der Barrierefunktion und damit zur verstärkten Austrocknung; letztere bewirkt eine vermehrte Irritabilität der Haut (Trockenheit, Spannen, Brennen). Feuchtigkeitscremes haben den Zweck, die Hornschicht zu quellen (um damit kleine Fältchen vorübergehend zum Verschwinden zu bringen - „Verjüngungseffekt“"). Ist die Haut von vornherein eher trocken (milde atopische Disposition), wird die genannte pathogenetische Kette um so eher ausgelöst. Die ständige Durchfeuchtung der Haut führt ferner zur Proliferation der Keimflora der Follikel (entzündliche Knötchen, Pusteln).

Prinzipiell können, bei geeigneter Disposition, alle Feuchtigkeitscremes zur perioralen Dermatitis führen, manche Produkte vielleicht häufiger als andere (zusätzliche irritative Ingredienzien?). Hauttestungen auf Kontaktallergien sind in aller Regel negativ.

Motive der Applikation von Cremes. Diese ist nicht nur ein (durch ständige Reklame glaubhaft gemachtes) vermeintliches Mittel zur Verzögerung der Hautalterung, sondern auch Teil des Selbstverständnisses nicht weniger moderner Frauen („Ich fühle mich ganz einfach gut und frisch“). Die ausgeprägte Empfindlichkeit der Haut wird nicht selten positiv konnotiert („Waschen Sie Ihr Gesicht mit Wasser?“ „Nein, um Gottes Willen“) und hingenommen, daß angeblich für jede Gesichtsregion und jede Tageszeit verschiedene (aber stets teure) Cremen erforderlich sind. Bei der perioralen Dermatitis ist eine "ganzheitliche“ Aufklärung nicht immer gefragt.

Therapie. Kortikosteroidsalben sind kontraindiziert (s.unten). Gut wirksam sind, wie bei der Rosazea, Breitbandantibiotika (Tetrazykline, Minozyklin); sie werden in milderen Fällen lokal, in schwereren systemisch verabreicht. Nach einer Anfangsperiode mit nicht seltener passagerer Verschlechterung bilden sich die Läsionen zurück; die Behandlung sollte jedoch durch mehrere Wochen weitergeführt werden.

Wesentlichster Punkt ist die Entwöhnung von der übersättigenden Cremeapplikation. Da abruptes Absetzen zur sofortigen Exazerbation führt, muß dies sukzessive geschehen. Am besten bewährt sich der Rat, die Cremeapplikation unabhängig von der Tageszeit im- 
mer nur dann durchzuführen, wenn sich das Gefühl der Trockenheit und Spannung einstellt. Da das physische Bedürfnis nach der Creme bald schwindet, nimmt die Häufigkeit der Applikation ab; allein durch diese Strategie kommen die meisten Fälle innerhalb einiger Wochen zur Abheilung.

\subsection{Krankheiten der Schweißdrüsen}

Die Krankheiten der Schweißdrüsen sind nicht sehr vielfältig. Man unterscheidet quantitative und qualitative Funktionsstörungen sowie Zustände, die auf Okklusion der Schweißdrüsenausführungsgänge basieren.

\subsubsection{Ekkrine Schweißdrüsen}

\section{Störungen der Zusammensetzung des Schweißes}

Mineralokortikoide regulieren den Salzgehalt des Schweißes; daher finden sich bei Funktionsstörungen der Hypophyse und Nebennierenrinde charakteristische Änderungen. Bei Aldosteronismus und CushingSyndrom sinkt die Natriumchlorid- und steigt die Kaliumkonzentration; umgekehrte Änderungen ergeben sich bei M. Addison (klinisch bedeutungslos, aber gewisser diagnostischer Wert). Eine 3- bis 5 fach erhöhte Salzkonzentration findet sich ferner im Schweiß von Kindern mit zystischer Fibrose („Plattentest“).

Bei Urämie steigt die Konzentration von Harnstoff im Schweiß an und kann sich sogar (wie das Salz bei zystischer Fibrose) in Form weißlicher Kristalle an der Haut absetzen.

Diverse Chemikalien, die mit dem Schweiß ausgeschieden werden, können zur ekkrinen Chromhidrose (gefärbter Schweiß; Antimalariamittel, Farbstoffe) oder Bromhidrose (stinkender Schweiß) führen (z.B. verleiht DMSO dem Schweiß einen knoblauchartigen Geruch).

\section{Störungen der Quantität produzierten Schweißes}

Hyperhidrose. Eine generalisierte Hyperhidrose ist häufig lediglich der Ausdruck der thermoregulatorischen Funktion der Schweißdrüsen, etwa bei Anstrengung, emotioneller Erregung oder fieberhaften (Infektions)Krankheiten (IL-1 erhöht die zentrale Temperatureinstellung). Sie tritt ferner bei orthostatischer Hypotension, Diabetes mellitus, M. Hodgkin, verschiedenen Hormonstörungen (Thyreotoxikose, Phäochromozytom, Karzinoidsyndrom, Hypopituitarismus), post- traumatischen oder degenerativen Rückenmarks- und zerebralen Syndromen sowie schließlich bei systemischer Verabreichung cholinergischer Substanzen oder Azetylcholinesteraseinhibitoren auf. Nächtliches Schwitzen ist ein Zeichen von Systemkrankheiten (z. B. Tuberkulose, Kollagenosen, Lymphome).

Die häufigste Ursache nächtlichen Schwitzens ist der Alkoholismus.

Lokalisierte Hyperhidrose tritt meist als axilläre oder als palmoplantare Hyperhidrose in Erscheinung. Erstere ist entweder Teilsymptom des generalisierten Schwitzens oder dispositioneller Natur, letztere vorwiegend emotionell bedingt („nervöses“ Schwitzen).

Das palmoplantare Schwitzen wird nicht vom thermoregulatorischen, sondern von einem eigenen Zentrum im ZNS reguliert und läuft über sympathische Fasern. Es tritt daher im Schlaf nicht auf. Es ist nicht nur ein erhebliches psychosoziales Problem, sondern behindert auch die manuellen Tätigkeiten.

Eine seltene lokalisierte Form ist ferner die umschriebene idiopathische Hyperhidrose, ein auf ein bestimmtes Areal (Gesicht, Extremitäten) beschränktes, anfallsartig auftretendes Schwitzen. Von diagnostischer Bedeutung ist die häufige Assoziation von lokalisierter Hyperhidrose mit inkompletten Läsionen peripherer Nerven und Läsionen des Hintertrakts des Rückenmarks, wobei das hyperhidrotische Areal jeweils in der Randzone des anästhetischen Areals lokalisiert ist. Eine Sonderform nervös bedingter lokalisierter Hyperhidrose ist das aurikulotemporale Syndrom Frey („pathologisches gustatorisches Schwitzen“). Hier kommt es, gewöhnlich nach einer Operation an der Parotis, zum Einwachsen von sekretomotorischen Fasern aus der Parotis in den aurikukotemporalen Ast des N.trigeminus. Die Folge ist einseitiges Schwitzen der temporalen Gesichtshaut gleichzeitig mit der Speichelproduktion bei Nahrungsaufnahme (Abb. 19.44).

Therapie. Diese ist generell nicht stets befriedigend. Bei generalisierter Hyperhidrose müssen zunächst die genannten systemischen Ursachen ausgeschlossen bzw., falls möglich, eliminiert werden. Eine Behandlung mit systemischen Anticholinergika ist wegen der atropinartigen Nebenwirkungen nur selten angezeigt.

Bei lokalisiertem Schwitzen sind zahlreiche Lokaltherapeutika, meist auf Basis konzentrierter Aluminiumsalze (z.B. $25 \%$ Aluminiumchlorid) verfügbar. Diese wirken durch Steigerung der Durchlässigkeit des Schweißdrüsenausführungsganges ( $\operatorname{man}$,schwitzt ins Gewebe") und sind bei axillärem Schwitzen gut brauchbar (Risken: Kontaktallergie, Periporitis). Exzessive axilläre Hyperhidrose kann, wenn zugrundeliegende Systemkrankheiten ausgeschlossen wurden, durch Exzision des schweißdrüsentragenden Hautareals in der Axilla behandelt werden. Diese Operation führt meist zu sehr gutem Erfolg und ist bei korrekter Durchführung nur von akzeptabler Narbenbildung begleitet. 


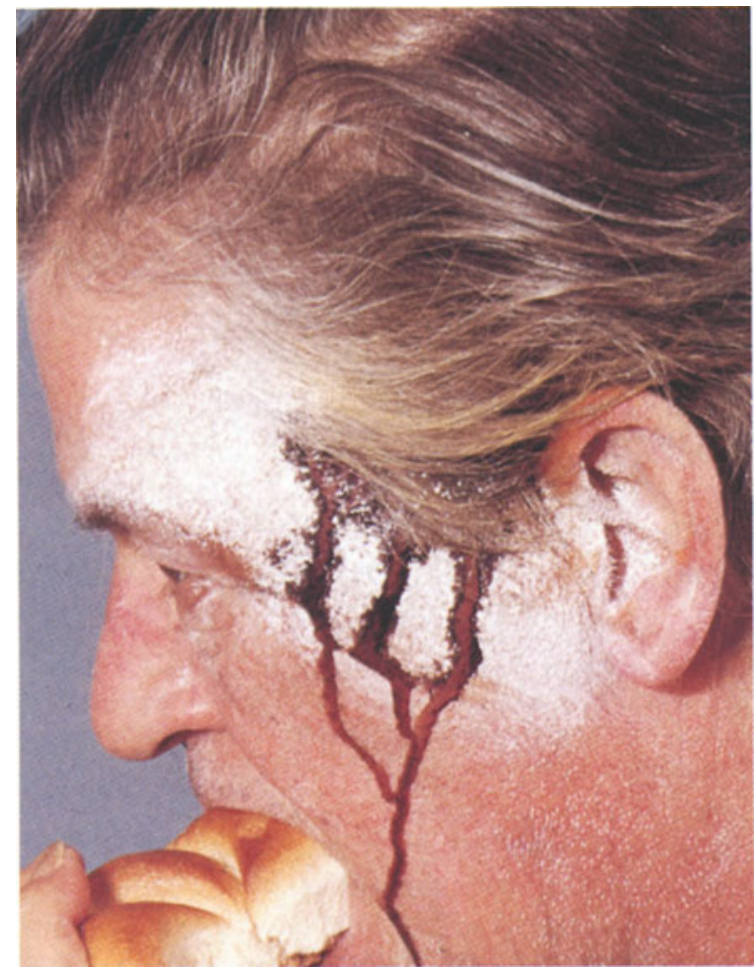

Abb. 19.44. Pathologisches gustatorisches Schwitzen: Demonstration mit dem Jodstärketest. Die Schläfenhaut wurde mit Jodlösung bestrichen und nach deren Eintrocknen mit Stärkepuder bestäubt. Selbst der Genuß einer trockenen Semmel löst sekretomotorische Impulse und Schweißsekretion aus

Bei palmoplantarem Schwitzen sind Lokaltherapeutika nur beschränkt wirksam und in der Anwendung unangenehm. Umständlich, aber sehr gut wirksam ist die Iontophorese mit Leitungswasser: Die Akren werden im Wasserbad einem Stromfluß von 15-25 mA ausgesetzt. Die Behandlungen erfolgen täglich durch ca. 30 Minuten, nach Ansprechen kann die Frequenz individuell reduziert werden (Erhaltungstherapie oft 1 Anwendung/ 2 Wochen). Wirkungsmechanismus: unbekannt.

Die ultima ratio in der Behandlung der palmaren Hyperhidrose ist die - früher nicht selten durchgeführte - zervikale Sympathektomie. Mit dieser werden die Beschwerden zumindest längerfristig beseitigt, doch kann sich als Komplikation ein Horner-Syndrom einstellen.

Eine seit kurzem erhältliche Alternative sind Injektionen mit Botulinustoxin.

„Ekkrine Bromhidrose“. Folge der Hyperhidrose ist ständige Durchfeuchtung der Hornschicht mit nachfolgender Proliferation der residenten Keimflora. Es kommt zur Zersetzung des Keratins mit Entwicklung üblen Körpergeruchs (kurze Fettsäuren, Amine; eine metabolische Leistung vorwiegend der Mikrokokken). Dieser ist insbesondere bei Patienten mit Ichthyosen oft sehr intensiv (ein weiteres soziales Handicap), bei „Normal"personen meist - bis auf die intertriginösen Areale und Füße - nicht merklich. Der Schweißgeruch der Füße ist oft auch mit sichtbaren Veränderungen verknüpft: wurmstichige, weißliche Verquellung der Sohlenhaut („pitted keratolysis"). Manchmal entfaltet auch das Kapillitium eine dezente Duftnote (hier sind allerdings auch Zerfallsprodukte aus dem Talg und gegebenenfalls der apokrinen Drüsen beteiligt).

Therapie. Hygiene und lokale Antisepsis.

Fallbericht: Eine Mutter kommt mit der 9 jährigen Tochter in die Sprechstunde und klagt über "unerträglichen" Geruch der auffallend voluminösen, aber ansonsten unauffälligen Haare des Kindes; dieses pflichtet dem wichtig bei. Sie seien schon bei vielen Ärzten gewesen, aber die hätten das „nicht geglaubt" oder „nicht gekannt". Eine Nasevoll ergibt tatsächlich einen milden ungelüfteten Geruch. Die Anamnese zeigt, daß das Kind viel schwitzt und die Haare, wegen der schönen Frisur, selten gewaschen werden. Nach Gebrauch eines antiseptischen Shampoos ist der Geruch gebessert („Aber ganz weg ist er nicht").

Überwertige Ideen von üblem Körper- und Haargeruch sind ein typisches Bild der Dysmorphophobie (s.S.726).

Die ekkrine Bromhidrose muß vom „fischigen“ Körpergeruch bei erblichen Aminosäurestoffwechselstörungen unterschieden werden (Phenylketonurie, Trimethylaminurie).

Hypohidrose und Anhidrose. Eine generalisierte Anhidrose tritt entweder bei Fehlen von Schweißdrüsen (anhidrotische ektodermale Dysplasie) oder bei schweren Dermatosen auf.Ursache ist hiebei oft die Okklusion der Ausführungsgänge - z. B. manche Ichthyosen, ausgedehnte Ekzeme etc., in anderen Fällen eine entzündungsbedingte vorübergehende oder bleibende Schädigung der Schweißdrüsen (z. B. toxische epidermale Nekrolyse), oft ist sie unbekannt (z. B. Sklerodermie, Sjögren-Syndrom,Angiokeratoma corporis diffusum).

Schweißdrüsen sind metabolisch sehr aktiv, haben einen hohen Sauerstoffbedarf und sind daher sehr empfindlich gegenüber Anoxie, toxischen Wirkungen und vor allem einer Kombination beider. Schweißdrüsennekrosen finden sich daher z. B. häufig bei Aufliegestellen nach versuchtem Suizid mit Barbituraten, CO-Vergiftung und analogen Situationen.

An- oder Hypohidrose bei morphologisch normalem Hautbefund findet sich bei verschiedenen neurologischen Störungen (multiple Sklerose, Läsionen des Thalamus, diabetische akrale Neuropathie) sowie (typisch) bei Hypothyreoidismus.

Lokalisierte, auf einzelne Schweißdrüsen beschränkte Anhidrose findet sich ferner bei und als Folge der $\mathbf{M i -}$ liaria.

\section{Läsionen durch Okklusion der Schweißdrüsenausführungsgänge}

Miliaria (Abb.19.45 u. 19.46). (Meist) entzündliche Reaktion auf Abflußstörungen im Schweißdrüsenausführungsgang durch Pfropfbildung aus Bakterien- 


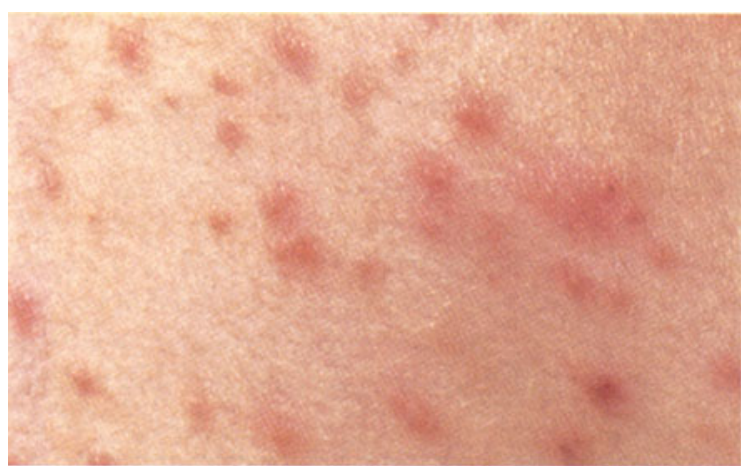

Abb. 19.45. Miliaria rubra

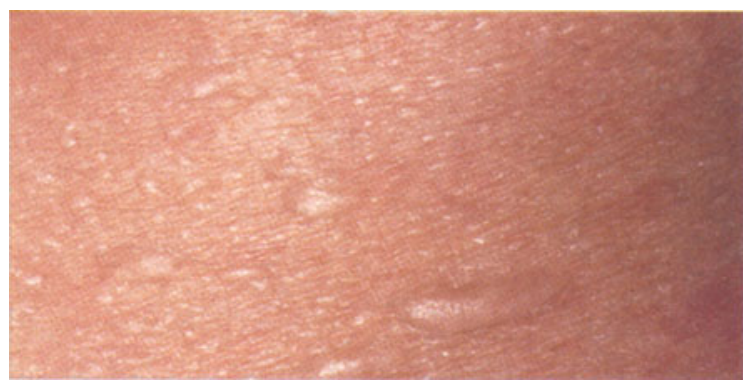

Abb. 19.46. Miliaria cristallina

massen der residenten Keimflora und gequollenem Keratin.

Bei Miliaria rubra erfolgt die Blockade unterhalb des Stratum granulosum; der Schweiß tritt ins Gewebe, sickert bis in die papilläre Dermis und bewirkt dort eine entzündliche Reaktion. Klinisch handelt es sich um eine papulovesikulöse exanthematische Eruption, die an den bedeckten Körperstellen des Rumpfes lokalisiert ist und heftig juckt und brennt. Miliaria rubra treten nur im Zusammenhang mit längerdauerndem Schwitzen auf und bedürfen zur Entstehung eines feuchten Klimas (Okklusiveffekt unter Kleidungsstücken). Sie sind daher besonders häufig bei Säuglingen (werden gern überwarm angezogen) und in den Tropen. Manchmal kommt es zur Vereiterung (Miliaria pustulosa) oder Ausbildung tieferer Infiltrate (Miliaria profunda). Die Miliaria bilden sich wenige Tage nach Eintritt in eine kühlere Situation zurück, die anhidrotische Folgeperiode dauert bis zu 2 Wochen (Lösung des Pfropfs durch natürliche Abschliferung).

Therapie. Vermeidung von weiterem Schwitzen (kühle Bäder etc.), lokale Kortikoidlotionen und antiseptische Maßnahmen.

Bei den Miliaria cristallina liegt die Abflußbehinderung im Stratum corneum; es kommt nicht zur Diffusion des Schweißes in die Dermis und daher auch nicht $\mathrm{zu}$ einer entzündlichen Reaktion. Miliaria cristallina erscheinen als multiple, kleine, mit wasserklarer Flüssigkeit gefüllte Bläschen.

Periporitis suppurativa: s. S. 240.

\subsubsection{Apokrine Schweißdrüsen}

Apokrine Chromhidrose. Ein seltener Zustand, bei dem der axilläre Schweiß eine blau-grüne bis schwarze Farbe annimmt; in seltenen Fällen auch ektop an Stirne und Schläfe. Auftreten erst nach der Pubertät. Afrikaner sind häufiger betroffen als Weiße. Pathogenese: dispositionelle Anhäufung von Lipofuszin in der apokrinen Schweißdrüse (bei starker Ausprägung schimmern die Schweißdrüsen in der Achsel bläulich durch).

Therapie. Keine.

Apokrine Bromhidrose. Übelriechender Achselschweiß. Ein bei Personen mit wenig intensiven Waschgewohnheiten häufiger Zustand. Der Geruch entsteht aus dem primär geruchlosen apokrinen Schweiß durch Wirkung von Mikrokokken und Koryneformen; häufig assoziiert mit Trichomykosis palmellina.

Läsionen durch Okklusion der apokrinen Schweißdrüsenausführungsgänge. Die Fox-Fordyce-Krankheit („apokrine Miliaria“) ist eine vorwiegend bei Frauen nach der Pubertät auftretende, relativ häufige chronische Dermatose der apokrine Drüsen-tragenden Regionen (Achseln, Genitalregion, Mamillen). Sie ist durch multiple heftig juckende Papeln, Zystchen, chronische Pyodermien, Lichenifikation und schließlich atrophisierende Alopezie gekennzeichnet. Ätiologie: Verstopfung der Schweißdrüsenausführungsgänge durch bakterielle Pfröpfe. Therapie: lokale Antisepsis.

Die Hidrosadenitis suppurativa ist eine tiefe, abszedierende Entzündung der apokrinen Schweißdrüsen (s. S. 240, und S. 679).

\subsection{Krankheiten der Nägel}

Die krankhaften Veränderungen des Nagelorgans sind sehr vielfältig, können jedoch auf ein begrenztes Spektrum von charakteristischen Störungsmustern zurückgeführt werden. Grundsätzlich können sich pathologische Prozesse des Nagelorgans entweder an der Nagelplatte selbst (meist Matrixschäden), am Nagelbett oder in der unmittelbaren Umgebung des Nagels abspielen. Überlappungen sind hierbei nicht selten. Der morphologische Ausdruck von Nagelveränderungen ist entweder eine Verformung, eine Farbänderung oder eine Änderung der Konsistenz. Auch hier sind Überlappungen die Regel. Alle genannten Veränderungen können anlagemäßig bedingt oder erworben, reversibel oder irreversibel sein. Nagelläsionen sind oft typische Begleitsymptome von Hautkrankheiten (Tabelle 19.8); andere sind für Systemkrankheiten charakteristisch. 
Tabelle 19.8. Dermatosen mit charakteristischen Nagelveränderungen

\begin{tabular}{|c|c|}
\hline Psoriasis & $\begin{array}{l}\text { Tüpfelnägel; psor.,Ölfleck“; } \\
\text { subunguale Hyperkeratosen }\end{array}$ \\
\hline Ekzem (akral) & Tüpfelnägel \\
\hline Lichen ruber & $\begin{array}{l}\text { Längsriefelung, Atrophie, } \\
\text { Pterygium, Anonychie }\end{array}$ \\
\hline Sézary-Syndrom & Onychodystrophie \\
\hline M.Darier & keilförmige Verdickung \\
\hline $\begin{array}{l}\text { Epidermolysis bullosa } \\
\text { congenita }\end{array}$ & Onychodystrophie, Anonychie \\
\hline Alopecia areata & Tüpfelnägel; Atrophie \\
\hline M.Wilson & $\begin{array}{l}\text { blau-braune Verfärbung der } \\
\text { Lunula (Kupfer!) }\end{array}$ \\
\hline
\end{tabular}

\subsubsection{Läsionen der Nagelplatte}

Pathomorphologie des Nagelwachstums. Eine gleichmäßige Ausbildung der Nagelplatte hat eine gleichförmige Proliferationsstätigkeit der Matrix und eine gleichförmige Zellzahl der Matrixzellpopulation zur Voraussetzung (die Dicke des Nagels ist Funktion der Zahl der Matrixzellen). Sind diese Voraussetzungen erfüllt, gleicht der kontinuierlich vorwachsende Nagel dem unbeschriebenen, kontinuierlich durchwandernden Papierstreifen eines Telegraphen. Bei Störungen der Nagelmatrix entstehen Läsionen, die von der Nagelplatte „wie die Zeichen des Morsealphabets auf dem Telegrammstreifen" herausgetragen werden.

Ein kurzdauerndes umschriebenes Trauma der Matrix führt zu einem Punkt, ein langdauerndes umschriebenes Trauma $\mathrm{zu}$ einem Längsstrich; ein kurzdauerndes Trauma der gesamten Matrix zu einem Querstrich, ein langdauerndes Trauma der gesamten Matrix zur gänzlichen Veränderung der Nagelplatte. Verschieden schnelle Proliferation an Teilen der Matrix führt zu gekrümmten, lateral abweichenden und, im Extremfall, zu zopfartig eingedrehten Nägeln.

Ein mildes Trauma der Nagelmatrix bewirkt eine passagere Hyperproliferation (Parakeratose). Solche kernhaltigen Hornzellen sind undurchsichtig und von geringerer interzellulärer Kohäsion. Je nach ihre Höhenlage innerhalb der Nagelplatte sind die Konsequenzen verschieden: bei oberflächlicher Lage (Traumatisierung der proximalen Matrix) brechen die lockeren Zellnester heraus und hinterlassen Substanzdefekte (Grübchen). Liegen sie in der Tiefe des Nagels (Traumatisierung distaler Matrixteile), werden sie durch die darüberliegende normale Nagelsubstanz am Platz gehalten und erscheinen dann als opake weiße Flecken.

Ein schwereres Trauma der gesamten Matrix bewirkt einen vorübergehenden Proliferationsstopp, der zur Verdünnung der Nagelplatte führt. Bei kurzdauerndem Trauma entsteht daher eine Querrille. Umschriebene längerdauernde Traumen (oder punktuelle Atrophie der Matrix - Nagel des alten Menschen) führen zu Längsrillen. Atrophie der gesamten Matrix bewirkt Atrophie des Nagels, schwerste Schädigung Nekrose und Verödung der Matrix zur Anonychie.

\section{!}

Alle Nagelläsionen, die auf einer Matrixstörung beruhen, wandern mit dem Nagel aus. Alle Nagelläsionen, die auf eine Störung des Nagelbetts beruhen, sind stationär. Traumen der Nagelmatrix erscheinen erst dann als Läsionen der Nagelplatte, wenn die betroffene Stelle unter der Kutikula hervorgewachsen ist (1-3 Monate).

Eine Darstellung der wichtigsten Nagelläsionen findet sich in Abb. 19.47.

\section{Nagelläsionen durch Matrixstörungen}

Tüpfelnägel (s.Abb.13.7a). Multiple, punktförmige Punzungen der Nagelplatte durch umschriebene, kurzdauernde milde hyperproliferative Traumen der proximalen Matrix. Sie finden sich - in geringer Zahl an normalen Nägeln, sind jedoch typisch bei ekzematösen Veränderungen der Fingerendglieder (Neuro-

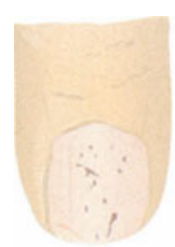

a

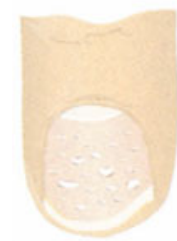

$\mathbf{f}$

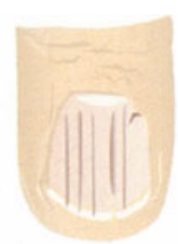

b

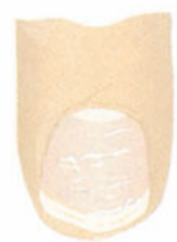

g

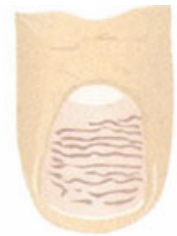

c

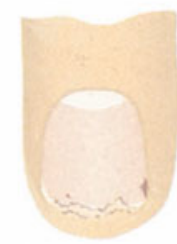

h

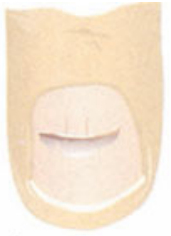

d

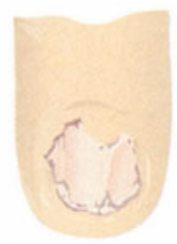

i

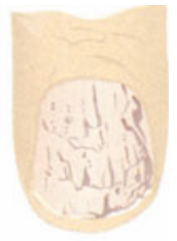

e

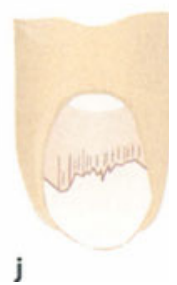

Abb. 19.47a-j. Nagelwuchsstörungen: a Tüpfelnagel, b Längsriefelung, c Querriefelung, d Beau-Linie, eTrachyonychie, f Leukonychia punctata, g Leukoychia linearis, h Onychoschisis, i Lichen ruberNagel (mit Pterygium unguis), j Onycholysis semilunaris 
dermitis!), bei Alopecia areata und v. a. bei Psoriasis. Bei Traumatisierung der gesamten Breite der Nagelmatrix kommt es zu wellenartigen Querrillen und Fragmentierungen der Nagelplatte („Trachyonychie“, „rauhe Nägel“; bei Paronychien, Stoffïwechselstörungen, Hyperthyreoidismus etc. sowie angeboren).

Leukonychia punctata. Weißliche Punkte, Flecke oder Striche durch umschriebene kurzdauernde Traumen der distalen Nagelmatrix (meistens mechanischer Natur). Einige solcher Läsionen stellen einen Normalbefund nach Bagatelltraumen dar. Ist die Matrix in der gesamten Breite betroffen entsteht ein weißer Querstrich. Eine solche „Leukonychia linearis“ ist meist das Resultat eines fieberhaften Infekts oder einer Intoxikation (typisch bei Arsen - „Mees-Streifen“); sie treten an allen Nägeln gleichzeitig auf und erlauben durch Messung des Abstands zur Matrix eine ungefähre Bestimmung des Zeitpunkts der abgelaufenen Schädigung.

Querrillen (Beau-Linien). Durch vorübergehende $\boldsymbol{H} \boldsymbol{y}$ poproliferation der Nagelplatte bei intensiveren Traumen (schwere Systemkrankheiten, Vergiftungen - Zytostatika). Sie erscheinen an allen Nägeln. Ist das Trauma langdauernd (etwa bei chronischen entzündlichen Veränderungen, Lichen ruber), geht ein Teil der Matrixpopulation zugrunde. Es resultiert ein dünner, weicher Nagel. Da die Reduktion der Matrixpopulation kaum je gleichförmig erfolgt, ergeben sich Dickenunterschiede des Nagels, die sich beim Herauswachsen als Längsriefelung manifestieren.

Das häufigste Beispiel für Längsriefelung der Nägel ist die altersbedingte Atrophie (Altersnagel: dünn, weich, längsgeriefelt). Eine Sonderform der Längsriefelung ist die sog. Dystrophia mediana canaliformis: Der Nagel ist durch eine tiefe, meist median gelegene Furche wie "eingeschnitten“ (posttraumatisch oder angeboren) (Abb.19.48a).

Onychodystrophie. Eine gänzliche Verformung der Nagelplatte durch langdauerndes Trauma der gesamten Matrix. Alle oben genannten pathophysiologischen Vorgänge können bei starker Ausprägung zur Onychodystrophie (Abb.19.48 b) führen. Das klinische Bild reicht von unregelmäßiger Buckelung des Nagels zu grober Rillung und Aufsplitterung bis zu zopfartig gedrehten, klauenartigen Nägeln (Onychogryphose, Abb.19.48 c). Häufigste Ursache der Onychodystrophie sind mechanische Traumen (einmalige schwere oder dauernde, unterschwellige - z.B. Schuhdruck). Dystrophe Nägel zeichnen sich häufig durch langsames Wachstum, Verdickung und außerordentliche Härte aus. Eine nicht so seltene, v.a. bei Kindern vorkommende erworbene Form der Onychodystrophie unklarer Genese ist das „Twenty nail syndrome“ (Befall sämtlicher Nägel).

Schwerste Traumen der Matrix (gewöhnlich mechanisch; entzündliche Prozesse wie Lichen ruber, Atrophie wie bei arteriellen Durchblutungsstörungen, Sklerodermie) können zum Untergang der Nagelma- trix führen. In diesem Fall kommt es zur Ablösung des Nagels und zur Überhäutung der Matrix von der umgebenden Haut (Pterygium unguis).

\section{Läsionen der Nagelplatte bei intakter Matrix}

Onychoschisis lamellosa (Abb.19.48d): Durch Traumen oder häufige Entfettung (Laugen, Detergenzien, Nagellackentferner) kommt es zu einer lamellierten Aufspaltung von distal her entlang einer physiologisch vorgegebenen Spaltebene (Grenze zwischen den vom proximalen und distalen Matrixteil gebildeten Nagelschichten). Kalkmangel, wie oft vermutet, spielt keine Rolle (Kalk hat am Nagel keine mechanische Funktion). Therapie: Ausschaltung der Noxen.

Weiche, brüchige Nägel. Die Ursache dieser häufigen, fast nur bei Frauen auftretenden Störung ist unbekannt. Vermutliche Ursache ist die häufige Entfettung durch Nagellackentferner.

\section{Onychomykosen. Siehe S. 288.}

Nagelveränderungen als Symptom von Systemkrankheiten. Bei „Half and half nails“ (Terry-Nägel) ist der proximale Anteil des Nagels weiß, der distale (normal) rot. Häufig bei Niereninsuffizienz oder Leberzirrhose. Ursache dieser Farbgebung unbekannt, liegt jedoch im Nagelbett, da permanent.

Koilonychie (Hohlnägel) kommt als angeborene Fehlbildung vor oder ist erworben (bei Eisenmangelanämie).

Uhrglasnägel sind vergrößert und sowohl transversal als auch longitudinal gerundet. Diese Erscheinung ist stets mit einer trommelschlegelartigen Vergrößerung der Endphalanx verbunden. Uhrglasnägel können einzeln oder generalisiert auftreten - ersteres stets bei lokalen Gefäßveränderungen (Aneurysma, arteriovenöse Fistel), letzteres entweder idiopathisch (autosomal-dominant mit männlicher Prädominanz; Teilsymptom der Pachydermoperiostose) oder erworben (Bronchuskarzinom, Rechtsherz, Leberzirrhose). Ursache: Hyperplasie des fibrovaskulären Gewebes zwischen Knochen und Nagelmatrix (vermutlich durch Aufregulierung von Wachstumsfaktoren durch mangelnde Sauerstoffsättigung).

\section{Fehlbildungssyndrome mit Nagelveränderungen}

Anonychie und Nageldystrophie können isoliert, ohne assoziierte Symptome, oder als Begleitdefekt einer Reihe von Fehlbildungssyndromen auftreten: hidrotische ektodermale Dysplasie, Dyskeratosis congenita, Progerie, Nagel-Patella-Syndrom (Dystrophie der Nägel, Fehlen oder Hypoplasie der Patella).

In typischer Weise verändert sind die Nägel bei M. Darier (Dystrophie mit medianer zwickelartiger Ver- 

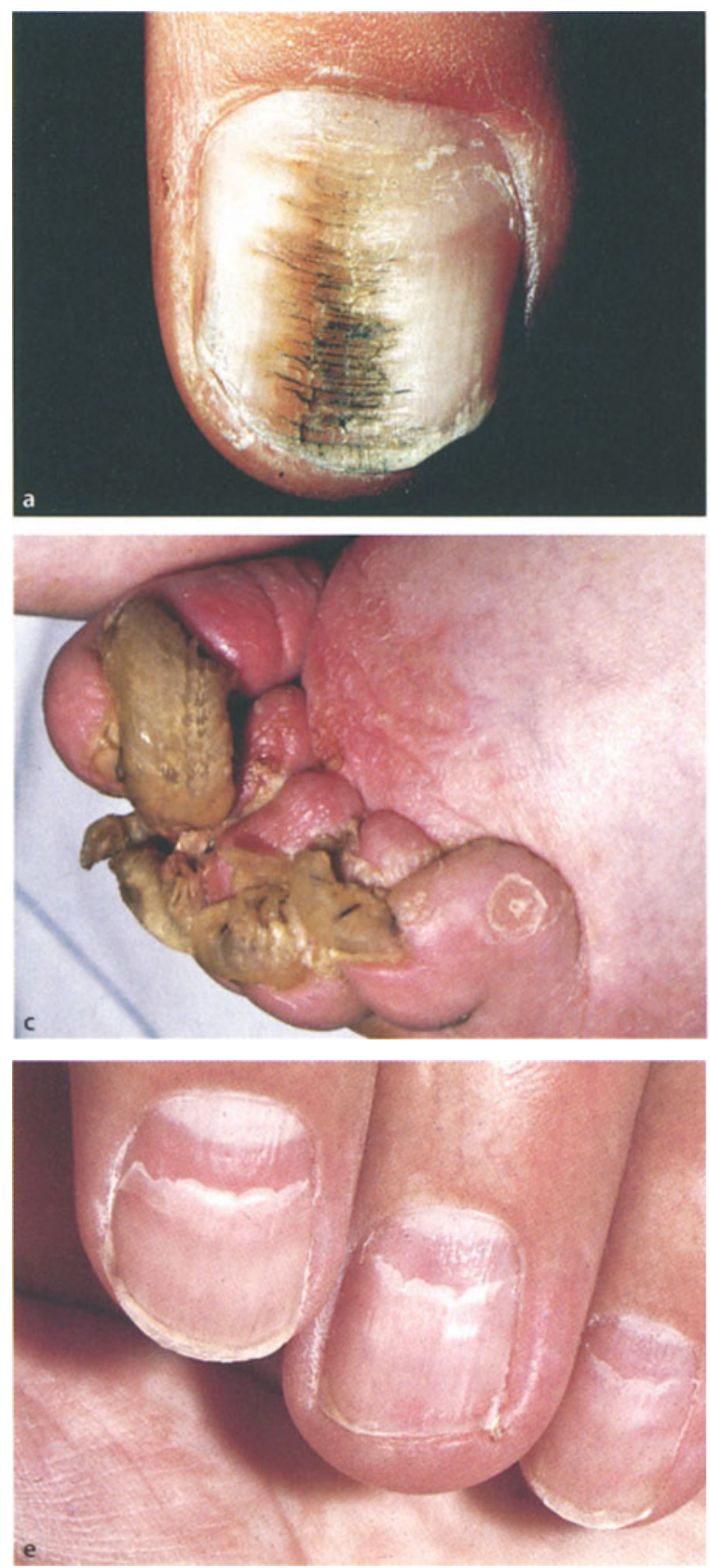

breitung der Nagelplatte) und Pachyonychia congenita. Letztere ist eine autosomal-dominante Genodermatose, die durch verdickte, langsam wachsende dystrophe Nägel, Leukoplakien der Mundschleimhaut und durch Neigung zu Ulzeration der Fußsohlen charakterisiert ist.

Therapie der Nagelveränderungen durch Matrixschäden. Keine wirksame bekannt. Die weit geübte Verabreichung von Gelatine und Zystein ist bei Onychodystrophie wirkungslos. Verschiedene kommerziell erhältliche Nagelhärter sind von nur begrenztem Nutzen. Nagelextraktion: nur auf Wunsch des Patienten bei gleichzeitiger Verödung der Matrix. Extraktion des Nagels allein ist bei Matrixschäden sinnlos, da der Nagel kaum je schöner nachwächst.
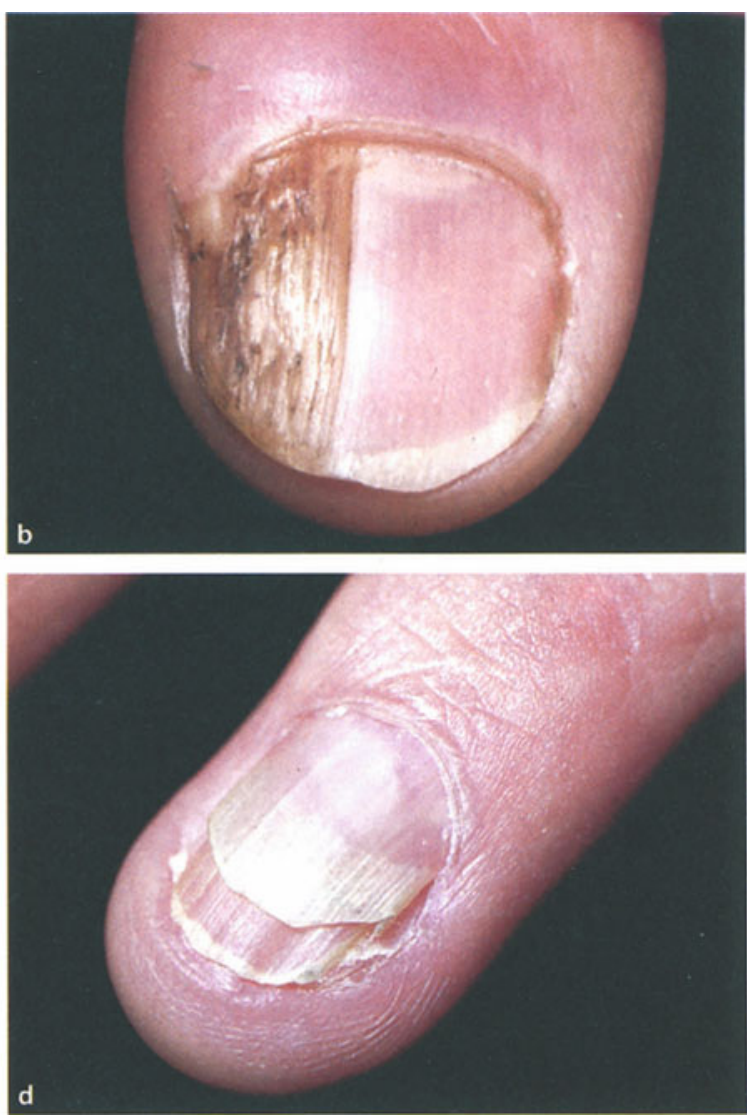

Abb. 19.48a-e. Typische Nagelwuchsstörungen. a Atrophia mediana unguis canaliformis, b partielle Onychodystrophie nach $\mathrm{Vi}$ ruswarzen am Nagelfalz, c Onychogryphose, d Onychoschisis, e Onycholyse. Beachte, daß die Nägel aller Finger abgehen und daß die proximalen Ränder der in Abstoßung begriffenen Nägel von der Nagelmatrix jeweils gleich entfernt sind (Beweis für ein gleichzeitiges Trauma an den Fingern - z. B. Chemotherapie)

\section{Pigmentierungsanomalien der Nagelplatte}

Die Nagelplatte ist bei Weißen durchscheinend, das rosafarbige Nagelbett schimmert daher durch; bei dunkelhäutigen Personen ist die Nagelplatte hingegen in verschiedenem Ausmaß pigmentiert.

Abnorme Melaninpigmentierung. Diffuse Hyperpigmentierung der Nägel findet sich bei M. Addison und beim Peutz-Jeghers-Syndrom. Umschriebene braune Längsstreifen der Nagelplatte sind zumeist Folge von Pigmentnävi, seltener eines akrolentiginösen Melanoms im Matrixbereich. Die Differentialdiagnose ist, solange das Melanom nicht durch Wachstum klinisch manifest wird, nur durch Biopsie möglich. 
Die Unterscheidung zwischen Nävus und Melanom der Nagelmatrix gehört zu den schwierigsten der Dermatologie. Zwar weisen bestimmte klinischen Zeichen auf ein Melanom (der braune Streifen ist meist dunkler, von kurzem Vorbestand und von Onychodystrophie begleitet), doch sind Biopsien stets angezeigt. Wichtig ist deren korrekte Durchführung (Stanzbiopsie aus der Nagelmatrix), da in der pigmentierten Nagelplatte oft nur Melanin nachzuweisen ist.

Pigmentierung durch Medikamente. Phenolphthalein und Silber lagern sich als grauer Niederschlag im Bereich der Lunula ab, Antimalariamittel (Chloroquin) im Nagelbett und an der Nagelplatte (blau-braun).

Pigmentierung bei Systemkrankheiten. Das sog. „Yellow-nail-Syndrom " ist durch verdickte, gelbe Nägel bei Lymphödemen der betroffenen Extremität charakterisiert. Bei M. Wilson lagert sich Kupfer im Bereich der Lunula ab (blau-braun).

Nagelverfärbung durch lokale Infektionen. Begleitinfektion durch Aspergillen und/oder Schimmelpilze (häufig bei Onychomykose durch Dermatophyten oder bei Onychodystrophie) führt zu fleckiger brauner oder schwarzer Verfärbung; grüne Verfärbung tritt bei Besiedelung mit Pseudomonas auf.

Leukonychia totalis. Eine harmlose, in ihrer Natur ungeklärte Weißfärbung aller Nagelplatten, meist angeboren. Differentialdiagnose: die oberflächliche Form der Onychomykose durch Dermatophyten (fleckig, unregelmäßig, Oberfläche fissuriert).

\subsubsection{Nagelläsionen mit Sitz am Hyponychium (Nagelbett)}

\section{Onycholysen (Loslösung der Nagelplatte vom Nagelbett)}

Die Nagelplatte haftet am Nagelbett durch die Verzahnung der vom Nagelbett gebildeten Hornzellen mit der Nagelplatte. Bei Schädigung dieser Verlötungsstelle kommt es zur Loslösung des Nagels. Solche Schäden können verschiedener Natur sein (traumatisch, chemisch, entzündlich u.a.m.) (Abb.19.48 e).

Traumatische Onycholyse. „Abgehen“ des Nagels einige Wochen nach stumpfem Trauma, meist assoziiert mit subungualem Hämatom.

Onycholysis semilunaris. Unterminierung des Nagels vom freien Ende her; die Ablösung reicht im medianen
Nagelteil am weitesten nach proximal („halbmondförmig") und ist nie vollständig (führt nicht zu Anonychie). Ursache: Extraktion der Hornschichtlipide durch ständige Befeuchtung, Alkalien und Detergenzien (Hausfrauen!): Differentialdiagnose: Onychomykose. Diese beginnt von den Ecken, unter dem abgehobenen Nagelrand Hornkrümel.

Nagelpsoriasis (subungualer Typ). Lamelliertes parakeratotisches Hornmaterial unter partiell abgehobener Nagelplatte (mangelhafte mechanische Verankerung) (s. Abb. 13.7b).

Infektiöse Onycholyse. Onychomykosen, Pseudomonas!

Photoonycholyse. Nagelablösung im Anschluß an eine phototoxische Reaktion am Nagelorgan. Seltene Nebenwirkung von Tetrazyklinen und Photochemotherapie, kann auch bei Porphyrien auftreten.

\section{Subunguale Hämorrhagien}

Subunguale Hämorrhagien sind fleckige, je nach Alter rote, blaue oder schwarze Blutansammlungen zwischen Nagelplatte und Nagelbett. Sie sind in der Regel leicht zu erkennen. Kleine, schwarze Hämorrhagien können klinisch oft schwer von subungualen Melanomen unterscheidbar sein.

Diagnose. Auflichtmikroskopie.

Geringfügige subunguale Blutungen nehmen durch die unter dem Nagel vertikal verlaufenden Papillarleisten eine strichförmige Figur an (sog. Splitterhämorrhagien). Auch diese sind zumeist traumatischer Genese (besonders bei distalem Sitz). Sie können jedoch auch (besonders bei proximalem Sitz) ein klassisches Hautzeichen schwerer Systemkrankheiten sein: Endocarditis lenta, systemischer Lupus erythematodes, chronische Glomerulonephritis.

\subsubsection{Nagelveränderungen durch Läsionen benachbarter Strukturen}

Das Wachstum der Nagelplatte wird durch Läsionen in ihrer unmittelbaren Umgebung beeinflußt. Beispiele sind Tüpfelnägel bei akralen Ekzemen, Onychodystrophie bei Paronychie, perionychialen Warzen (Abb.19.48 b), Mukoidzyste der distalen Phalanx, Nagelfalznekrosen bei Dermatomyositis u.a.m.

Die Haut um das Nagelorgan ist nicht selten Sitz von benignen und malignen Tumoren: Junktionsnävi, akrolentiginöse Melanome, Bowen-Karzinome. Sowohl Melanome als auch Karzinome sind manchmal schwer von den häufigen Granulomata pyogenica bei Unguis incarnatus zu unterscheiden. 


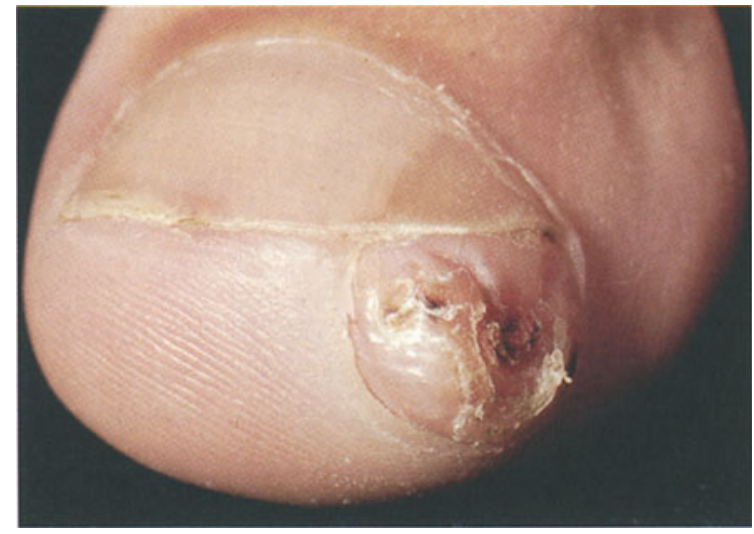

Abb. 19.49. Subunguales Osteochondrom. Ein unter dem lateralen Nagelrand sitzender, harter, adhärenter Knoten

Ungues incarnati (eingewachsene Nägel) entstehen durch chronische Traumatisierung und pyogene Superinfektion des seitlichen Nagelfalzes durch eine Nagelkante. Prädilektionsstelle: lateraler Hallux. Auslösende Faktoren: Schuhdruck, dispositionsmäßig stark gewölbte Nagelplatte, Ausschneiden der Nagelecken (hierdurch „versperrt“ das seitliche Nagelbett dem vorwachsenden Nagelrand den Weg: Folge: Druckulkus, Pyodermie, Schwellung der Endphalange mit noch tieferem Einpressen des Nagels, Granuloma pyogenicum. Unguis incarnatus ist eine sehr schmerzhafte chronische Läsion, deren Therapie entweder konservativ (Antibiotika, Lokaltherapie, Nagel auswachsen lassen) oder chirurgisch erfolgt (Operation nach Nicoladoni: Resektion des seitlichen Nagels mit Verödung des Matrixanteils).

Die Nagelgegend ist ferner Sitz fibromatöser Tumoren (juvenile Fibrome - Knoblauchzehenfibrom) (s. Abb.18.72), Koenen-Tumoren bei M.Pringle (s. Abb.17.39). Ein charakteristischer subungualer oder an der Nagelecke entstehender Tumor ist ferner das subunguale Osteochrondrom (Abb.19.49): ein benigner, harter, mit dem Knochen verbackener Knoten, der die Nagelplatte aufwölbt und bei Belastung Beschwerden verursacht. Es wird nicht selten mit einem Unguis incarnatus verwechselt.

\subsection{Krankheiten der Mundschleimhaut}

Die Mundschleimhaut ist bei vielen Hautkrankheiten mitbetroffen und zählt oft auch zu deren Prädilektionstellen (Tabelle 19.9). Darüber hinaus findet man an ihr zahlreiche regionsspezifische Läsionen und Krankheitsbilder, die sich aus der besonderen anatomischen und funktionellen Situation der Mundhöhle ergeben.
Tabelle 19.9. Dermatosen mit Prädilektion für die Mundschleimhaut

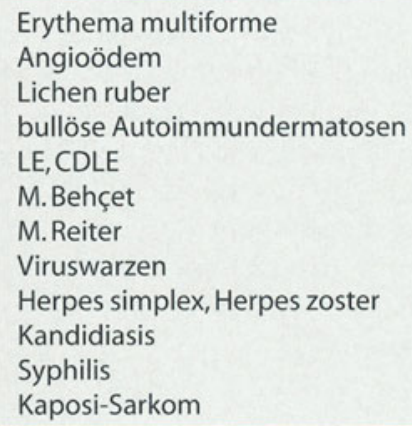

\subsubsection{Biologie und Pathophysiologie der Mundschleimhaut}

Die Mundhöhle ist ein ständig von Speichel bespülter Raum, dessen Innenauskleidung funktionsspezifisch von verschiedener Gestaltung ist. Sie ist das natürliche Habitat einer diversen und zahlreichen residenten Keimflora (höhere Keimdichte findet sich nur noch im Kolon!), die durch ein wohlfunktionierendes unspezifisches und spezifisches Abwehrsystem im Schach gehalten wird.

Der Speichel wird in den großen Speicheldrüsen (Parotis, Glandula sublingualis) pulsatil, in den kleinen kontinuierlich produziert. Seine Funktionen sind: Medium zur Erzeugung des Speisebreis, Beförderung der gelösten Stoffe zu den Geschmackrezeptoren, Bereitung einer "rutschigen“ Schleimhautoberfläche (Muzine), Abtransport der Keimflora, Transport natürlicher Abwehrstoffe (Lysozym, sekretorisches IgA) und Wuchsstoffe (EGF, TGF).

In der Mundhöhle lassen sich funktionell 3 Räume unterscheiden, in denen die Schleimhaut verschieden gestaltet ist:

- die Umschlagszone zur Außenwelt, das Lippenrot: Dieses besteht aus einem mäßig verhornten Plattenepithel mit freien Talgdrüsen, zahlreichen Nervenendigungen, einem reichen Gefäßplexus und wenig Melanozyten (Prädilektionsstelle für Sonnenbrand!);

- der für die Nahrungsverarbeitung bestimmte Teil: harter Gaumen, Zungenrücken, Zähne und äußere und innere Gingiva. Hier ist das Epithel dick, paraoder hyperkeratotisch verhornt und teils oberflächlich strukturiert: Zungenpapillen und Querrillen (Rugae) des harten Gaumens - mechanische Funktion. Hier ist das mastikatorische Epithel unbeweglich und fest an der Unterlage (Periost) verankert;

- Reserve- und Leiträume: Innenseite von Lippen und Wangen, Ventralseite der Zunge, Mundboden, weicher Gaumen. Hier ist die Schleimhaut dünn, unverhornt, beweglich (Lamina propria ist reich an elastischen Fasern und Gefäßen). 
Die Zunge ist ferner Träger der Geschmackspapillen.

Insgesamt ist die Mundschleimhaut sehr reibefest, hat einen hohen Turnover (ca. 5 Tage) und heilt damit sehr schnell. Sie ist relativ unempfindlich gegen Hitzereize (heißer Tee wird im Mund vertragen, der Finger empfindet Schmerz). Die Mundschleimhaut besitzt Melanozyten, erscheint aber bei Weißen nicht pigmentiert; bei Afrikanern ist regelmäßig, bei Weißen mit dunkler Komplexion häufig eine fleckige Pigmentierung zu erkennen (Gingiva, Wangen).

Spezifische Reaktionsweisen der Mundschleimhaut. Erytheme sind an der Mundschleimhaut wenig gut erkennbar (Ausnahme: Rachenring); Blasen und Pusteln platzen schnell (sind daher selten zu beobachten) und wandeln sich in Erosionen bzw. Ulzera um. Morphologische Leitveränderung der Mundschleimhaut ist die weißliche Verfärbung, die Ausdruck verstärkter Verhornung ist (meist als Antwort auf chronische Reize) und den überwiegenden Teil der Läsionen in diesem Bereich begleitet. Eine analoge Reaktion des Zungenrückens ist die Hypertrophie der Papillen (Haarzunge).

Normale Mundschleimhaut ist durchscheinend (rosa); bei Verhornung wird sie undurchsichtig (weiß). Weißliche Veränderungen wurden früher summarisch als Leukoplakien bezeichnet; da man bald erkannte, daß sowohl harmlose wie prämaligne Zustände als solche manifest werden, unterschied man zwischen planen (reaktiven) und verrukösen (präkanzerösen) Leukoplakien. Allerdings ist diese Unterscheidung weder im Konzept noch in der Praxis sehr nützlich, so daß vorgeschlagen wurde, den Begriff der Leukoplakie überhaupt zu verlassen.

\subsubsection{Akut entzündliche Zustände}

Akute Entzündung der Mundschleimhaut (Stomatitis) ist häufig Folge von Verbrühungen oder Verätzungen (Prädilektionstellen: Lippen, Zunge, Gaumen), seltener einer toxischen oder allergischen Kontaktdermatitis (Zahnpflegemittel, Zahnprothesen) oder von Medikamentenintoleranz (fixes Arzneimittelexanthem, Erythema multiforme). Schwere „Mukositis“ entsteht bei Radiotherapie und/oder Chemotherapie (z. B. Methotrexate). Stomatitis mit Erosionen bzw. Ulzera ist auch Begleitsymptom von Infektionskrankheiten (Kandidiasis, Gingivostomatitis herpetica, Herpes zoster, Herpangina, Lues II u. a.m.) sowie von manchen Systemkrankheiten (Lupus erythematodes, bullöse Autoimmundermatosen, zyklische Neutropenie).

\section{Chronisch-rezidivierende Aphthen}

Ein häufiger, chronisch-rezidivierender Prozeß unbekannter Ursache, der durch multiple, schmerzhafte, rundliche Ulzerationen der Mundschleimhaut („Aphthen") gekennzeichnet ist.

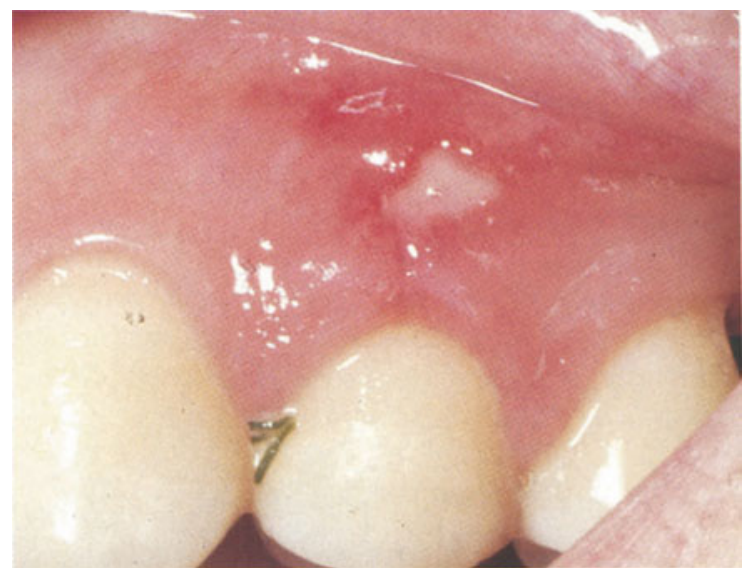

Abb. 19.50. Chronisch rezidivierende Aphthen, Minortyp

Chronisch-rezidivierende Aphthen haben nichts, wie häufig angenommen, mit der Herpes simplex-Infektion zu tun, deren Primärmanifestation früher "Stomatitis aphthosa" genannt wurde. Zur Verwirrung trägt bei, daß im englischen Schrifttum der Begriff ,aphthous stomatitis“ auch heute noch für chronisch-rezidivierende Aphthen gebraucht wird. Aphthen heißen auf griechisch nichts anderes als Ulcera.

Epidemiologie. In milder Ausprägung und vorübergehend sehr häufig (Prävalenz bis $20 \%$ ). Frauen sind bevorzugt betroffen. Krankheitsbeginn häufig in Kindheit und Jugend. Die Häufigkeit der Rezidive schwankt zwischen Wochen und Jahren und pflegt nach der Lebensmitte nachzulassen.

Klinik. Man unterscheidet drei Verlaufsformen: die häufigen Minor-, und die seltenen Major- und herpetiformen Aphthen. Es ist nicht klar, ob diese Formen Varianten desselben oder eigene Krankheitsbilder darstellen.

Bei der Minorform (Abb. 19.50) entstehen, nach einer ca. eintägigen Prodromalzeit mit brennenden und juckenden Sensationen, eine oder mehrere hyperästhetische erythematöse Läsionen, die zentral oberflächlich nekrotisieren (manchmal ein kurzlebiges Bläschen bilden) und sich in ein sehr schmerzhaftes, rundes, „wie ausgestanztes", schmierig belegtes Geschwür mit gerötetem Halo umwandeln. Die Einzelläsion hat meist nur wenige Millimeter Durchmesser, bei Konfluenz kommt es zu serpiginösen Ulzera. Prädilektionsstellen sind Lippen- und Wangenschleimhaut (Rezessus!), seltener Gingiva und Gaumenschleimhaut. Die Schmerzhaftigkeit macht Essen und Sprechen schwierig. Begleitsymptome: Sialorrhö, Foetor ex ore. Die Läsionen heilen üblicherweise nach 1-2 Wochen narbenlos ab.

Die Majorform („Grande aphthose“, Mikulicz-Aphthen) ist selten, hat aber eine ungleich schwerere, belastendere Symptomatik. Die Ulzera sind groß $(>1 \mathrm{~cm}$ Durchmesser), tief und derb infiltriert mit oft wallartig erhabenen Rändern. Die Abheilung dauert erheblich länger und erfolgt mit Narben.

Seltenste Verlaufsform sind die herpetiformen Aphthen: sehr zahlreiche, oberflächliche, konfluierende Lä- 
sionen. Das Bild hat große Ähnlichkeit zur Gingivostomatitis herpetica, unterscheidet sich jedoch durch weniger ausgeprägte regionale Lymphadenitis, negativen Virusnachweis und hohe Rezidivneigung.

Bei der HIV-Infektion sind Aphthen aller Art ein häufiges Symptom.

Histologie. Subepitheliale und perivaskuläre lympho(CD8 +) -leukozytäre Infiltrate, schüsselförmige Nekrose bis in die papilläre Dermis (manchmal tiefer). Keine klassische nekrotisierende Vaskulitis.

\section{Ätiologie und Pathogenese. Unbekannt.}

Erwogene und nicht gesicherte Hypothesen sind: zytotoxische Autoimmunreaktion gegen Mundschleimhautepithel oder kleine muköse Speicheldrüsen, Intoleranzreaktion gegen bakterielle Produkte, Immunkompexvaskulitis. Manche Fälle von Aphthen werden als Abortivform des M. Behçet interpretiert.

Die Zahl der pro Attacke auftretenden Aphthen ist ebenso verschieden wie die Dauer der Intervalle. Aphthen werden häufig durch Bagatelltraumen der Mundschleimhaut ausgelöst (versehentlicher Biß in die Wangenschleimhaut, Stich von Fischgräten; oft auch nur hartes Brot oder scharfgewürzte Speisen) - ähnlich dem Pathergiephänomen (s. dieses).

Labor. Meist unauffällig In seltenen Fällen Veränderungen des Blutbildes (zyklische Neutropenie, Eisenmangelanämie). Assoziation mit HLA-B5, -B12, -B27.

Therapie. Eine wirksame kausale Therapie ist nicht bekannt. Lokaltherapie zielt auf Linderung (Mundspülungen, Lokalanästhetika), lokale Antisepsis (Wasserstoffperoxyd) sowie Tetrazyklin- und Kortikosteroidpräparate. In schweren Fällen werden mit wechselndem Erfolg systemische Kortikoidstöße und Immunsuppressiva (Cyclosporin A) versucht.

Prognose. Selbstlimitiert, doch können die Attacken jahrzehntelang fortdauern.

Differentialdiagnose. Milder oder inzipienter M. Behcet, aphthöse Läsionen bei M. Reiter, Erythema multiforme, erosiver Lichen ruber, Pemphigus vulgaris, chronisch-rezividierender Herpes simplex, Herpangina, Hand-foot-mouth-Krankheit. Bei einzelnen (v.a. Major-) Aphthen müssen ein Lymphom, ein Plattenepithelkarzinom, bei mehreren Systemvaskulitiden (Wegener-Granulomatose) ausgeschlossen werden.

\section{Gingivitis-Komplex}

Entzündungen des Periodontiums und der Gingiva gehören zum Bereich der Zahnheilkunde. Der Dermatologe wird manchmal mit der schnell progredienten Periodontitis konfrontiert, eine akute Rötung, Schwellung der Gingiva mit disseminierten Nekrosen, die zu vorzeitigem Zahlverlust führt. Sie wird vorwiegend bei Personen mit gestörter Abwehrlage gefunden (z. B. zy- klischer Neutropenie, HIV-Infektion); ein juveniler und ein adulter Typ wird unterschieden.

Eine Sonderform ist die akute nekrotisierende ulzerative Gingivitis, die durch das fusospirilläre Gemisch (Bacterium fusiforme, Spirochäta refringens) erregt wird. Sie tritt bei schlechter Hygiene und beeinträchtigter Abwehrlage (z.B. Truppen im Kriegseinsatz I. Weltkrieg) manchmal epidemisch auf und ist durch plötzlich auftretende Schmerzhaftigkeit, Blutungen und rapide matschige, jauchige Nekrose der zahnnahen Gingiva gekennzeichnet. Begleitsymptome sind Sialorrhoe, Foetor ex ore, Fieber, Lymphadenopathie. Die Infektion kann sich auf den weichen Gaumen und den Schlundring ausweiten (Plaut-Vincent-Angina). Therapie: Penizillin, lokale Antisepsis.

\subsubsection{Chronische Irritationen der Mund- schleimhaut}

Adäquate Antwort der Mundschleimhaut auf chronische physikalische, chemische und entzündliche Reize ist die weißliche Verfärbung durch Hyperkeratose (ein der Tylose analoger Prozeß; s. oben).

Die mildeste Ausprägung ist das häufige Leuködem: eine diffuse zart-weißliche Verfärbung und Verdickung meist nur der Wangenschleimhaut. Vermutliche Ursache: Rauchen und Friktiontrauma (Reiben der Zähne oder auch z.B. der gebräuchlichen rotierenden Zahnbürsten an der Wangenschleimhaut). Massiver ausgeprägt ist die sogenannte Morsicatio (Biß), eine polsterartige weißliche Verbreiterung der Wangenschleimhaut entlang der Zahnschlußleiste, die oft die Negativabbilder der Zähne eingepreßt trägt. Sie ist durch gewohnheitsmäßiges Einziehen der Wange zwischen die Zähne und nachdenkliches Kauen bedingt und muß vom Lichen ruber, dem „White sponge"-Nävus und der hypertrophen Kandidiasis unterschieden werden (Abb.19.51).

Ähnliche diffuse Weißverfärbung kann man bei gewohnheitsmäßigem Genuß heißer Getränke und bei starken Pfeifenrauchern beobachten. Bei letzteren ist der harte Gaumen weißlich verfärbt, später auch rauh und verletzlich (Leukokeratosis nicotinica palati). Sie ist ein chemisch-thermischer Kombinationsschaden, schneidet typischerweise scharf an der Grenze zum weichen Gaumen $a b$ und ist von einzelnen roten Pünktchen durchsetzt (unverhornte Ausführungsgänge der Schleimdrüsen). Die Leukokeratosis nicotinica bildet sich langsam zurück, wenn das Rauchen aufgegeben wird, ist jedoch Prädilektionsstelle für Karzinome der Mundschleimhaut.

Ähnliche, noch gravierendere Läsionen finden sich bei Zigarettenrauchern, die „umgekehrt" rauchen (d.h. mit dem brennenden Zigarettenende in der Mundhöhle). Zigarettenraucher entwickeln präkanzeröse Leukoplakien vorwiegend an 


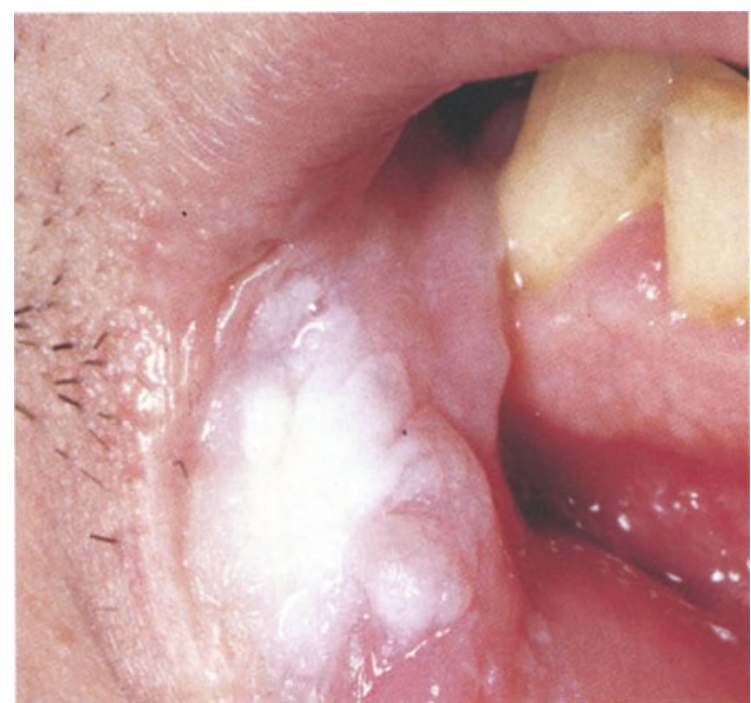

Abb. 19.51. Plane Leukoplakie der Unterlippe (Ursache: chronisches Kauen)

der Unterlippe, Zigarrenraucher an der Zunge. Überlappungen sind häufig.

Wirkt das chronische Trauma fokal ein, entwickeln sich umschriebene Hyperkeratosen (sogenannte flache, nicht präkanzeröse Leukoplakien): meist unscharf abgegrenzte, homogen opaque, weißliche Flecken mit glatter Oberfläche. Sie sind auf den Einwirkungsort der meist klar erkennbaren Noxe beschränkt (Zahnkanten, -ruinen, Druckstellen schlecht sitzender Zahnprothesen). Sie sitzen meist an Wangen- und Lippenschleimhaut und Zungenseitenfläche. Differentialdiagnose. Verruköse Leukoplakie (s. auch Präkanzerosen, S. 556), Lichen ruber, chronisch-diskoider Lupus erythematodes, Narben, submuköse Fibrome.

Präkanzeröse (verruköse) Leukoplakien sind zwar in der Regel von rauher Oberfläche, scharf und unregelmäßig begrenzt und lassen den Bezug zu einer mechanischen Noxe vermissen, doch ist die klinische Unterscheidung unsicher und muß durch eine Biopsie unterstützt werden, wenn die Leukoplakie nach Entfernung etwaiger möglicher Noxen bestehen bleibt. Dies gilt insbesondere für Leukoplakien bei Risikopatienten (Raucher) und bei Lokalisation auf der Zungenunterseite und am Mundboden (hier sind friktionale Leukoplakien selten, Karzinome jedoch häufig).

Orale Haarleukoplakie (s. Abb. 25.55). Ein typisches dermatologisches Merkmal der HIV-Infektion (jedoch auch selten anderer Formen der Immundefizienz), das auf lokaler Infektion mit dem Epstein-Barr-Virus beruht. Klinik: ein subjektiv symptomloser weißer Bezirk des seitlichen Zungenrandes, der durch Betonung der Schleimhautfalten und Papillenhypertrophie eine unregelmäßige, „haarige“ Oberfläche entfaltet. Oft Superinfektion mit Kandida.

\subsubsection{Näviforme und neoplastische Läsionen der Mundschleimhaut}

„White sponge“-Nävus (s. Abb. 18.3). Ein relativ seltener, autosomal-dominant vererbter Zustand, bei dem die Wangenschleimhaut (und/oder Gaumen, Zungenund Lippenschleimhaut) in einem oder mehreren wohlabgegrenzten Arealen weiß verfärbt, verdickt und gefurcht ist. Die Läsion entspricht einem Naevus verrucosus, entsteht in der Kindheit, bleibt stationär und ist subjektiv symptomlos.

Mit Leukoplakien assoziierte Erbkrankheiten. Die Pachyonychia congenita (s. S. 517) ist neben den Veränderungen an Handflächen, Fußsohlen und Nägeln auch durch Leukoplakien besonders an mechanisch belasteten Regionen der Mundschleimhaut gekennzeichnet (harter Gaumen, Zungenrücken, Zungenseiten).

Die Dyskeratosis congenita (s. S. 535, s. Abb. 17.43) ist ein der Fanconi-Anämie verwandter Zustand, der u.a. durch Mundschleimhautläsionen (erosive Entzündung, später Leukoplakien mit Neigung zu maligner Entartung) gekennzeichnet ist.

Verruköse Leukoplakie und Plattenepithelkarzinom der Mundschleimhaut. Präkanzeröse Leukoplakien sind durch ihre Form, Lokalisation und ihre rauhe Oberfläche gekennzeichnet (s.oben). Sie sind zu Beginn oft unscheinbar, werden bald fleckig weiß-rötlich und entwickeln bei beginnender Invasion fokale Erosionen. Nach Monaten bis Jahren entwickeln sie sich zu derb infiltrierten, schüsselförmig exulzerierten Herden mit unregelmäßig (papillär-gebuckelter) Oberfläche und Begrenzung.

Das Plattenepithelkarzinom der Mundschleimhaut ist nicht selten (ca.1.00o neue Fälle/Jahr in Österreich). Hauptrisikofaktoren sind Rauchen und Alkohol (scharfe Getränke), zusätzlich chronisches entzündliches und mechanisches Trauma (Prothesen). Männer sind häufiger befallen als Frauen. Manifestation meist in der zweiten Lebenshälfte, die Inzidenz steigt mit dem Lebensalter. Karzinome der Mundhöhle sind viel aggressiver als Plattenepithelkarzinome der Haut; sie metastasieren in der Regel schnell. Die 5-Jahres-Überlebensrate liegt im Durchschnitt bei 60\%. Die Therapie besteht aus kombinierten chirurgischen, strahlen- und chemotherapeutischen Maßnahmen.

Lippenkarzinome entsprechen in Verhalten und Prognose mehr den Karzinomen der Haut.

Verruköses Karzinom der Mundschleimhaut (Floride orale Papillomatose, s. Abb.18.20). Eine durch sehr langsame Progredienz, verrukös-hypertrophe Oberfläche, geringfügige Atypie im histologischen Bild, späte Invasion und seltene Metastasierung gekennzeichnete Sonderform (s. S.560). 


\subsubsection{Typische Veränderungen der Zunge}

Haarzunge (Lingua nigra, Abb. 19.52). Ein häufiger und harmloser Zustand, der die Maximalform der „belegten Zunge" darstellt. Durch reaktive Hypertrophie der filiformen Papillen am Zungenrücken bei Einwirken chronischer Reize (Rauchen, Austrocknen des Mundes, Fieber) entsteht ein strähniges mattenartiges Geflecht

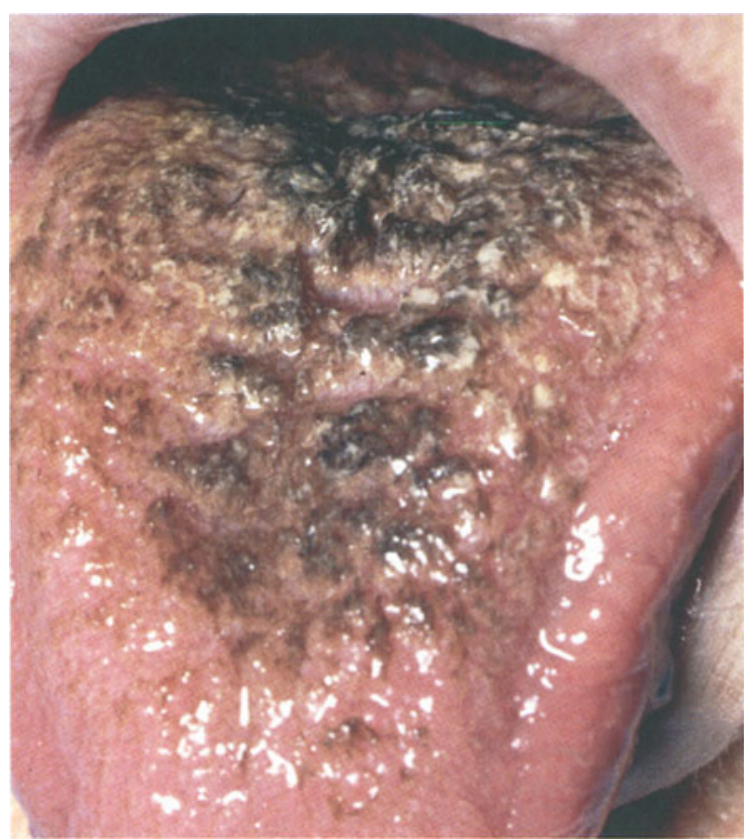

Abb. 19.52. Lingua nigra bei Raucher

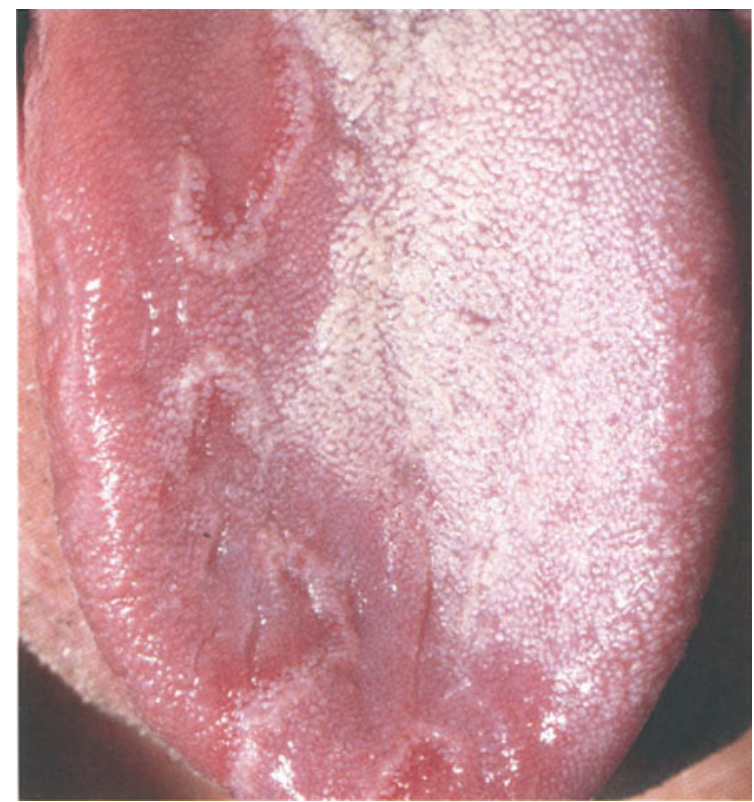

Abb. 19.53. Lingua geographica. Polyzyklisch begrenzte Areale, in denen die hyperkeratotischen Papillen (wie an der kontralateralen Seite noch zu sehen) abgestoßen sind. Keine Erosion! mit mißfarbigen, partiell wegschabbaren Belägen. Debris und darin verfangene Speisereste sind ein guter Nährboden für Mikroorganismen, die eine Verfärbung von weißlich bis gelb-braun und schwarz bewirken können (letzteres die Farbe von Schimmelpilzen Überwucherung bei z. B. Antibiotikatherapie).

Therapie. Elimination der Ursache, lokale Antisepsis (Wasserstoffperoxyd).

Lingua geographica (Exfoliatio areata linguae, Abb. 19.53). Eine sehr charakteristische, gutartige, chronisch entzündliche Affektion der Schleimhaut des Zungenrückens; sie ist durch ein Nebeneinander von Regionen mit hypertrophen und atrophen filiformen $\mathrm{Pa}$ pillen gekennzeichnet, wobei die Begrenzung sehr scharf, polyzyklisch und bizarr (landkartenähnlich) verläuft. Die atrophen Regionen erscheinen gerötet und verursachen subjektiv Brennen (cave Gewürze, heiße Getränke). Die Krankheit besteht oft lebenslang. Eine Sonderform ist die Atrophia mediana rhomboidalis linguae. Genese: Es liegt eine chronische Entzündung der Zungenschleimhaut unbekannter Ursache zugrunde, die in einer ersten Phase zur Hypertrophie und im späteren Verlauf zur Abstoßung der hypertrophen Papillen in großen Fetzen führt. Anschließend werden die hypertrophen Papillen wieder aufgebaut, es entsteht daher ein sehr wechselhaftes Bild. Häufig bei Rauchern.

Die Exfoliatio areata linguae wurde auch als Schleimhautmanifestation der Psoriasis vulgaris gedeutet.

Lingua plicata (Lingua scrotalis, Abb.19.54). Eine bei etwa $2 \%$ der Normalbevölkerung vorgefundene architektonische Anomalie der Zunge, die durch tiefe multiple Furchung (nach der deftigen Sprache der alten Dermatologen "hodensackähnlich“) gekennzeichnet ist. Häufig bei Mongolismus, Teilsymptom des Melkersson-Rosenthal-Syndroms.

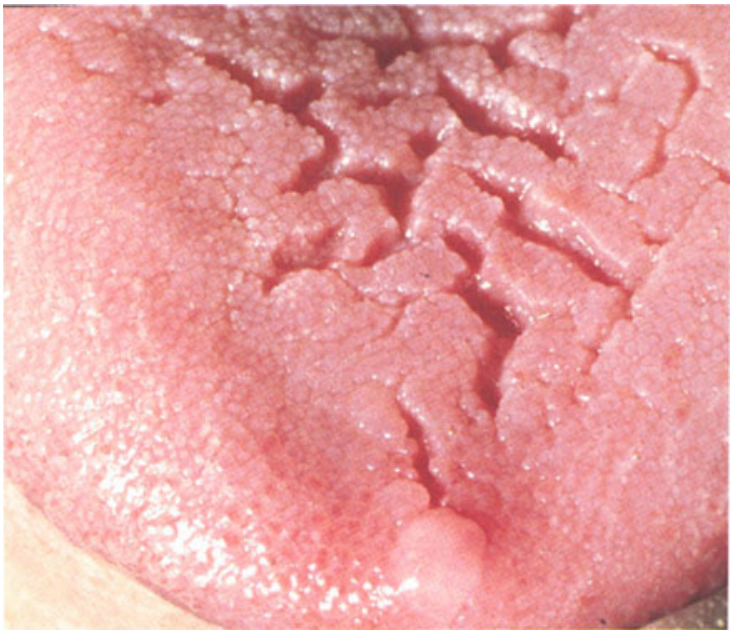

Abb. 19.54. Lingua plicata 


\subsubsection{Pigmentstörungen der Mundschleimhaut}

Physiologische Pigmentierung. Bei Weißen normalerweise kaum sichtbar, bei dunkelhäutigem ethnischen Hintergrund meist deutlicher: fleckig, symmetrisch, vorwiegend an der mastikatorischen Mukosa lokalisiert (Gingiva, harter Gaumen). Bei chronischer mechanischer oder entzündlicher Irritation erscheint die Pigmentierung akzentuiert (z. B. über den prominenten Anteilen der Gingiva).

Makulöse orale Melanose (Abb. 19.55). Ein nicht sehr seltener Zustand, der durch einen oder einige, bis einige Zentimeter große schwärzliche Flecken mit scharfer, oft unregelmäßiger Begrenzung gekennzeichnet ist. Prädilektion: Lippenrot. Diese Läsion ist das Analogon zur genitalen makulösen Melanose: klinisch einer Lentigo maligna ähnlich, histologisch jedoch lediglich basale Hyperpigmentierung ohne melanozytäre Anomalien. Zur Sicherung der Diagnose sollte in jedem Falle eine Biopsie erfolgen.

Pigmentnävi. Diese sind in der Mundschleimhaut selten; alle Typen von Nävi kommen vor, besonders häufig sind blaue Nävi (Differentialdiagnose: Amalgameinsprengung). Da die morphologischen Charakteristika nicht so klar ausgeprägt sind wie auf der Haut, sind Biopsien stets angezeigt.

Mundschleimhautmelanom. Relativ selten (ca. $2 \%$ aller Melanome). Sie treten vorwiegend im dritten Le-

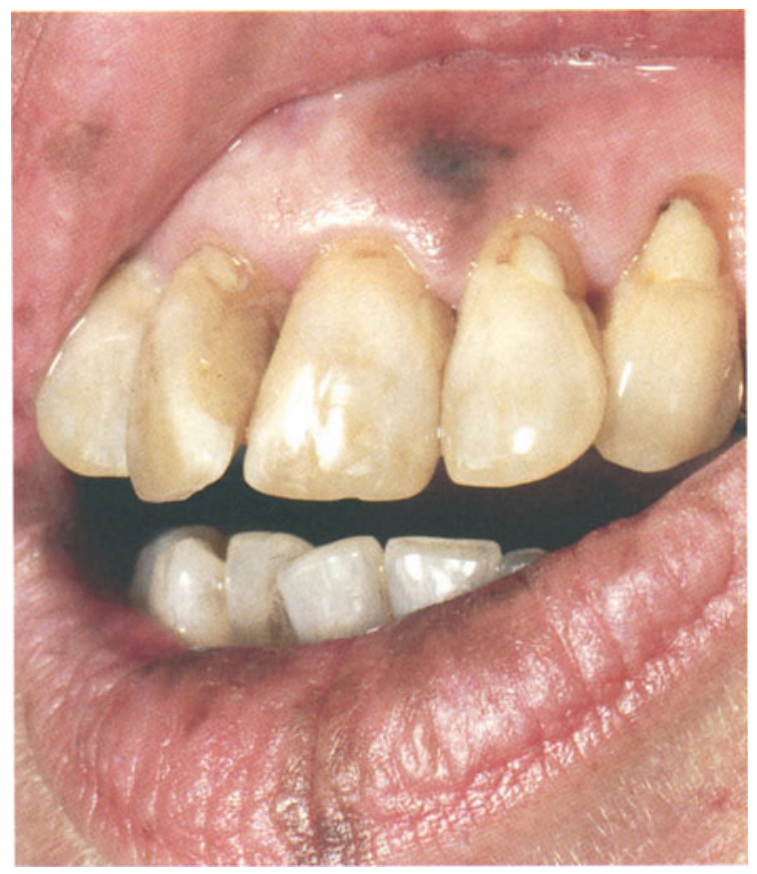

Abb. 19.55. Lentiginose der Mundschleimhaut (Gingiva, Lippenrot) bensdrittel auf, bei dunklen Ethnien relativ häufiger als bei Weißen. Prädilektionstellen: die pigmentierten Areale der Mundschleimhaut (s.oben). Melanome der Mundschleimhaut sind klinisch oft uncharakteristisch und häufig unpigmentiert $(20 \%)$. Sie haben generell eine schlechtere Prognose als Melanome der Haut.

Mukokutane Melanose mit gastrointestinaler Polypose (Peutz-Jeghers-Syndrom). (s.S.538). Hautsymptome sind ephelidenähnliche, gelegentlich zu größeren Herden konfluierende hellbraune bis schwärzliche Flecken perioral, am Lippenrot sowie an der Lippenund Wangenschleimhaut.

Differentialdiagnose. Epheliden (unterscheiden sich nur durch andere Lokalisation), makulöse orale Melanose und Pigmentierung bei M. Addison (fleckig-diffus).

Mundschleimhautpigmentierung durch andere Pigmente. Am häufigsten sind Amalgameinsprengungen: bläulich durchschimmernde Läsionen unter intakter Mukosa, meist in Nähe eines plombierten Zahnes oder auch fern eines solchen (Einschuß durch den rotierenden Bohrer). Selten sind graue Bleieinlagerungen in der marginalen Gingiva bei chronischer Bleivergiftung (Mees-Streifen) und Pigmentierung nach Tetrazyklinen.

\subsubsection{Weitere charakteristische Ver- änderungen der Mundschleimhaut}

Cheilitis granulomatosa (Abb.19.56). Diese nicht seltene Dermatose unbekannter Ätiologie tritt etwa gleich häufig isoliert oder im Rahmen des Melkersson-Rosenthal-Syndroms auf (s. unten). Es ist durch eine subjektiv symptomlose, relativ derbe (nur teilweise ausdrückbare!), einseitige rüsselartige Schwellung der Ober- oder Unterlippe, manchmal beider, und der angrenzenden Wangenpartien gekennzeichnet. Die Schwellung tritt attackenartig auf (wird zumeist anfangs für ein Angioödem gehalten) und bildet sich nach einigen Wochen unter Hinterlassung einer derben Restschwellung zurück. Wiederholte Rezidive (die Abstände schwanken zwischen Tagen und Monaten) führen zur Verstärkung der Restschwellung, die dann permanent bestehen bleibt. Manifestation im mittleren Erwachsenenalter. Außer der Lippen können selten auch andere Gesichtsteile betroffen sein: die Wangenschleimhaut (Pareitis granulomatosa), Stirn (Uranitis granulomatosa) u.a.m.

Histologie. In frühen Phasen Ödem und lymphozytäre Infiltration des tiefen Binde- und Muskelgewebes, die im späteren Verlauf einen sarkoidalen Charakter annimmt. Tiefe Biposie zur Diagnose erforderlich!

Therapie. Unbefriedigend. Systemische Kortikosteroide sind zwar oft wirksam, die erforderlichen Dosen 


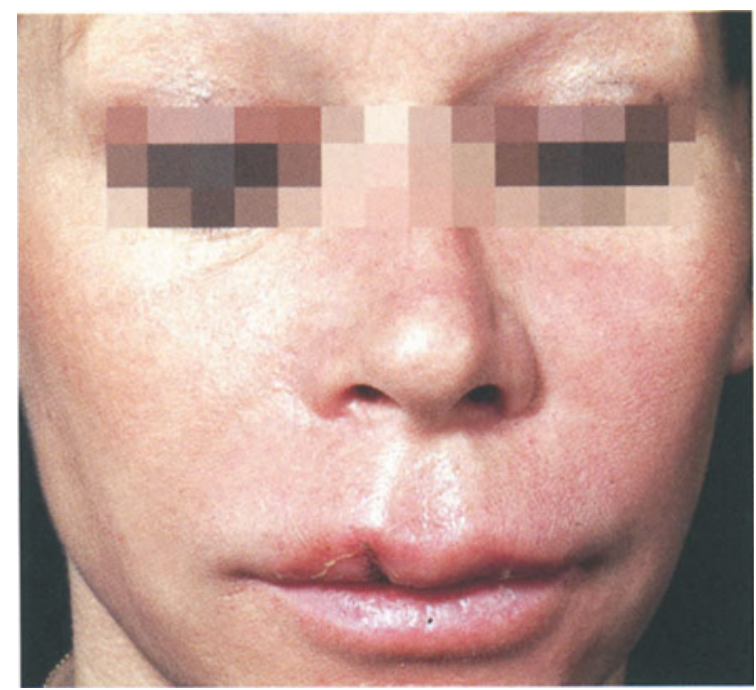

Abb. 19.56. Melkersson-Rosenthal-Syndrom, Cheilitis granulomatosa. Beachte die vorwiegend linksseitige Lippenschwellung (typischerweise bis zum Nasenansatz reichend)

jedoch relativ hoch. Relativ gut wirksam ist das Lepramittel Clofazimin (Langzeittherapie).

Melkersson-Rosenthal-Syndrom. Dieser nicht so seltene Symptomkomplex unbekannter Ursache ist durch die Trias von Lingua plicata, Cheilitis granulomatosa und rezidivierende periphere Fazialisparesen gekennzeichnet. Lingua plicata ist schon bei Geburt vorhanden, die rezidivierenden Fazialisparesen können der Cheilitis granulomatosa vorausgehen oder erst mit jahrelanger Verzögerung nachfolgen. Ursache der Fazialisparese: Strangulierung des Nerven durch Granulationsgewebe im Canalis Faloppii.

Schleimzyste. Eine der häufigsten Läsionen der Mundschleimhaut: eine bis $1 \mathrm{~cm}$ große, mit visköser klarer, bläulich durchschimmernder Flüssigkeit gefüllte fluktuierende Zyste. Prädilektionsstelle: Lippenrot und Mukosa der Unterlippe. Traumatisch bedingte Ruptur des Ausführungsganges einer Schleimdrüse, Akkumulation des Schleims im dermalen Gewebe. Es handelt sich also strenggenommen nicht um eine Zyste (definitionsgemäß ein epithelausgekleideter Hohlraum). Im späteren Verlauf chronisch entzündliche Reaktion („Schleimgranulom“).

Differentialdiagnose. Seniles Angiom („Blutsee“) der Unterlippe.

Granularzelltumor (Abrikosoff-Tumor) (s. Abb.18.96) Ein seltener benigner Tumor, der auch überall sonst, mit Vorliebe jedoch an der Zunge auftritt: ein langsam wachsender, harter, symptomloser Knoten, der bis zu mehreren Zentimetern groß werden und gelegentlich auch ulzerieren kann. Die Abkunft dieses Tumors ist nicht genau bekannt (s. Kap. 624).

Differentialdiagnose. Plattenepithelkarzinom.

Therapie. Knappe Exzision.
Multiples Hamartom-Syndrom (Cowden-Syndrom) (s. Abb.17.46). Ein seltenes, autosomal-dominantes Erbleiden, das sich durch außerordentlich zahlreiche Hamartome der Haut und des gesamten Gastrointestinaltrakts kennzeichnet (s. S. 538). Die Läsionen der Mundschleimhaut sind dichtstehende, zu riesigen Platten mit himbeerartiger Oberfläche konfluierende Adenofibrome. Sehr hohes Risiko von Mamma-Karzinomen und anderen Malignitäten.

Harmlose, den Patienten oft beunruhigende Anomalien. Fordyce (freie) Talgdrüsen an der Wangenschleimhaut in Höhe der Zahnschlußleiste (ein Streifen multipler kleiner, gelb durchschimmernder Punkte); weiters sich höckrig durch die Mukosa der Unterlippe abzeichnende kleine Speicheldrüsen (Cheilitis granularis).

\subsection{Krankheiten der äußeren Genitalien}
Die äußeren Genitalien können einerseits Sitz des gesamten Spektrums von Hautkrankhei- ten und mitunter deren Prädilektionsstellen sein (Tabelle 19.10). Andererseits sind sie Schauplatz der sexuell übertragbaren Krank- heiten (s. Kap. 25, Venerologie), schließlich aber auch von eigenständigen dermatologischen Krankheitsbildern, die durch die anatomisch- physiologischen Bedingungen dieser Regio- nen geprägt sind.

Gemeinsam ist diesen Dermatosen, daß sie vom Patienten häufig nicht emotionslos getragen, sondern mit übermäßiger Sorge, Scham oder schlechtem Gewissen belegt werden. Häufig wird grundlos sexuelle Übertragbarkeit befürchtet, der Gang zum Arzt hinausgezögert oder werden Normalbefunde als krankhaft interpretiert (Selbstbeobachtungsphänomene).

Tabelle 19.10. Dermatosen mit Prädilektion für die Genitalregion

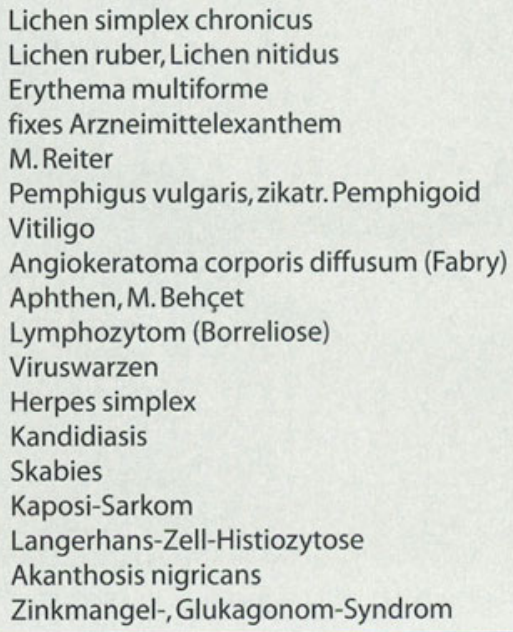




\subsubsection{Regionsspezifische Dermatosen des männlichen äußeren Genitales}

Die Haut von Penis und Skrotum besitzt in Aufbau und Physiologie einige Besonderheiten: Der Penis trägt zahlreiche freie (d.h. nicht an Haarfollikel gebundene) Talg- und apokrine Schweißdrüsen; die Hornschicht der Glans penis und des inneren Vorhautblatts ist sehr dünn, die Barrierewirkung gering. Im Präputialraum herrscht daher ein Klima der „feuchten Kammer"; in ihm kann sich Smegma ansammeln (Hornschichtdebris, Drüsensekret und Keime). Die Keimflora des Präputialraumes beherbergt außer den üblichen Keimen häufig Gramnegative (E. coli, Klebsiellen, Pseudomonas), Candida species, Staphylococcus aureus und Streptokokken der Gruppe B. Sie steht im labilen Gleichgewicht der Kolonisierung; Änderungen der Milieufaktoren wie Phimose (mangelnde Rückschiebbbarkeit des Präputiums), Diabetes mellitus oder Immundefizienz lassen das Gleichgewicht leicht zur Infektion umschlagen.

Die Feuchtigkeit des Präputialraums ist der wichtigste prädisponierende Faktor für viele Infektionen: Kondylome, Herpes genitalis, Kandida-Balanitis. Diese Infekte, zusammen mit der chronisch irritierenden Wirkung des Smegma, werden dafür verantwortlich gemacht, daß Peniskarzinome fast ausschließlich bei Nicht-zirkumzidierten Männern auftreten. Die Zirkumzision schafft trockene Verhältnisse an der Glans penis und damit eine erheblich günstigere Grundsituation. Als Argument gegen sie wird gebraucht, daß ca. $1 \%$ der Neugeborenen Infektionen oder andere operationsbedingte Komplikationen erleiden und daß Balanitiden zwar weitgehend, aber nicht gänzlich ausgeschaltet werden. Die Sensitivität der Glans ist bei Zirkumzidierten trotz der reaktiv dickeren Hornschicht nicht beeinträchtigt. Bei Zirkumzision im Erwachsenenalter kann allerdings die Ungeschütztheit der bislang bedeckten Glans zu Irritationen und Entzündungen führen.

Mechanisch besonders beanspruchte Stellen sind das Frenulum präputii und der Sulcus coronarius glandis. An diesen Stellen lokalisieren sich daher vornehmlich Verletzungen und Infektionen, aber auch Dermatosen (im Sinne eines Köbner-Phänomens, z.B. Lichen sclerosus).

Epidermis und Hornschicht der Skrotalhaut sind gleichfalls dünn (Cave - schnelle Resorption von z.B. Kortikosteroiden!). Die Haut ist reich an Haarfollikeln, Talg- und Schweißdrüsen und deshalb oft feuchtlich. Sowohl die Haut des Penis als auch des Skrotums haben ein sehr locker gewebtes Bindegewebe; bei Entzündungen stellen sich daher oft massive Ödeme ein.

\section{Balanoposthitis}

Balanoposthitis (Entzündung von Glans und innerem Vorhautblatt) ist sehr häufig; sie ist klinisch durch Rötung, Schwellung, Nässen, Brennen und Jucken, ver- mehrte Smegmabildung und (selten) Erosionen bzw. sogar Ulzerationen gekennzeichnet. Die Veränderungen schneiden an der Umschlagstelle zum äußeren Vorhautblatt scharf ab. Die Abheilung erfolgt in der Regel mit Restitutio ad integrum; bei chronischer Balanitis kann eine Fibrose des Präputiums entstehen, die zur Phimose (s. unten) führt bzw. eine solche verstärkt. Zur Entstehung der Balanoposthitis können prinzipiell folgende Faktoren beitragen:

- mechanische Faktoren (Friktion);

- Mazeration durch die Feuchte-Kammer-Situation (häufiger bei relativer Phimose bzw. überlangem Präputium);

- Entfettung durch Seifen;

- Überwuchern der Keimflora bzw. Infektion (E. Coli, Candida);

- altersbedingte Atrophie der Epidermis.

Diese Ursachen haben naturgemäß in verschiedenen (Alters-) Gruppen unterschiedliches Gewicht. Folgende Formen der Balanoposthitis können unterschieden werden (Überlappungen kommen natürlich vor):

Balanoposthitis bei präpubertären Knaben. Diese tritt bei ca. $5 \%$ auf und ist häufig mit kongenitaler relativer oder absoluter Phimose (oft bei überlangem,„,rüsselförmigem " Präputium) oder partieller Konglutination der Glans assoziiert. Sie tritt meist als akuter episodischer, oft purulenter Infekt in Erscheinung; Erreger: Staphylokokken, Streptokokken der Gruppe B. Aufsteigende Infektion (Urethritis) ist möglich.

Balanoposthitis beim jungen, geschlechtsreifen Mann. Insgesamt in diesem Lebensabschnitt seltener. Im Vordergrund stehen sexuell erworbene Infektionen oder deren Folgen, z. B. Begleitbalanitis bei Condylomata acuminata, urethralem Fluor bei Gonorrhoe, Chlamydieninfektion u. a. m. Häufig sind eher milde irritative Kontaktbalanitiden, die durch sexuelle Überaktivität, Kontakt mit Partnerinnen mit vaginalem Fluor (Kandidavulvitis, Trichomoniasis, anaerobe Vaginitis "Meine Freundin hat so einen scharfen Ausfluß") oder auch Kontakt mit chemischen Agentien (Kontrazeptiva, Kondome) zustande kommen. In der Regel selbstlimitiert bzw. Abheilung nach Behandlung der Infektion. Eine seltene, morphologisch charakteristische Form ist ferner die Balanitis circinata bei M. Reiter (s. Abb. 13.19).

Balanoposthitis beim reifen Mann. In diesem Alter nehmen Infektionen ab, konstitutionelle Faktoren jedoch zu. Ein charakteristisches Zustandsbild ist die sog. Reinlichkeitsbalanitis (Abb.19.57 a); manche Männer waschen, aus übertriebener Reinlichkeit, das Glied täglich ein- oder mehrmals mit Seife. Die ständige Entfettung schädigt die ohnehin physiologisch schwache Barriere weiter, es kommt zur Mazeration. Das klinische Bild ist typisch: eine diffuse, stumpfe Rötung, 

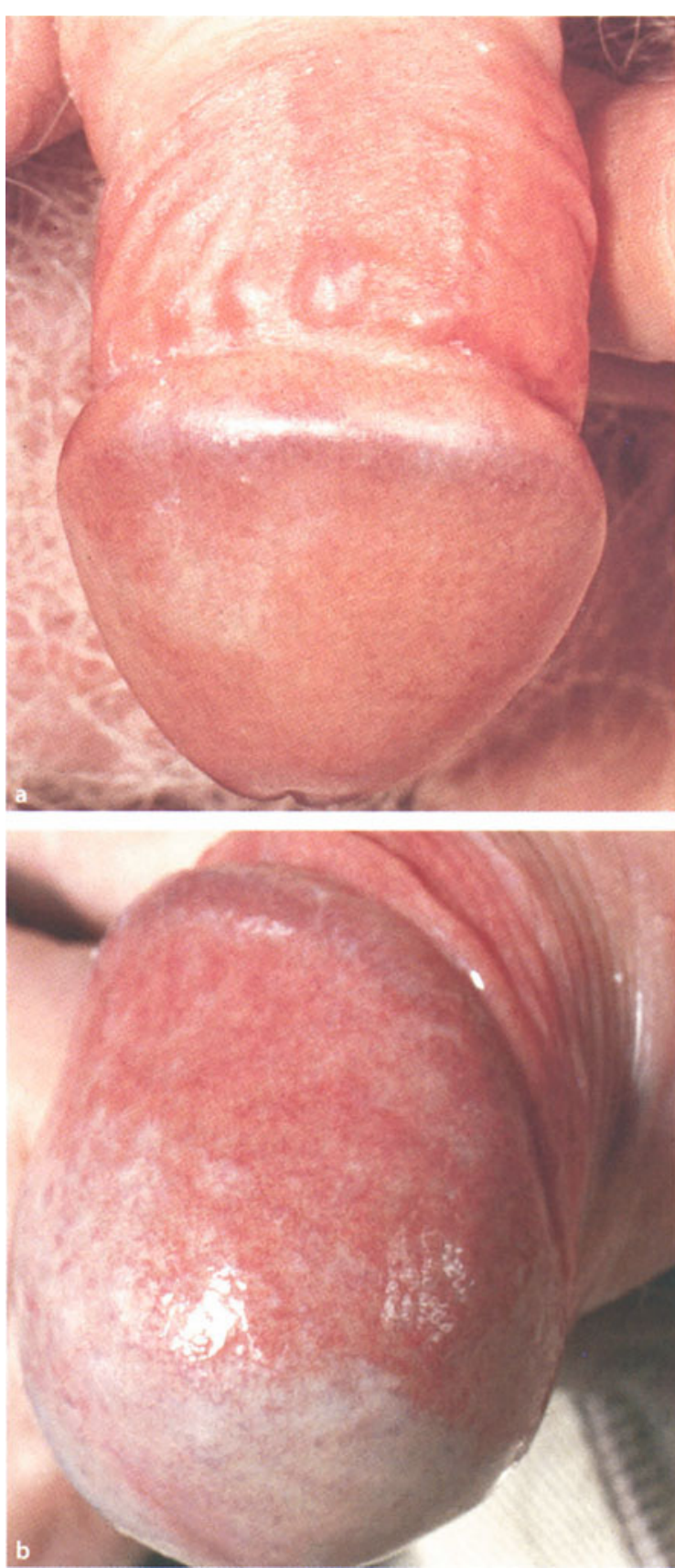

Abb. 19.57a, b. Typische Läsionen der Glans penis. a „Reinlichkeitsbalanitis". Gesamte Glans und inneres Vorhautblatt betroffen, Haut leicht ödematös, stumpf gerötet, matt, vermehrt Smegmabildung. $\mathbf{b}$ Atrophe Balanitis. Betroffen ist die proximale Glans und das innere Präputialblatt; die Läsion ist scharf begrenzt, glänzend (,lackfarben") mit Teleangiektasien, frischen und älteren punktförmigen Einblutungen

Schwellung (Verdickung der Falten) und ständiges Abgehen mazerierter Hornmassen. Oft wird die Reinlichkeitsbalanitis durch Kortikosteroidbehandlung perpetuiert und verschlechtert.

Die Reinlichkeitsbalanitis ist eine sehr häufige, chronische Dermatose, die den Betroffenen extrem belästigt und fast stets als „Pilz“ diagnostiziert und behandelt wird.
Seltener sind infektiöse Balanitiden; Diabetes mellitus ist in ca. $30 \%$ mit chronisch-rezidivierender bakterieller (E. coli) oder Kandida-Balanoposthitis assoziiert.

Lang bestehende Balanoposthitis (häufig diabetisch) kann zur progredienten Fibrose mit fast knorpelartiger weißlich-transluzenter Verdickung der Vorhaut und Verengung des Umschlagringes im Extrem auf Sondendicke mit Miktionsbeschwerden führen (Balanitis xerotica obliterans, postentzündliche Phimose). Bei Versuchen, die Vorhaut zu reponieren, entstehen sehr schmerzhafte Rhagaden, deren Infektion die fibrotische Schrumpfung noch weiter beschleunigt (Circulus vitiosus). Durch die Smegmaretention entstehen manchmal akute Eiterungen im Präputialsack.

Ein 42 jähriger Mann hatte immer schon eine etwas enge Vorhaut, die sich jedoch gänzlich reponieren ließ (relative Phimose). In der Jugend hatte er mehrmals Entzündungen, die jedoch problemlos abheilten. Vor drei Jahren gewann er eine neue Partnerin, mit der er ausgiebige Sexualbeziehungen einging. Es kam dabei zunächst einmalig, später immer wieder zu „Einrissen" der Vorhaut, die den Verkehr schmerzhaft gestalteten. Seit einem Jahr ist die Vorhaut nahezu stets entzündet. Vor 3 Wochen stellte sich eine rapide Verengung ein, die eine Reposition unmöglich machte. Eine Zirkumzision wurde in die Wege geleitet.

Balanitis xerotica obliterans ist auch das Endstadium eines Lichen sclerosus.

Balanoposthitis des alten Mannes (atrophe oder plamazelluläre Balanitis, Zoon-Balanitis, Abb.19.57b). Ein typisches und häufiges Bild, das schon im 6. Lebensjahrzehnt beginnen kann, aber im Greisenalter kulminiert. An der Glans (vorwiegend im proximalen Teil - hier ,klebt“ die Vorhaut beim Zurückrollen) und am inneren Vorhautblatt finden sich ein oder mehrere scharf abgegrenzte (lackartig) glänzende erosive Herde, in denen zarte punktförmige frische und ältere Einblutungen erkennbar sind. Die Histologie zeigt Fehlen der Hornschicht, atrophe ödematöse Epidermis und ein mildes, plasmazellreiches Entzündungsinfiltrat.

\section{!}

Chronische Entzündungen der hautnahen Schleimhäute sind meist reich an Plasmazellen.

Ursache: Altersbedingte Atrophie der Epidermis, chronische Mazeration und dadurch erhöhte Verletzlichkeit, häufig auch starke Kolonisierung mit Gramnegativen.

Therapie. Schaffung einer möglichst trockenen Situation im Präputialsack, gegebenenfalls auch lokale Antisepsis. Bei starken Beschwerden ist die Zirkumzision indiziert (anschließend meist schnelles Abheilen). 


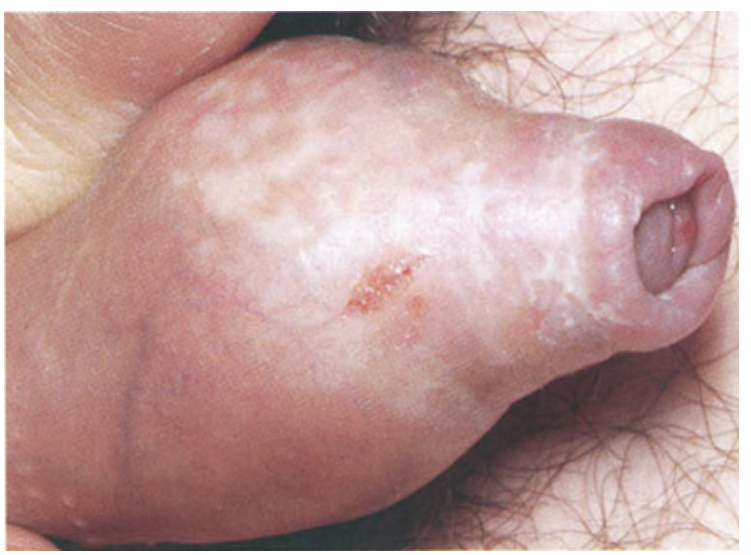

Abb. 19.58. Lichen sclerosus et atrophicans als Ursache einer absoluten Phimose

Differentialdiagnose. Erythroplasie; diese ist gleichfalls durch einen oder einzelne, scharf begrenzte Herde gekennzeichnet, die Oberfläche ist jedoch matt, stumpf gerötet (deckfarben), oft leicht granuliert und ohne Einblutungen. Erosiver Lichen ruber.

\section{Phimose und Paraphimose}

Unter Phimose versteht man eine Enge der Vorhaut, die es schwierig (relative Phimose) oder unmöglich macht (absolute Phimose), diese zu reponieren. Sie ist entweder angeboren oder erworben; in ersterem Fall ist sie häufig mit langem, rüsselförmigen Präputium assoziiert. Im letzteren kann sie vorübergehend durch entzündliche Schwellung (z. B. bei Podophyllinbehandlung von Kondylomen) oder permanent durch postinflammatorische Fibrose entstehen (häufig diabetische Balanoposthitis, Lichen sclerosus, Abb.19.58). Komplikationen sind Sekretstau, eitrige Balanoposthitis, Schwierigkeiten und Verletzungen beim Geschlechtsverkehr.

Eine Paraphimose (Abb. 19.59) entsteht, wenn bei relativer Phimose die Vorhaut zurückgezogen wird und dann wegen Ödembildung nicht mehr reponiert werden kann. Gefahr der Nekrose im Bereich des Schnürrings und der Glans. Therapie: Versuch der manuellen Reposition durch Auspressung des Ödems der Glans; bei Unmöglichkeit Spaltung des Präputiums. Selbst bei erfolgreicher Reposition empfiehlt sich die Zirkumzision zur Verhütung von Rezidiven.

Entzündliche Phimosen und Paraphimosen entstehen häufig bei venerischen Infektionen („genital ulcer disease").

\section{Weitere regionsspezifische Dermatosen}

Penile Fibromatose (Peyronie) (Induratio penis plastica). Eine häufig mit palmoplantarer Fibromatose (Dupuytren-Kontraktur) assoziierte plaqueförmige Verdichtung der Dorsalseite der Tunica albuginea unbekannter Ursache. Sie beginnt meist in der Lebensmitte, ist langsam progredient, führt zur Verkrümmung

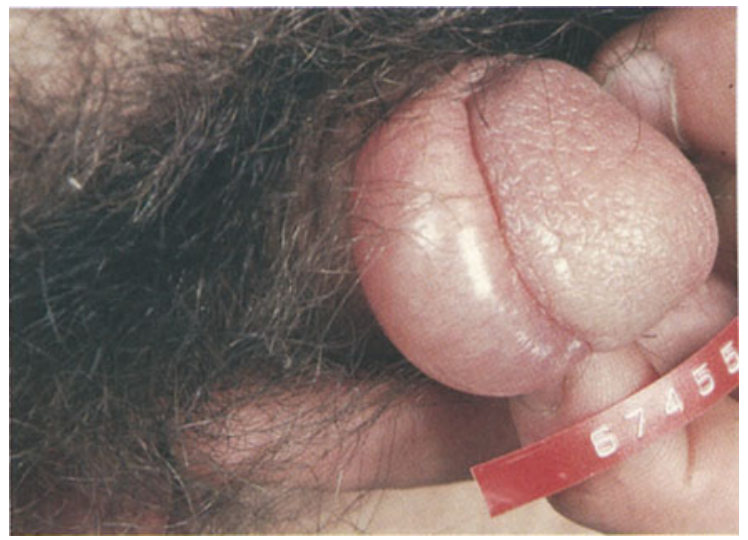

Abb. 19.59. Paraphimose („spanischer Kragen"). Nach forcierter Reposition bei relativer Phimose wirkt die Umschlagstelle zwischen äußerem und innerem Präputialblatt wie ein Schnürring. Massives Ödem von Präputium und Glans

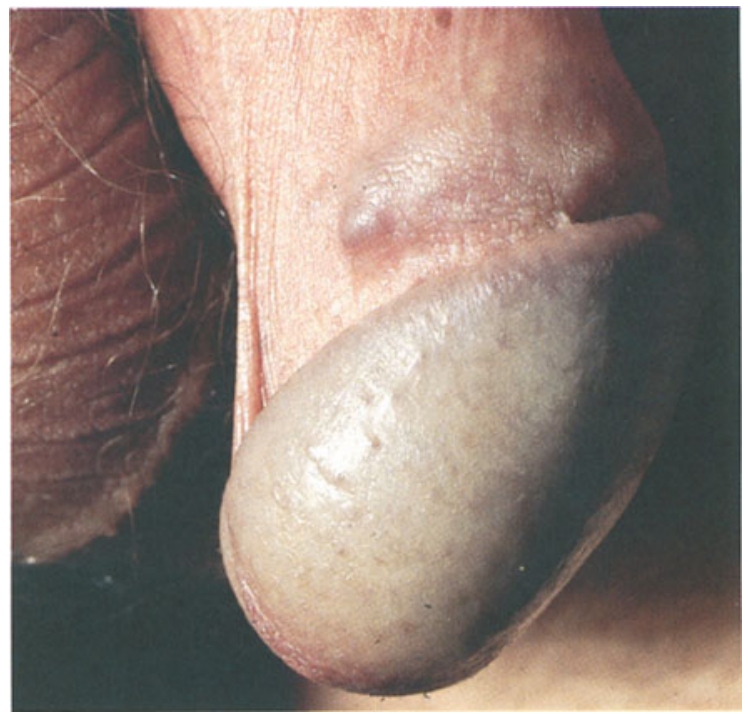

Abb. 19.60. Lymphopathia venerea. Derbe, bläulich durchschimmernde strangartige Verhärtung am Sulcus coronarius

bei Erektion und Schmerzen beim bzw. Unmöglichkeit des Koitus (s.S. 602).

Kranzfurchenlymphangitis (Lymphopathia venerea) (Abb.19.60). Eine derbe, schmerzlose strangartige Verhärtung parallel und knapp proximal zum Sulcus coronarius, die einem verdickten, entzündlich infiltriertem Lymphgefäß entspricht. Ätiologie: unklar; Assoziation mit Traumen und vehementem Geschlechtsverkehr. Spontanheilung nach einigen Wochen.

Fehlbildungen, Anomalien. Die mediane Raphezyste ist ein aus urothelialem Epithel aufgebauter Gang an der Raphe penis, meist in Frenulumnähe. Meist asymptomatisch, manchmal Entzündungen.

Hirsuties papillaris coronae glandis (Abb.19.61): multiple kleine derbe, diskret stehende weißliche (verhornte) Papeln der Glans unmittelbar an der Kranzfurche. Eine harmlose Anomalie bei ca. $20 \%$ der Männer. 


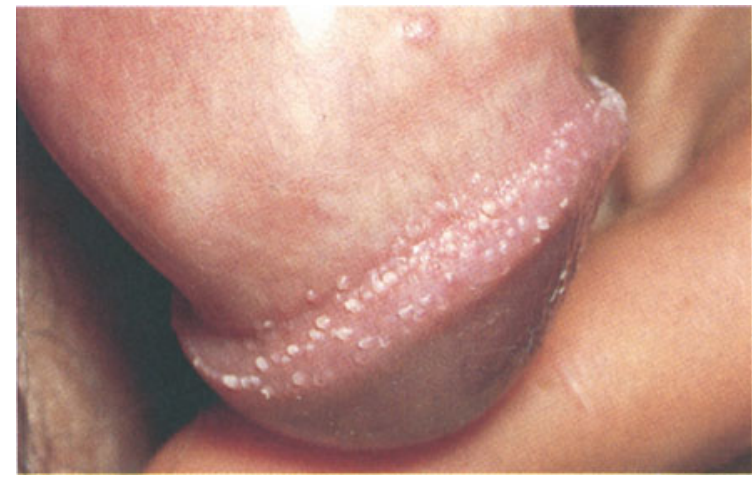

Abb. 19.61. Hirsuties papillaris coronae glandis. Nebenbefund: ein kleines Kondyloma acuminatum am inneren Präputialblatt

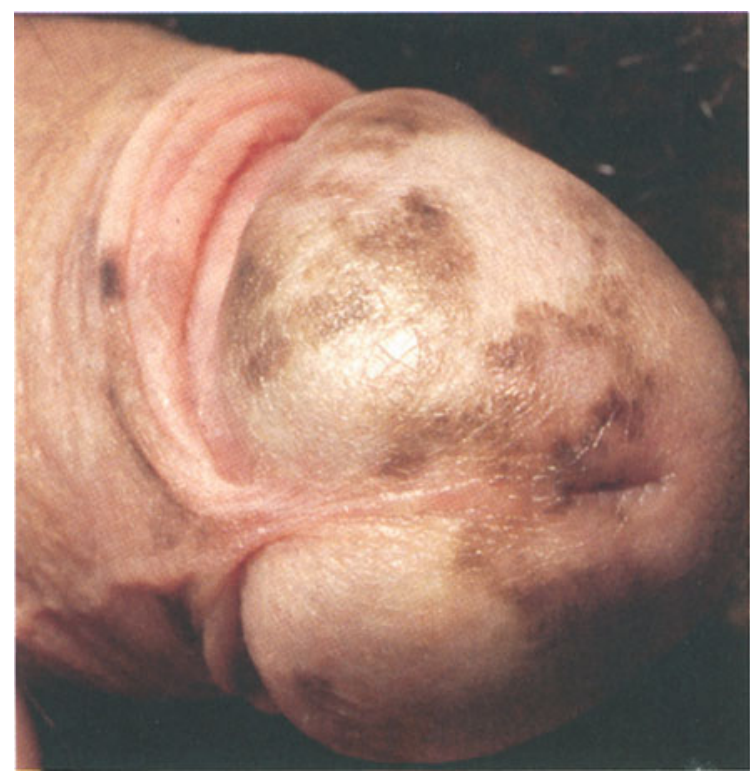

Abb. 19.62. Lentiginose der Glans penis

Werden von vielen Patienten für krankhaft gehalten. Histologie: Angiofibrome.

Bei manchen Säugetieren (Hunde, Katzen) sind solche Papeln oft stark ausgebildet und haben eine mechanische Funktion. Beim Menschen Atavismus.

Makulöse penile Melanose (Abb.19.62). Eine seltene harmlose, jedoch beunruhigende Dermatose, die durch einzelne oder mehrere dunkelbraun-schwarze, scharf und polzyklisch begrenzte Flecken an der Glans charakterisiert ist. Die Läsionen ähneln einer Lentigo maligna, entsprechen histologisch jedoch nur einer basalen Hyperpigmentierung ohne melanozytäre Atypien. Auftreten im frühen oder mittleren Erwachsenenalter. Differentialdiagnose: Melanom. Die Diagnose der makulösen penilen Melanose muß immer histologisch verifiziert werden.

Die penile makulöse Melanose ist in der Regel auf den Penis beschränkt; gleichartige Läsionen kennt man auch an den Lippen (und der Vulva).
Regionsspezifische Präkanzerosen und Karzinome. Viruspapillome durch High-risk-HPV-Typen sind Erreger der für die Genitoanalregion spezifischen Condylomata plana (s. S. 264). Die Erythroplasie (s. Abb. 18.15) ist eine dem M. Bowen entsprechende obligate Präkanzerose; sie erscheint als irregulär gestalteter leicht granulierter Fleck an Glans oder Präputium (s. S. 557). Ein regionssepzifisches Karzinom sind schließlich die Riesencondylomata Buschke-Löwenstein

\subsubsection{Häufige, nicht regions- spezifische Läsionen des männlichen Genitales}

Lichen sclerosus et atrophicans (s. Abb. 15.39). Eine relativ häufige, bei Frauen ungleich häufigere sklerodermiforme Dermatose meist des Genitales, die durch weißliche hyperkeratotische Papeln, Verlust der Elastika und Brüchigkeit der Dermis mit Neigung zu Einblutungen gekennzeichnet ist. Im Endstadium Atrophie und Schrumpfung (s.S. 478).

Lichen simplex chronicus des Skrotum. Das Skrotum ist nicht selten Sitz eines chronischen intertriginösen Ekzems und Ursache eines oft sehr lästigen genitalen Pruritus. Gefahr: Entrittspforte für das oft vehement verlaufende genitale Erysipel.

Weitere für die Region charakteristische Läsionen sind multiple Talgzysten des Skrotum, die Angiokeratomata scroti u. a.m.

\subsubsection{Regionsspezifische Krankheiten des weiblichen äußeren Genitales}

Die Labia majora tragen reichlich Haare, Talg- und Schweißdrüsen, die zarten Labia minora sind in ihrem äußeren Teil von verhornender Epidermis mit freien Talgdrüsen, innen jedoch von nichtverhornendem Schleimhautepithel bedeckt (Vestibulum vaginae). Das Vestibulum erstreckt sich von der Klitoris bis zur hinteren Kommissur und beinhaltet die Mündungen von Urethra, Vagina, der Bartholin-Drüsen sowie kleinerer Drüsen und Gänge. Es ist der empfindlichste Teil der Vulva, reichlich mit Nervernendigungen versorgt, aus lockerem, schwellungsbereitem Gewebe aufgebaut und wegen des dünnen Epithels mit einer nur mäßigen Barrierefunktion ausgestattet (Vorsicht bei lokaler Kortikosteroidbehandlung!).

Auch (und ganz besonders) im Vestibulum herrscht wegen des Epitheltyps und des auch physiologisch milde vorhandenen Fluor vaginalis ein Klima der feuchten Kammer, das bei stärkerem Fluor die gesamte Vulva betrifft. Vagina und Vestibulum besitzen ihre eigene resi- 
dente Keimflora, die bei Milieuänderungen oder Infektionen leicht umschlagen und pathologischen Keimen (z. B. Candida albicans) Raum geben kann. Fluor, Friktion durch enge Unterkleidung und die regional hohe Körpertemperatur schaffen die geeignete Voraussetzungen zu lokalen chronischen Irritationen.

Vestibulitis. Ein durch meist nur geringe Rötung im Bereich des Vestibulums und erhebliche Berührungsschmerzhaftigkeit bei Fehlen sonstiger objektiver Symptome gekennzeichneter Zustand. Die Patientinnen sind zum Geschlechtsverkehr kaum imstande, auch Radfahren etc. ist mit erheblichen Beschwerden verbunden. Therapie: symptomatisch, psychologische Hilfe (psychosomatische Komponente).

Vestibulitis ist natürlich auch Begleitsymptom von Fluor vaginalis infektiöser oder nicht-infektiöser Ursache und Vulvitis (z. B. bei Kandidainfektion).

Pruritus vulvae, Lichen simplex vulvae. Ein sehr häufiges Symptom, das etwa $10 \%$ der gynäkologischen (und einen nicht unbeträchtlichen Teil der dermatologischen) Konsultationen ausmacht. Es kann Begleitsymptom objektiver lokaler Läsionen (z. B. Lichen ruber, Pedikulosis, Kandidiasis, Kontaktekzeme und Lichen sclerosus) oder auch von Systemkrankheiten sein (z. B. M. Hodgkin, Diabetes mellitus, Verschlußikterus). In mehr als der Hälfte der Fälle läßt sich eine Ursache jedoch nicht aufdecken; offensichtlich handelt es sich um einen Circulus vitiosus von Juckreiz und Kratzen, dessen ursprünglicher Trigger nicht mehr nachweisbar ist (ähnliches ist von manchen anderen Körperöffnungen bekannt, die sämtlich kitzel- bzw. juckbereite Regionen sind - Anus, Konjunktiven, Lippen etc.). Chronischer Pruritus vulvae führt zu oft beträchtlicher Lichenifikation.

Pruritus vulvae ist ein außerordentlich belastendes Problem. An seiner Entstehung sind oft psychiatrische (endogene oder klimakterische Depression) oder psychologische Momente beteiligt.

Therapie. Ausschaltung bzw. Behandlung etwaiger Ursachen, Vermeiden weiterer Irritationen, Versuch lokaler Kortikoide (nicht als Dauerbehandlung geeignet).

Ein verwandter Zustand ist die Vulvodynie (Schmerzhaftigkeit der Vulva). Auch sie kann Symptom von Entzündungen und Infekten (z.B. Kandidavulvitis oder HPV-Infektion) oder seniler Atrophie sein und ist bei Fehlen objektiver Befunde nicht selten Ausdruck einer Involutionsdepression. Die Vulvodynie ist eine Ursache der Dyspareunie (schmerzhafter Geschlechtsverkehr); sie ist nicht mit Lichen simplex chronicus assoziiert.

Atrophie der Vulva, Plasmazell-Vulvitis. Bei postmenopausalen Frauen kommt es zur meist milden, manchmal ausgeprägten Atrophie des gesamten äußeren Genitales ohne weitere objektive Zeichen. Sie kann von Vulvodynie begleitet sein. Therapie: lokale Östrogenpräparate.

$\mathrm{Zu}$ unterscheiden ist die Atrophie bei Lichen sclerosus, die in ihrem Endstadium zum Verschwinden der Labia minora und teilweise der Labia majora führen kann.

An der Vulva älterer Frauen finden sich seltener umschriebene Herde, die klinisch und histologisch der Zoon-Balanitis entsprechen.

Bartholinitis, Bartholin-Zyste. Eine heftig schmerzhafte Entzündung der Bartholin-Drüse (kaudaler Bereich der Labia majora, Einmündung des Ausführungsganges im Vestibulum), die bei Gonorrhoe (s. Kap. „Gonorrhoe") oder pyogenen Infekten auftreten kann. Chronische Entzündung mit Okklusion des Ausführungsganges führen zur Zystenbildung. Therapie: entsprechende Antibiotika, evtl. Inzision. Bartholin-Zysten werden durch Marsupialisation saniert (Schaffung eines permanenten Ausganges).

Vaginale Adenose. Ein seltener Zustand, der durch die Persistenz von Epithel des Müller-Ganges im vorwiegend oberen Anteil der Vagina, manchmal bis ins Vestibulum, gekennzeichnet ist. Klinisch mehrere scharf und unregelmäßig begrenzte erythematöse Läsionen, die leicht bei Berührung und spontan bluten. Das Bild ist von einem erosiven Lichen ruber klinisch kaum unterscheidbar. Histologisch Metaplasie primitiver Epithelien. Therapie: soweit möglich, operativ. Oberflächliche Entfernung (z. B. Laserung) führt zum Rezidiv aus tiefgelegenen Epithelinseln.

Die vaginale Adenose wird schon in utero angelegt und führte bei mütterlicher Einnahme von Stilböstrol (heute nicht mehr erhältlich) zu ausgedehnten Läsionen, die sich häufig in Vaginalkarzinome umwandelten. Sie kommt nicht selten auch ohne medikamentöse Induktion bei jungen Mädchen vor, verläuft jedoch asymptomatisch oder bildet sich zurück. Möglicherweise unter dem Einfluß von Kontrazeptiva oder hormoneller Substitution kann es im Klimakterium zu ausgedehnten Läsionen kommen.

Weitere regionsspezifische Läsionen. Ähnlich wie beim männlichen Genitale können sich am weiblichen die vulväre makulöse Melanose, Condylomata plana, ein extramammärer M. Paget und Riesencondylomata acuminata Buschke-Löwenstein ausbilden (s.oben).

\subsubsection{Häufige, nicht regionsspezifische Läsionen des weiblichen Genitales}

Lichen sclerosus et atrophicans. Das weibliche Genitale ist Hauptlokalisation dieser grundsätzlich überall auftretenden Dermatose (s. S. 478). Es handelt sich um manchmal extrem juckende weißliche Papeln, die, zu Plaques konfluiert, das Genitale und meist auch die 
Analregion umschließen („8-Figur“). Zwei Inzidenzgipfel: präpubertäre Mädchen (bei diesen spontane Abheilung möglich, s. Abb. 15.40) und Frauen mittleren Lebensalters. Nach jahrelangem Verlauf Atrophie mit Verstreichen von Teilen des Genitales und Strikturen (s. oben).

Der Lichen sclerosus des weiblichen Genitales gilt als fakultative Präkanzerose (Karzinomrisiko ca. 5\%); regelmäßige Kontrollen, evtl. auch operative Entfernung schwer befallenen Gewebes sind indiziert. Bei milden Formen ist eine Unterspritzung mit Kortikoid-Kristallsuspension vorübergehend sehr wirkungsvoll, Rezidive sind jedoch häufig (kann wegen der Gefahr der Atrophie nicht häufig wiederholt werden).
Lichen ruber planus. Mitbeteiligung der Vulva bei Lichen ruber ist häufig, selten jedoch der erosive Lichen ruber des Vestibulums und der Vagina. Es handelt sich um ausgedehnte, schmerzhafte, scharf und unregelmäßig begrenzte düsterrote und leicht blutende Herde, die sich als extrem therapieresistent erweisen. Diagnose: Histologie. Differentialdiagnose: Pemphigus, zikatrizierendes Pemphigoid, vaginale Adenose.

Vulvakarzinome sitzen häufig im Vorderteil des Vestibulum und sind oft - ebenso wie der extramammäre M. Paget - initial unscheinbar (erythematöse Verhärtungen). 